\title{
Hydrogeology and Migration of Septic-Tank Effluent in the Surficial Aquifer System in the Northern Midlands Area, Palm Beach County, Florida
}

By Wesley L. Miller

\section{U.S. GEOLOGICAL SURVEY}

Water-Resources Investigations Report 91-4175

Prepared in cooperation with

PALM BEACH COUNTY

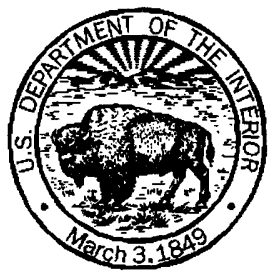




\title{
U.S. DEPARTMENT OF THE INTERIOR \\ MANUEL LUJAN, JR., Secretary
}

\author{
U.S. GEOLOGICAL SURVEY \\ Dallas L. Peck, Director
}

For additional information write to:

District Chief

U.S. Geological Survey

Suite 3015

227 North Bronough Street

Tallahassee, Florida 32301
Copies of this report may be purchased from:

U.S. Geological Survey

Books and Open-File Reports Section Federal Center

Box 25425

Denver, Colorado 80225 


\section{CONTENTS}

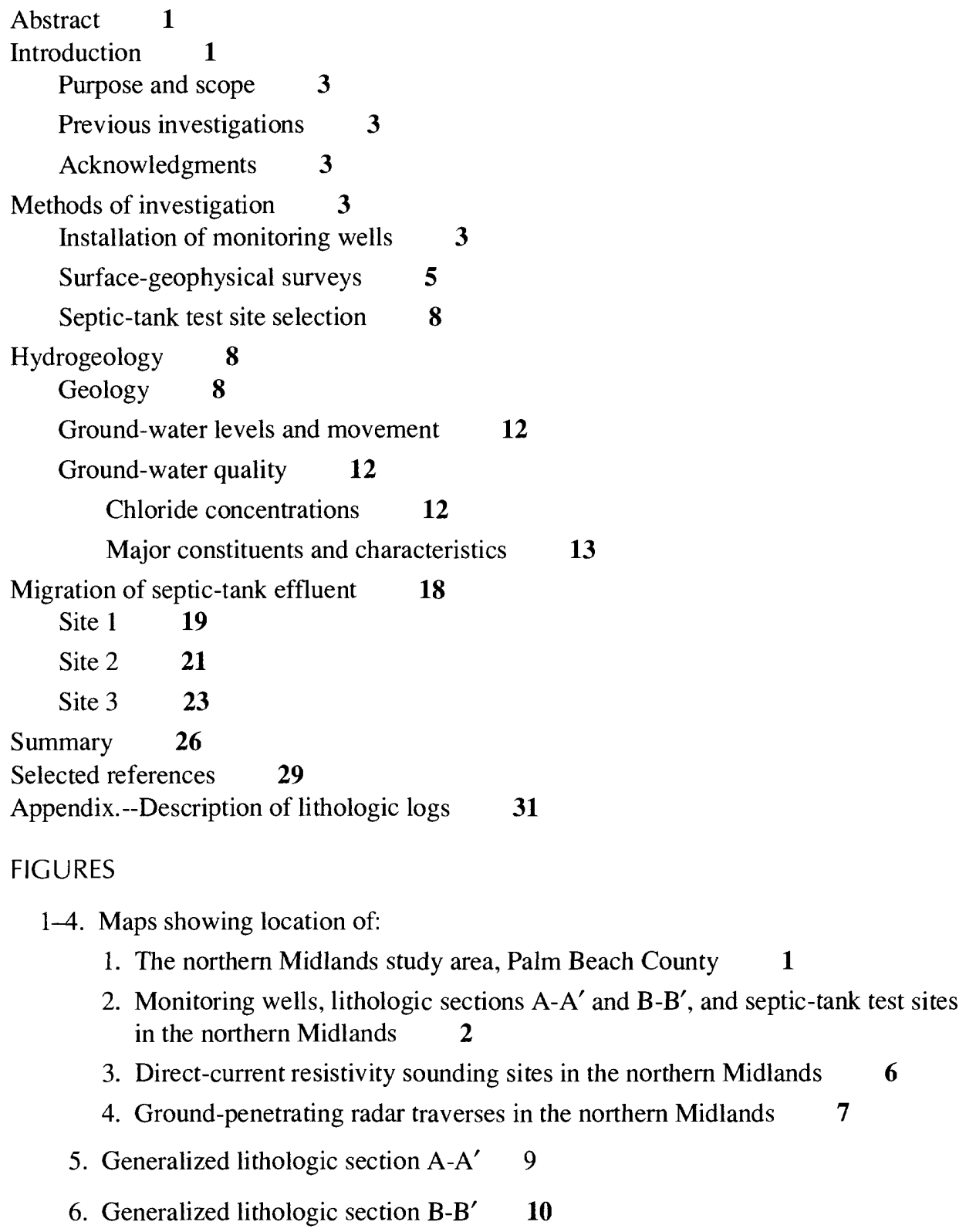

Chloride concentrations

12

Major constituents and characteristics

Migration of septic-tank effluent $\quad \mathbf{1 8}$

Site $1 \quad 19$

Site $2 \quad 21$

Site $3 \quad 23$

Summary $\quad 26$

Selected references $\quad 29$

Appendix.--Description of lithologic logs $\quad 31$

\section{FIGURES}

1-4. Maps showing location of:

1. The northern Midlands study area, Palm Beach County 1

2. Monitoring wells, lithologic sections $A-A^{\prime}$ and $B-B^{\prime}$, and septic-tank test sites in the northern Midlands 2

3. Direct-current resistivity sounding sites in the northern Midlands 6

4. Ground-penetrating radar traverses in the northern Midlands 7

5. Generalized lithologic section A-A' 9

6. Generalized lithologic section B-B' $\mathbf{1 0}$

7-8. Maps showing:

7. Depth below land surface of uppermost marl layers in the northern Midlands 11

8. Location of chloride profiles $A-A^{\prime}$ and $B-B^{\prime}$ and arrays of quality-of-water wells in the northern Midlands

15

9-10. Sections showing lines of equal chloride concentrations along profile:

9. $\mathrm{A}-\mathrm{A}^{\prime}$ in the northern Midlands $\mathbf{1 6}$

10. $\mathrm{B}-\mathrm{B}^{\prime}$ in the northern Midlands $\mathbf{1 7}$

11-13. Maps showing:

11. Septic-tank test site 1, location of nearby wells (PB-1609A-H), and minimum and maximum concentrations of ammonia plus organic nitrogen 
12. Septic-tank test site 2, location of nearby wells (PB-1590A-G), and minimum and maximum concentrations of ammonia plus organic nitrogen

13. Septic-tank test site 3, location of nearby wells (PB-1589A-F), and minimum and maximum concentrations of ammonia plus organic nitrogen

\section{TABLES}

1. Well inventory data for the study area

2. Well inventory data for the septic-tank test sites

3. Chloride concentrations in samples collected during test-well drilling in the northern Midlands 13

4. Chloride concentrations in water from selected wells in the northern Midlands

5-7. Concentrations of major constituents, nutrients, and related characteristics of water from:

5. Wells PB-1560 and PB-1561 in array 1 in the northern Midlands

19

6. Wells PB-1583, PB-1584, and PB-1585 in array 2 in the northern Midlands

7. Wells PB-1524, PB-1552, and PB-1553 in array 3 in the northern Midlands

8-10. Ground-water levels at septic-tank test sites in the northern Midlands prior to water-quality sampling:
8. Septic-tank test site 1
22
9. Septic-tank test site 2
22
10. Septic-tank test site 3
22

11-13. Concentrations of selected constituents in ground water at septic-tank test sites in the northern Midlands, 1986-87:
11. Septic-tank test site 1
24
12. Septic-tank test site $2 \quad \mathbf{2 6}$
13. Septic-tank test site 3
28 


\begin{tabular}{rll} 
Multiply & By & To obtain \\
foot $(\mathrm{ft})$ & 0.3048 & meter \\
mile $(\mathrm{mi})$ & 1.609 & kilometer \\
acre & 0.4047 & hectare \\
square mile $\left(\mathrm{mi}^{2}\right)$ & 2.590 & square kilometer \\
foot per day $(\mathrm{ft} / \mathrm{d})$ & 0.3048 & meter per day \\
\hline
\end{tabular}

Sea level: In this report "sea level" refers to the National Geodetic Vertical Datum of 1929 (NGVD of 1929)--a geodetic datum derived from a general adjustment of the first-order level nets of the United States and Canada, formerly called Sea Level Datum of 1929.

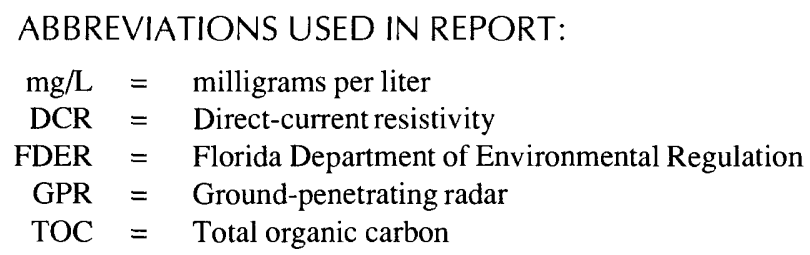




\title{
Hydrogeology and Migration of Septic-Tank Effluent in the Surficial Aquifer System in the Northern Midlands Area,Palm Beach County, Florida
}

\author{
By Wesley L. Miller
}

\section{ABSTRACT}

The northern Midlands area in Palm Beach County is an area of expected residential growth, but its flat topography, poor drainage, and near-surface marl layers retard rainfall infiltration and cause frequent flooding. Public-water supplies and sewer services are not planned for the area, thus, residents must rely on domestic wells and septic tanks. The water table in the northern Midlands area is seldom more than 5 feet below land surface, and regional ground-water flows are east, southwest, and south from the north-central part of the area where groundwater levels are highest. Ground-water quality in the western part of the area and in the Loxahatchee Slough is greatly influenced by residual seawater emplaced during the Pleistocene Epoch. Chloride and dissolved-solids concentrations of ground water in the surficial aquifer system in these areas often exceed secondary drinking-water standards. Residual seawater has been more effectively flushed from the more permeable sediments elsewhere in the eastern and southeastern parts of the study area. Tests at three septic-tank sites showed traces of effluent in ground water (38-92 feet from the septictank outlets ) and that near-surface marl layers greatly impede the downward migration of the effluent in the surficial aquifer system throughout the northern Midlands.

\section{INTRODUCTION}

Pressures are increasing for construction of single-family residences in an unincorporated area of about $270 \mathrm{mi}^{2}$ in northeastern Palm Beach County (fig. 1). Palm Beach County officials have recently designated the area a part of the "Midlands," a planning area encompassing unincorporated lands both north and south of the West Palm Beach, C-51, Canal (fig. 2). Residential development in the northern Midlands area is areally limited by land uses, such as the West Palm Beach Catchment Area and Loxahatchee Slough to the east, the Corbett Wildlife Management Area to the west, and an industrial complex to the northwest (fig. 2), which prohibit development.

The northern Midlands is categorized as very low to low-density residential; that is, one dwelling unit per 2 to 5 acres (Palm Beach County Department of Planning, Building, and Zoning, 1980). Most of the land was sold as 1.25 -acre lots during the 1960's, but most of the lots have not been developed. The density is not limited by the Palm Beach County Comprehensive Plan and is expected to increase in the future. The development of home sites is expected to be unevenly distributed within the northern Midlands as clusters of homes develop near improved drainage facilities and roads. About 2,500 homes exist in the northern Midlands at present (1991). County officials have recently projected that 15,000 to 20,000 homes served by septic tanks and individual wells will exist in the area by the year 2000 .

Although the northern Midlands is topographically one of the highest parts of Palm Beach County, with land-surface altitudes of 15 to $25 \mathrm{ft}$ above sea level, much of the land is often inundated because of heavy rainfall, the occurrence of

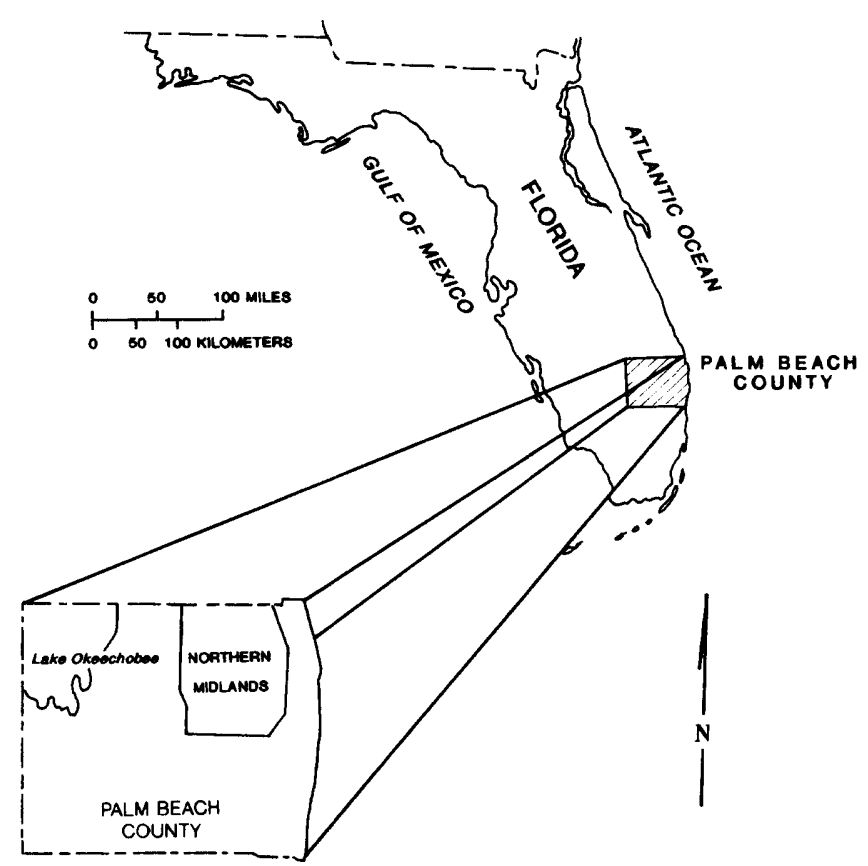

Figure 1. Location of the northern Midlands study area, Palm Beach County. 


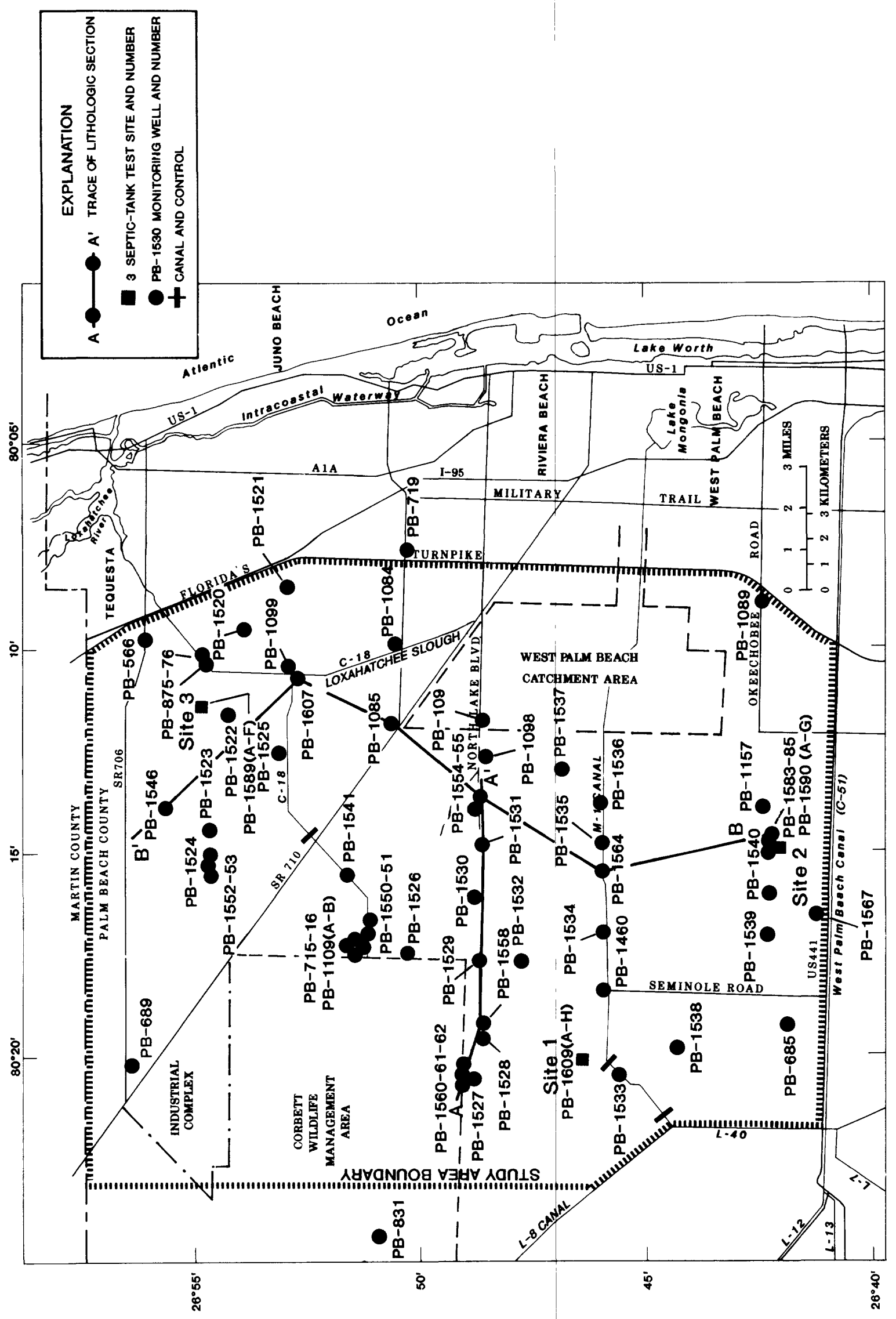

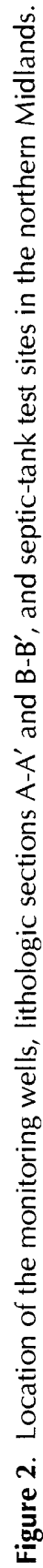


near-surface marls that retard rainfall infiltration, and poor surface drainage. Regional water-table contour maps prepared since 1970 (Land and others, 1973; Rodis and Land, 1976; Schneider, 1977; Swayze and Miller, 1984; Miller, $1985 \mathrm{a} ; 1985 \mathrm{~b}$ ) consistently indicate this area to be on the eastern flank of a ground-water divide and upgradient of several public water-supply well fields that serve the coastal area. The most recent of these maps shows that combined withdrawals from domestic wells in a new development just west of the West Palm Beach Catchment Area (fig. 2) have lowered the water-table sufficiently to reverse the ground-water flow direction in the eastern half of the affected area.

Pockets of residual seawater containing high chloride concentrations have been identified both within the northern Midlands and immediately to the west (Miller and Lietz, 1976; Swayze and Miller, 1984; Miller, 1988), but boundaries of the areas are undefined. Lower permeabilities in the surficial aquifer system and the occurrence of near-surface marls have retarded dilution or flushing of residual Pleistocene seawater (Miller, 1988).

Concerns about the effects of future development on the resources of the area include possible effects of large numbers of individual septic tanks and wells on ground-water quality and water levels, the scarcity of predevelopment hydrogeologic data, and the possible lack of potable ground water. To address these concerns, the U.S. Geological Survey, in cooperation with Palm Beach County, initiated a study in 1985 to describe the hydrogeology of the area and to evaluate the potential migration of septic-tank effluent in ground water in the area.

\section{Purpose and Scope}

This report describes the lithology of the uppermost part of the surficial aquifer system, identifies preresidential development ground-water quality characteristics, provides a water-table map of the northern Midlands, and describes septictank effluent migration (vertical and horizontal) at three test sites in the northern Midlands. The study results presented in this report also increase the data base of predevelopment hydrogeologic and water-quality data for the area.

The work conducted as part of this study included construction of 60 test and monitoring wells and data collection at 19 wells constructed during previous studies (fig. 2, tables 1 and 2). Of the new wells, 21 wells were constructed at three residences selected as septic-tank test sites. These shallow monitoring wells were used to measure ground-water levels and to collect water-quality samples in the immediate vicinity of septic tanks to examine migration of effluent. The remaining 39 wells constructed were selectively used for collecting water-quality samples, for making water-level measurements, and for gathering lithologic data. Geologic samples collected during drilling were used to prepare lithologic logs for 30 wells (appendix I).

Direct-current resistivity (DCR) and ground-penetrating radar (GPR) surface-geophysical surveys were made throughout the study area to supplement lithologic and waterquality data. Locations of these surveys are shown in figures 3 and 4.

\section{Previous Investigations}

Numerous U.S. Geological Survey reports contain information pertinent to the northern Midlands of Palm Beach County. Countywide and more localized reports containing geologic, hydrologic, and water-quality information on this and adjacent areas include those by Schroeder and others (1954), Land and others (1973), Miller and Lietz (1976), Rodis and Land (1976), Scott (1977), Fischer (1980), Swayze and Miller (1984), and Miller (1985a; 1985b; 1986; 1988). The only report specifically relating to the northern Midlands is one by Peterson (1988), which describes DCR surface-geophysical data collected as part of this investigation.

\section{Acknowledgments}

The author is indebted to many individuals whose assistance made this report possible. Appreciation is expressed to James Register, Kathryn Fleming, and Michael Slayton for permitting the septic tanks and drainfields at their residences to be used as test sites. Gratitude is also expressed to Frank J. Gargiulo, Palm Beach County Health Department, for his assistance in the initial design of the investigative program.

\section{METHODS OF INVESTIGATION}

Monitoring wells were drilled, geophysical surveys were prepared, and septic-tank test sites were selected in the northern Midlands to obtain data necessary for the investigation. Methods used for each part of this effort were determined by the primary types of data desired and the criteria used to ensure validity of the data obtained.

\section{Installation of Monitoring Wells}

Each monitoring well was installed (fig. 2) for one or more purposes: ground-water level monitoring, lithologic interpretation, preresidential development ground-water quality characterization, or determination of septic-tank effluent migration. The primary use of the well determined the drilling technique used. All wells were completed with casing and screen. 
Table 1. Well inventory data for the study area

[Drilled (borehole) depth and finished depths not necessarily the same. P, polyvinyl chloride; S, steel; e, estimated; --, not screened]

\begin{tabular}{|c|c|c|c|c|c|}
\hline $\begin{array}{c}\text { Well } \\
\text { number }\end{array}$ & $\begin{array}{c}\text { Site } \\
\text { identification } \\
\text { number }\end{array}$ & $\begin{array}{c}\text { Completed } \\
\text { well } \\
\text { depth } \\
\text { (feet) } \\
\end{array}$ & $\begin{array}{l}\text { Screen } \\
\text { length } \\
\text { (feet) }\end{array}$ & $\begin{array}{c}\text { Altitude } \\
\text { of well } \\
\text { (feet above } \\
\text { sea level) } \\
\end{array}$ & $\begin{array}{c}\text { Casing } \\
\text { material }\end{array}$ \\
\hline $\begin{array}{l}P B-109 \\
P B-566 \\
P B-685 \\
P B-689\end{array}$ & $\begin{array}{l}264841080114901 \\
265604080094401 \\
264208080192201 \\
265633080203001\end{array}$ & $\begin{array}{l}14 \\
11 \\
17 \\
17\end{array}$ & $\begin{array}{l}-- \\
-- \\
--\end{array}$ & $\begin{array}{l}22.75 \\
17.00 \mathrm{e} \\
16.45 \\
27.43\end{array}$ & $\begin{array}{l}\text { S } \\
\text { S } \\
\text { S } \\
\text { S }\end{array}$ \\
\hline $\begin{array}{l}P B-715 \\
P B-716 \\
P B-719 \\
P B-831\end{array}$ & $\begin{array}{l}265114080173101 \\
265114080173102 \\
265018080074101 \\
265106080241402\end{array}$ & $\begin{array}{l}67 \\
15 \\
24 \\
25\end{array}$ & $\begin{array}{l}5 \\
5 \\
5 \\
5\end{array}$ & $\begin{array}{l}19.73 \\
20.72 \\
17.20 \mathrm{e} \\
24.90\end{array}$ & $\begin{array}{l}S \\
S \\
S \\
P\end{array}$ \\
\hline $\begin{array}{l}P B-875 \\
P B-876 \\
P B-1084 \\
P B-1085\end{array}$ & $\begin{array}{l}265439080102904 \\
265439080102903 \\
265027080100201 \\
265027080115702\end{array}$ & $\begin{array}{r}22 \\
41 \\
138 \\
200\end{array}$ & $\begin{array}{r}4 \\
4 \\
8 \\
- \\
-\end{array}$ & $\begin{array}{l}18.46 \\
15.07 \\
16.60 \mathrm{e} \\
18.00 \mathrm{e}\end{array}$ & $\begin{array}{l}P \\
P \\
P \\
P\end{array}$ \\
\hline $\begin{array}{l}P B-1089 \\
P B-1098 \\
P B-1099 \\
P B-1109 A\end{array}$ & $\begin{array}{l}264225080084701 \\
265835080130201 \\
265250080103601 \\
265115080173102\end{array}$ & $\begin{array}{r}135 \\
80 \\
90 \\
128\end{array}$ & $\begin{array}{l}5 \\
10 \\
10 \\
10\end{array}$ & $\begin{array}{l}15.78 \\
18.26 \\
19.61 \\
24.71\end{array}$ & $\begin{array}{l}P \\
P \\
P \\
P\end{array}$ \\
\hline $\begin{array}{l}P B-1109 B \\
P B-1157 \\
P B-1460 \\
P B-1520\end{array}$ & $\begin{array}{l}265115080173102 \\
264216080134403 \\
264553080182701 \\
265412080092701\end{array}$ & $\begin{array}{r}40 \\
100 \\
30 \\
22\end{array}$ & $\begin{array}{r}10 \\
5 \\
5 \\
3\end{array}$ & $\begin{array}{l}24.00 \mathrm{e} \\
18.19 \\
23.54 \\
18.23\end{array}$ & $\begin{array}{l}P \\
P \\
P \\
P\end{array}$ \\
\hline $\begin{array}{l}P B-1521 \\
P B-1522 \\
P B-1523 \\
P B-1524\end{array}$ & $\begin{array}{l}265255080083901 \\
265417080130301 \\
265445080140301 \\
265443080152001\end{array}$ & $\begin{array}{l}22 \\
22 \\
22 \\
22\end{array}$ & $\begin{array}{l}3 \\
3 \\
3 \\
3\end{array}$ & $\begin{array}{l}17.61 \\
18.50 \mathrm{e} \\
21.40 \mathrm{e} \\
21.51\end{array}$ & $\begin{array}{l}\mathrm{P} \\
\mathrm{P} \\
\mathrm{P} \\
\mathrm{P}\end{array}$ \\
\hline $\begin{array}{l}P B-1525 \\
P B-1526 \\
P B-1527 \\
P B-1528\end{array}$ & $\begin{array}{l}265256080123201 \\
265017080173201 \\
264856080203701 \\
264834080123401\end{array}$ & $\begin{array}{l}22 \\
21 \\
20 \\
20\end{array}$ & $\begin{array}{l}3 \\
3 \\
3 \\
3\end{array}$ & $\begin{array}{l}19.15 \\
21.00 \mathrm{e} \\
21.20 \mathrm{e} \\
20.02\end{array}$ & $\begin{array}{l}\mathrm{P} \\
\mathrm{P} \\
\mathrm{P} \\
\mathrm{P}\end{array}$ \\
\hline $\begin{array}{l}P B-1529 \\
P B-1530 \\
P B-1531 \\
P B-1532\end{array}$ & $\begin{array}{l}264832080173301 \\
264841080161101 \\
264841080144201 \\
264833080173401\end{array}$ & $\begin{array}{l}22 \\
23 \\
20 \\
22\end{array}$ & $\begin{array}{l}3 \\
3 \\
3 \\
3\end{array}$ & $\begin{array}{l}21.15 \\
21.10 \mathrm{e} \\
20.44 \\
20.85\end{array}$ & $\begin{array}{l}\mathrm{P} \\
\mathrm{P} \\
\mathrm{P} \\
\mathrm{P}\end{array}$ \\
\hline $\begin{array}{l}P B-1533 \\
P B-1534 \\
P B-1535 \\
P B-1536\end{array}$ & $\begin{array}{l}264555080203401 \\
264553080161701 \\
264554080144801 \\
264550080132201\end{array}$ & $\begin{array}{l}22 \\
22 \\
22 \\
22\end{array}$ & $\begin{array}{l}3 \\
3 \\
3 \\
3\end{array}$ & $\begin{array}{l}22.25 \\
21.59 \\
20.00 \mathrm{e} \\
19.45\end{array}$ & $\begin{array}{l}\mathrm{P} \\
\mathrm{P} \\
\mathrm{P} \\
\mathrm{P}\end{array}$ \\
\hline $\begin{array}{l}P B-1537 \\
P B-1538 \\
P B-1539 \\
P B-1540\end{array}$ & $\begin{array}{l}264547080125301 \\
264420080194301 \\
264224080165501 \\
264222080152401\end{array}$ & $\begin{array}{l}22 \\
22 \\
22 \\
22\end{array}$ & $\begin{array}{l}3 \\
3 \\
3 \\
13\end{array}$ & $\begin{array}{l}19.00 \mathrm{e} \\
19.00 \mathrm{e} \\
19.50 \mathrm{e} \\
19.50 \mathrm{e}\end{array}$ & $\begin{array}{l}P \\
P \\
P \\
P\end{array}$ \\
\hline $\begin{array}{l}P B-1541 \\
P B-1546 \\
P B-1550 \\
P B-1551\end{array}$ & $\begin{array}{l}265145080152701 \\
265606080135501 \\
265134080172701 \\
265134080172702\end{array}$ & $\begin{array}{r}20 \\
140 \\
135 \\
130\end{array}$ & $\begin{array}{l}3 \\
40 \\
55 \\
60\end{array}$ & $\begin{array}{l}21.60 \mathrm{e} \\
20.11 \\
23.00 \mathrm{e} \\
23.00 \mathrm{e}\end{array}$ & $\begin{array}{l}P \\
P \\
P \\
P\end{array}$ \\
\hline $\begin{array}{l}P B-1552 \\
P B-1553 \\
P B-1554 \\
P B-1555\end{array}$ & $\begin{array}{l}265443080152002 \\
265443080152003 \\
264843080125001 \\
264843080125002\end{array}$ & $\begin{array}{r}100 \\
37 \\
40 \\
130\end{array}$ & $\begin{array}{l}5 \\
20 \\
30\end{array}$ & $\begin{array}{l}20.84 \\
21.28 \\
20.15 \\
20.49\end{array}$ & $\begin{array}{l}P \\
P \\
P \\
P\end{array}$ \\
\hline $\begin{array}{l}\text { PB-1558 } \\
\text { PB-1560 } \\
\text { PB-1561 } \\
\text { PB-1562 } \\
\text { PB-1564 }\end{array}$ & $\begin{array}{l}264834080193402 \\
264856080203702 \\
264856080203703 \\
264856080203704 \\
264555080151701\end{array}$ & $\begin{array}{r}190 \\
56 \\
163 \\
250 \\
131\end{array}$ & $\begin{array}{l}60 \\
10 \\
6 \\
20 \\
60\end{array}$ & $\begin{array}{l}19.71 \\
23.34 \\
22.83 \\
22.12 \\
20.08\end{array}$ & $\begin{array}{l}P \\
P \\
P \\
P \\
P\end{array}$ \\
\hline $\begin{array}{l}P B-1567 \\
P B-1583 \\
P B-1584 \\
P P-1585 \\
P B-1607\end{array}$ & $\begin{array}{l}264101080163001 \\
264057080151001 \\
264057080151002 \\
264057080151003 \\
265248080103801\end{array}$ & $\begin{array}{r}190 \\
160 \\
70 \\
110 \\
164\end{array}$ & $\begin{array}{r}70 \\
10 \\
10 \\
10 \\
100\end{array}$ & $\begin{array}{l}17.00 \mathrm{e} \\
20.48 \mathrm{e} \\
20.48 \mathrm{e} \\
20.48 \mathrm{e} \\
18.00 \mathrm{e}\end{array}$ & $\begin{array}{l}P \\
P \\
P \\
P \\
P\end{array}$ \\
\hline
\end{tabular}


Table 2. Well inventory data for the septic-tank test sites

[Casing material: $\mathrm{P}$, polyvinyl chloride; $\mathrm{S}$, steel]

\begin{tabular}{|c|c|c|c|c|c|c|}
\hline $\begin{array}{c}\text { Site } \\
\text { number }\end{array}$ & $\begin{array}{l}\text { Well } \\
\text { number }\end{array}$ & $\begin{array}{c}\text { Site } \\
\text { identification } \\
\text { number } \\
\end{array}$ & $\begin{array}{l}\text { Depth } \\
\text { (feet) }\end{array}$ & $\begin{array}{l}\text { Screen } \\
\text { length } \\
\text { (feet) }\end{array}$ & $\begin{array}{l}\text { Altitude } \\
\text { of well } \\
\text { (feet above } \\
\text { sea level) } \\
\end{array}$ & $\begin{array}{c}\text { Casing } \\
\text { material }\end{array}$ \\
\hline 1 & $\begin{array}{l}P B-1609 A \\
P B-1609 B \\
P B-1609 C \\
P B-1609 D \\
P B-1609 E \\
P B-1609 \mathrm{~F} \\
P B-1609 G \\
P B-1609 H\end{array}$ & $\begin{array}{l}264658080200001 \\
264658080200002 \\
264658080200003 \\
264658080200004 \\
264658080200005 \\
264658080200006 \\
264658080200007 \\
264658080200008\end{array}$ & $\begin{array}{l}13 \\
13 \\
10 \\
10 \\
12 \\
14 \\
12 \\
11\end{array}$ & $\begin{array}{l}4 \\
4 \\
4 \\
4 \\
4 \\
4 \\
4 \\
4\end{array}$ & $\begin{array}{l}18.49 \\
20.63 \\
21.78 \\
21.97 \\
21.42 \\
21.50 \\
21.37 \\
19.64\end{array}$ & $\begin{array}{l}P \\
P \\
P \\
P \\
P \\
P \\
P \\
P\end{array}$ \\
\hline 2 & $\begin{array}{l}P B-1590 A \\
P B-1590 B \\
P B-1590 C \\
P B-1590 D \\
P B-1590 E \\
P B-1590 F \\
P B-1590 G\end{array}$ & $\begin{array}{l}264057080151004 \\
264057080151005 \\
264057080151006 \\
264057080151007 \\
264057080151008 \\
264057080151009 \\
264057080151010\end{array}$ & $\begin{array}{l}20 \\
15 \\
18 \\
10 \\
15 \\
15 \\
20\end{array}$ & $\begin{array}{l}2 \\
2 \\
2 \\
2 \\
2 \\
2 \\
2\end{array}$ & $\begin{array}{l}20.48 \\
21.73 \\
21.44 \\
21.06 \\
21.36 \\
20.62 \\
20.25\end{array}$ & $\begin{array}{l}\mathrm{P} \\
\mathrm{P} \\
\mathrm{P} \\
\mathrm{P} \\
\mathrm{P} \\
\mathrm{P} \\
\mathrm{P}\end{array}$ \\
\hline 3 & $\begin{array}{l}\mathrm{PB}-1589 \mathrm{~A} \\
\mathrm{~PB}-1589 \mathrm{~B} \\
\mathrm{~PB}-1589 \mathrm{C} \\
\mathrm{PB}-1589 \mathrm{D} \\
\mathrm{PB}-1589 \mathrm{E} \\
\mathrm{PB}-1589 \mathrm{~F}\end{array}$ & $\begin{array}{l}265458080113001 \\
265458080113002 \\
265458080113003 \\
265458080113004 \\
265458080113005 \\
265458080113006\end{array}$ & $\begin{array}{r}8 \\
8 \\
5 \\
8 \\
10 \\
20\end{array}$ & $\begin{array}{l}2 \\
2 \\
2 \\
2 \\
2 \\
2\end{array}$ & $\begin{array}{l}20.01 \\
18.17 \\
18.09 \\
18.10 \\
18.01 \\
18.94\end{array}$ & $\begin{array}{l}\text { S } \\
\text { S } \\
\text { S } \\
\text { S } \\
\text { S } \\
\text { S }\end{array}$ \\
\hline
\end{tabular}

Three arrays of wells were installed at varying distances hydraulically upgradient of three septic-tank test sites to determine water quality at various depths in the surficial aquifer system prior to increased residential development in the area. These wells (PB-1524, PB-1552, and PB-1553 in the northern part of the area; PB-1560, PB-1561, and PB-1562 in the western part, and PB-1583, PB-1584, and PB-1585 in the southern part) (fig. 2) were drilled by the reverse-air rotary method to avoid aquifer contamination with drilling fluids. The wells ranged in depth from 22 to $250 \mathrm{ft}$ (table 1).

An additional 21 wells (PB-1520 to PB-1523 and PB-1525 to PB-1541), 20 to $23 \mathrm{ft}$ deep, for ground-water level measurements, and 15 wells (PB-1590A-G and PB$1609 \mathrm{~A}-\mathrm{H}$ ), 10 to $20 \mathrm{ft}$ deep at the septic-tank test sites (fig. 2, tables 1 and 2), were drilled by the rotary method using only local ground water as a drilling fluid. Wells PB-1589A-F, 5 to $20 \mathrm{ft}$ deep at septic-tank test site 3 in the northeastern part of the area (fig. 2; table 2), were driven with a handheld hydraulic hammer because of space limitations.

\section{Surface-Geophysical Surveys}

DCR and GPR surveys (figs. 3 and 4) were conducted throughout the northern Midlands to supplement groundwater quality and lithologic data. Information obtained from the surveys also was used to indicate areas where additional water-quality and geologic data were needed.
DCR soundings were obtained at 94 sites in the northern Midlands (fig. 3) using a DCR meter and a Wenner electrode configuration (Zohdy and others, 1974). Most soundings were spaced at 1- to 2-mi intervals along dirt roads to form seven east-west traverses and four north-south traverses, totaling about $50 \mathrm{mi}$ of surface-geophysical transects. These data were used to locate areas of probable high chloride concentrations in water in the surficial aquifer system and to evaluate proposed shallow monitoring well site locations in the area. The DCR sounding data and a more detailed description of the technique are described by Peterson (1988).

GPR was used to determine the areal extent, continuity, and depths of near-surface marls in the northern Midlands. The septic-tank test sites were included in the areas surveyed. GPR was selected because of known attenuation of radar signals by colloidal-size particles, such as clays and marls (Olhoeft, 1984). A continuous stream of electromagnetic pulses is discharged from a radar antenna-receiver. Each transmitted pulse travels through the subsurface until it reaches a geologic unit with different transmission properties, such as a marl unit. When the pulse hits this unit, part of the pulse is reflected back to the antenna-receiver, while the rest of the pulse travels into and through the reflecting unit unless it is totally attenuated. A continuous stream of reflected pulses is received by the antenna and fed into a graphic recorder which produces the profile. The proportion of colloidal-size particles (marl) and the thickness of each unit into which the pulse travels determine attenuation of the pulse and the depth of penetration. 


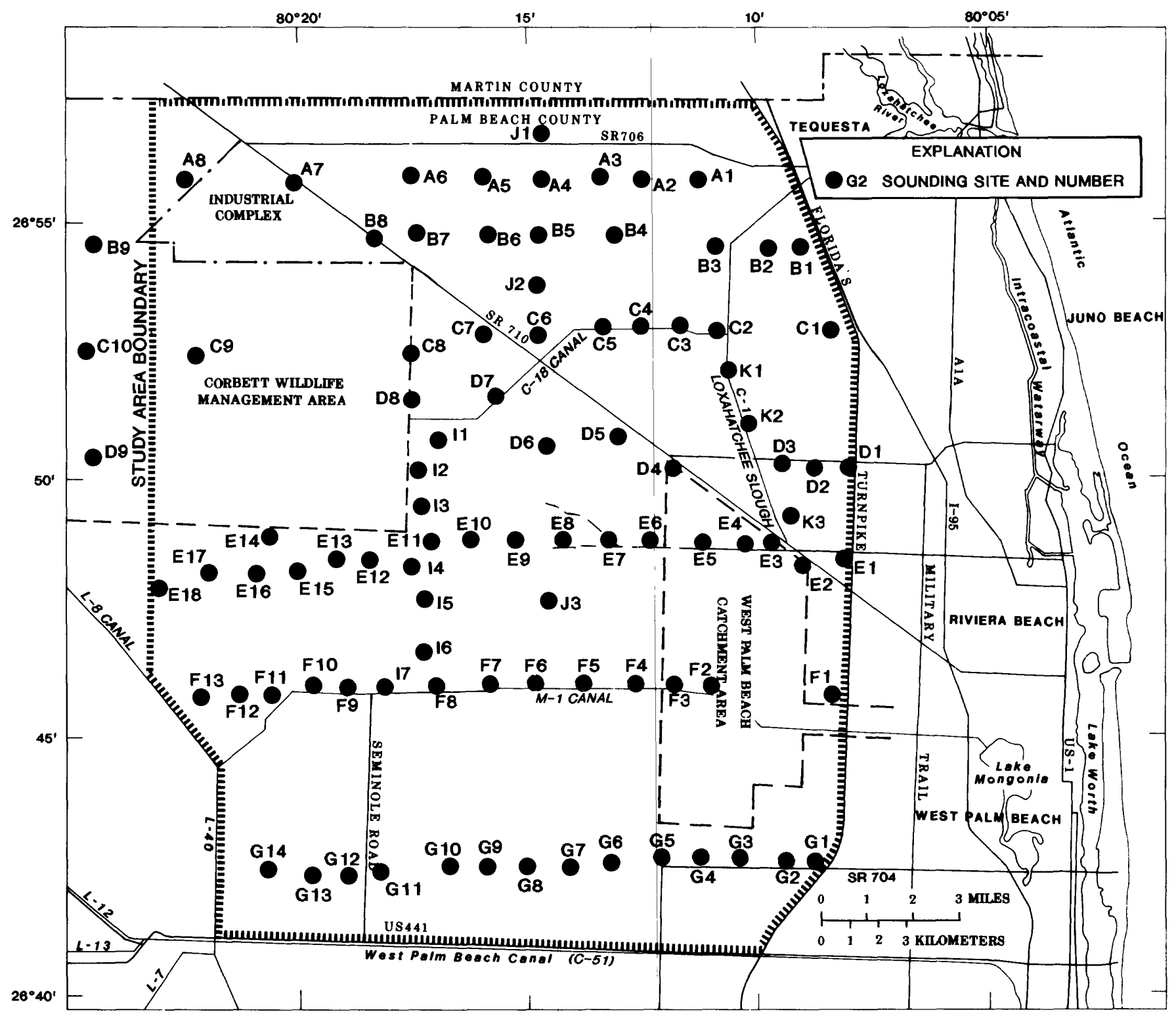

Figure 3. Location of direct-current resistivity sounding sites in the northern Midlands. 


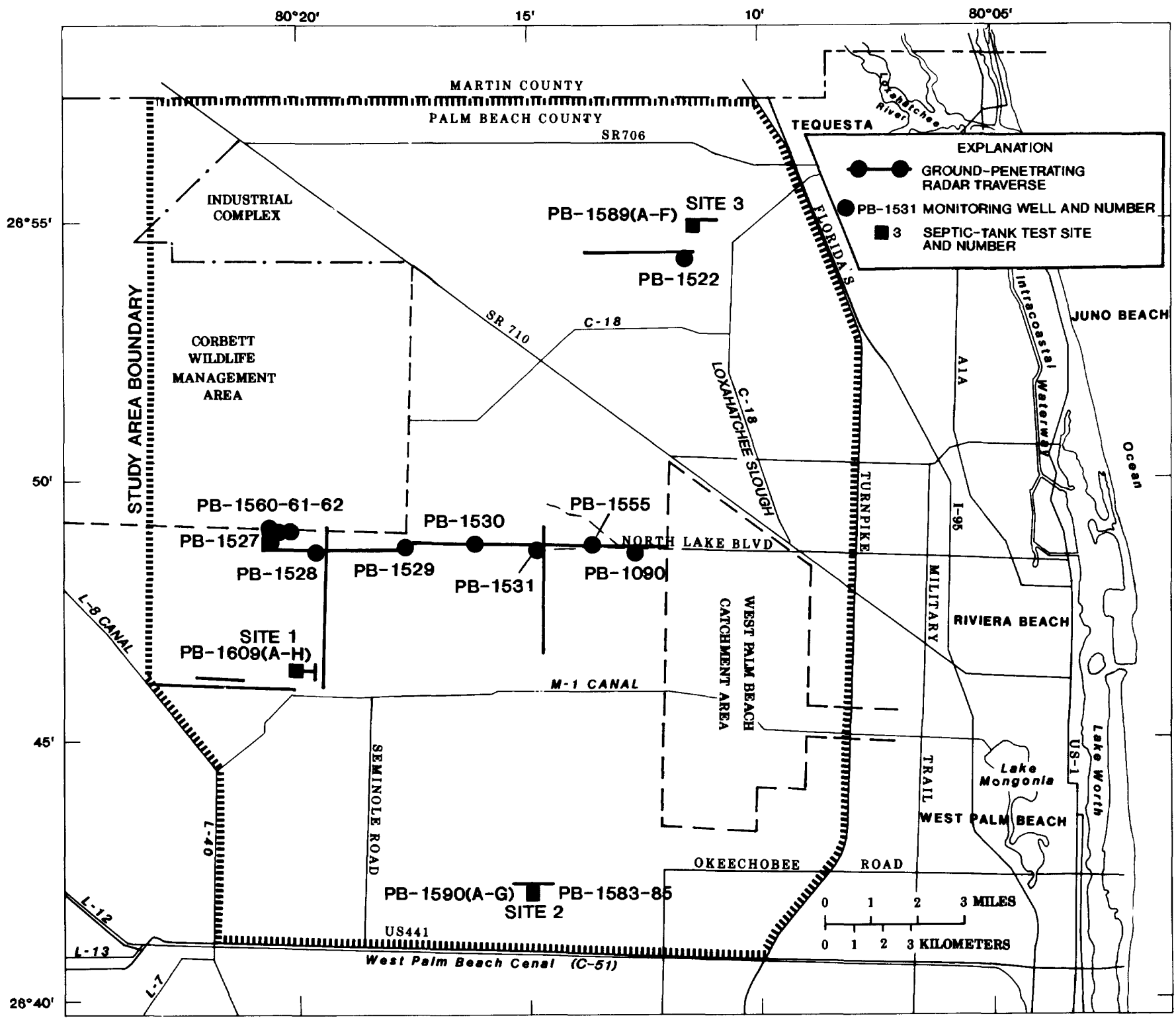

Figure 4. Location of ground-penetrating radar traverses in the northern Midlands. 
Eleven continuous GPR profiles (fig. 4) were run and repeated, traveling in the opposite direction, to determine reproducibility, and a short section of one profile was frequently repeated to ensure that the equipment was working properly. Depth to the uppermost marl units, indicated by GPR, was calibrated using lithologic logs and depths to water for nearby wells and marl outcrops in nearby canals and excavations.

\section{Septic-Tank Test Site Selection}

Three residences were selected as test sites (fig. 2) to investigate migration of septic-tank effluent in the ground water. When the investigation began, the septic tank and drainfield at site 1 had been in use for 5 years, and those at sites 2 and 3 had been in use 11 or 12 years. The drainfields (Canter and Knox, 1985, p. 22-29) at all three sites were downgradient from the septic tanks, relative to regional hydraulic gradients (Miller, 1985a; 1985b). Drainfield distribution lines at all three sites were consistently in saturated materials throughout the investigation.

Selection of the septic-tank test sites was delayed until geologic data obtained during drilling of water-level and water-quality monitoring wells elsewhere in the area and the DCR data had been evaluated. This approach was used to ensure that each test site was hydrogeologically similar to large parts of the study area surrounding the individual sites.

\section{HYDROGEOLOGY}

This section describes the geology, ground-water levels and movement, and ground-water quality of the surficial aquifer system in the northern Midlands. The geologic discussion is limited to the uppermost part of the surficial aquifer system, although lithologic logs (appendix I) contain data for depths to the base of the surficial aquifer system. Ground-water levels and movement in the area are discussed as they relate to geology, topography, and cultural features. Ground-water quality (tables 3-5) under predevelopment conditions and under the influence of pockets of residual seawater are also described.

Lithologic and ground-water quality data collected throughout thc network of wells (fig. 2) were interpreted using supplementary DCR (Peterson, 1988) and GPR data.

\section{Geology}

The uppermost part of the surficial aquifer system (to a depth of $50 \mathrm{ft}$ below land surface) is primarily composed of unconsolidated sand and marl. Localized lenses of shell and shelly limestone were penetrated during construction of the monitoring wells. Previous studies indicate that these sediments are part of the Fort Thompson Formation and Pamlico Sand deposited during the Pleistocene Epoch (Parker and others, 1955; Miller, 1988).

Semiconfining layers of muddy organic sand and silt or marl are common between land surface and a depth of about $40 \mathrm{ft}$ throughout most of the northern Midlands (figs. 5 and 6). A clayey marl unit, 4- to $10-\mathrm{ft}$ thick near land surface, is apparent throughout the northern Midlands area. In most of the area, the top of this marl unit is about 4 to $10 \mathrm{ft}$ below land surface, and probably was deposited in a lagoonal or swampy environment in which organic debris also accumulated. The marl is dark-olive-gray to bluish-green and is composed of micrite or lime mud, containing 25 to 30 percent fine to very fine quartz sand. At some sites, it contains 10 to 20 percent shell fragments. Another semiconfining layer of muddy organic sand occurs below the marl layer. The sand is darkyellowish-brown to olive-gray and is composed of fine to very fine quartz grains and silt-size organic material. In places, units containing 20 to 30 percent shell fragments are interlayered with organic sand.

Organic fine sand and shallower marl layers form a nearly continuous semiconfining section of sediments, which tends to retard (but not prevent) downward infiltration of rainfall, thereby reducing the rate of recharge to, and the effective flushing of, the main producing zones of the surficial aquifer system. Hydraulic conductivities for the semiconfining section were determined to be less than $25 \mathrm{ft} / \mathrm{d}$, as compared with those of main producing zones that ranged from 40 to $1,230 \mathrm{ft} / \mathrm{d}$ (L.J. Swayze, U.S. Geological Survey, written commun., 1989).

In general, the uppermost marl unit commonly occurs 4 to $5 \mathrm{ft}$ below land surface. However, because most of the drilling of test and monitoring wells was along canal levees and road rights-of-way, where the upper $4 \mathrm{ft}$ has been disturbed and replaced with fill, the marl could have been less than $4 \mathrm{ft}$ from the undisturbed land surface. Marl units were observed at land surface in many undisturbed locations. The marl layer at well PB-1533 near the southwest corner of the area (fig. 2) is $8 \mathrm{ft}$ below the surface. Information from wells drilled near the northeastern corner of the area indicates that the upper marl unit there is between 5 and $10 \mathrm{ft}$ below land surface. Lithologic logs, observations along canal and other excavations, and data from GPR surveys were used to prepare the map showing depth to the marl (fig. 7). It shows the approximate depth below land surface of the uppermost confining marl layer and indicates that within most of the area the marl occurs within $5 \mathrm{ft}$ of land surface. The shallow position of near-surface marl and its low permeability will affect the operation of the septic tanks proposed for this part of Palm Beach County by limiting effluent infiltration and migration. 

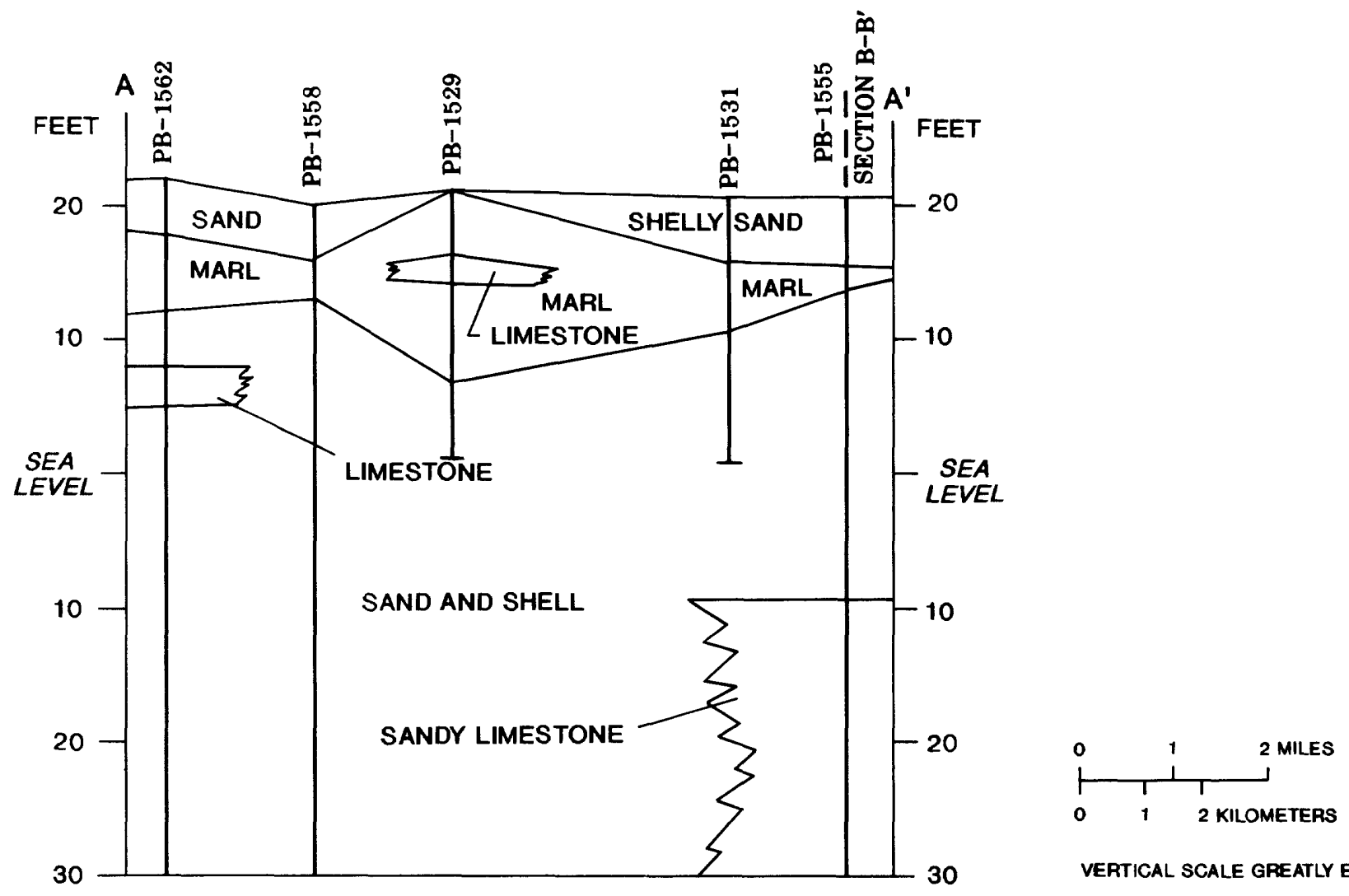

VERTICAL SCALE GREATLY EXAGGERATED

Figure 5. Generalized lithologic section $A-A^{\prime}$. 


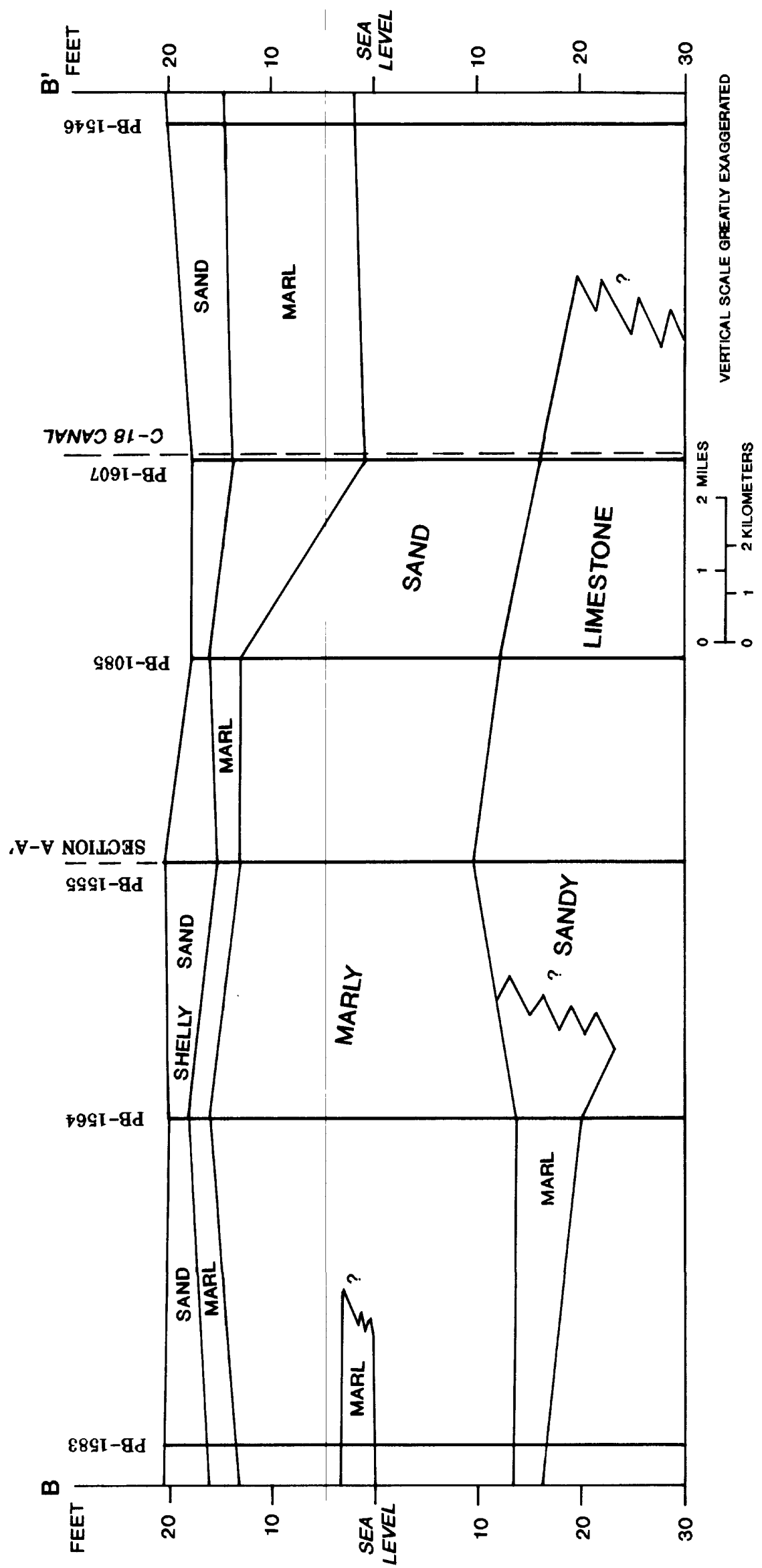

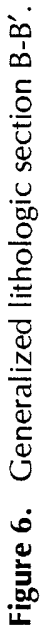




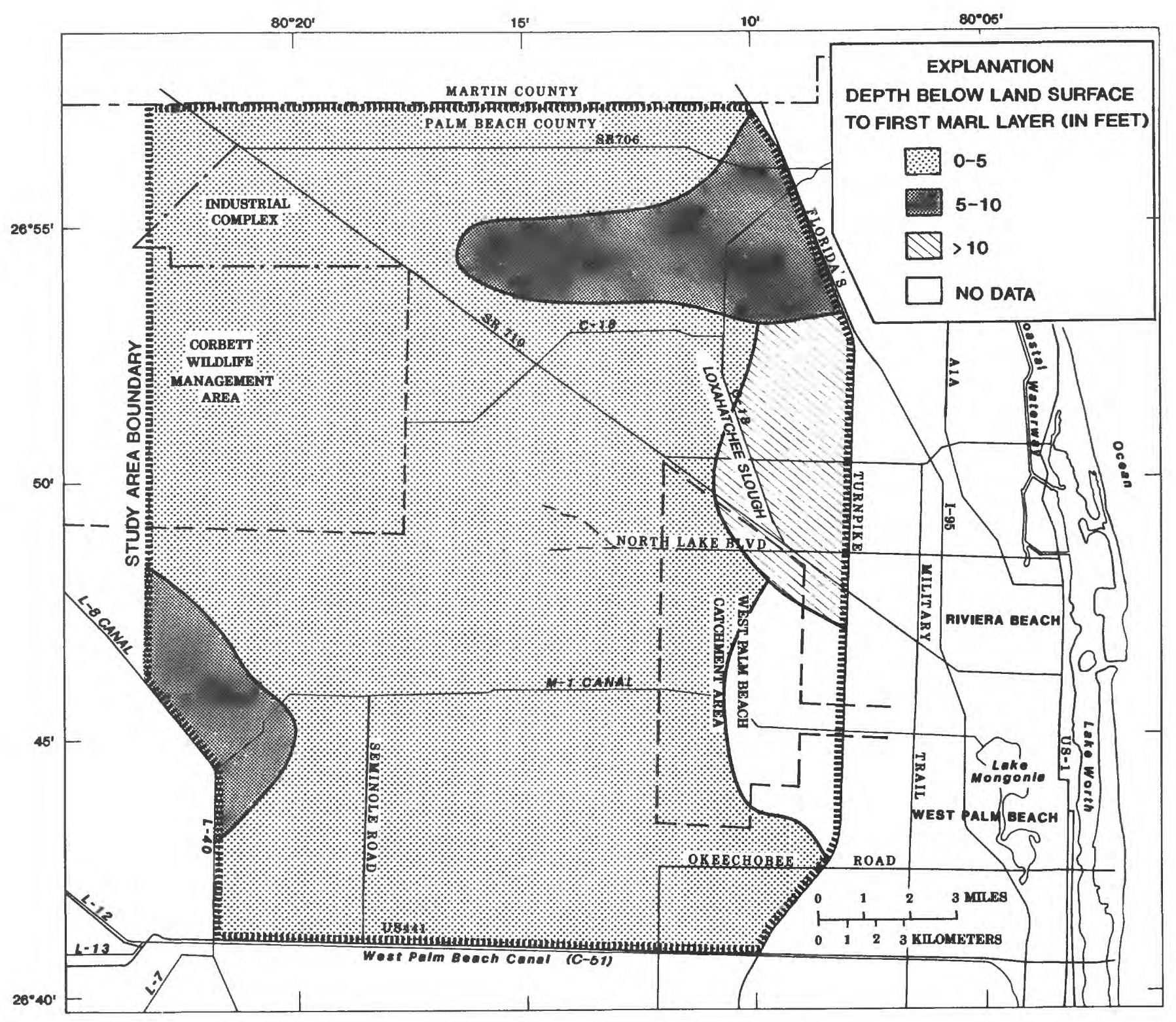

Figure 7. Depth below land surface of uppermost marl layers in the northern Midlands. 


\section{Ground-Water Levels and Movement}

Much of the study area is affected by frequent flooding as a result of near-surface low-permeability marl, heavy seasonal rainfall, flat topography, and lack of adequate drainage by canals. In general, the water table is highest in the northwestern part of the area and lowest in the eastern and southern parts where drainage canals have been dug to reduce flooding (fig. 2).

The altitude and configuration of the water table in the area north of the C-51 Canal and northeast of the L-8 Canal were depicted in reports prepared by Miller (1985a; 1985b). The most prominent feature of these water-table maps is a ground- water mound in the northwestern part of the area where the water-table altitude exceeded $22 \mathrm{ft}$ above sea level. Based on these maps, the regional directions of ground-water flow are east toward the Atlantic Ocean, southwest toward the L-8 Canal, and south toward the C-51 Canal. The groundwater mound in the northwestern area conforms with land-surface altitudes in that area. In the south-central part of the study area, ground-water levels were maintained by regulated flows and stages in the L-8 and M-1 Canals that drain to the West Palm Beach Catchment Area. Wide spacing of water-level contours in the northeastern part of the study area in the maps prepared by Miller indicate a relatively flat water table that results from the drainage effect of the southern and southwestern reaches of the C-18 Canal.

\section{Ground-Water Quality}

Ground-water quality prior to extensive residential development in the northern Midlands was determined by several sampling and analytical approaches. Water samples were collected at $10-\mathrm{ft}$ intervals during drilling of 10 wells that fully penetrate the surficial aquifer system (table 3 ) to identify variations in chloride concentrations with depth. Periodically, water samples were collected and analyzed for chloride concentrations at 46 wells, ranging in depth from 15 to $250 \mathrm{ft}$ (table 4), to determine whether concentrations varied during the study. Also, analyses of major constituents, nutrients, and related characteristics of water from three arrays of wells that tap producing zones in the surficial aquifer system (fig. 8) were made to characterize groundwater quality upgradient from the septic-tank sites at widely separated areas. Analyses were performed by the U.S. Geological Survey laboratory.

\section{Chloride Concentrations}

Ground water in the northern Midlands (fig. 2) has a large range of chloride concentrations because of varying extents of dilution or flushing of residual seawater in the sediments. Water samples collected from 51 wells $(15-250 \mathrm{ft}$ deep) during drilling and after completion in 1986-87 contained chloride concentrations (tables 3 and 4) ranging from $6 \mathrm{mg} / \mathrm{L}$ (well PB-1538) to $5,950 \mathrm{mg} / \mathrm{L}$ (well PB-1562). Residual seawater in the western part of the study area and the Loxahatchee Slough (Miller, 1988, p. 23-33) is the principal source of high chloride concentrations in ground water. In those parts of the northern Midlands most affected by pockets of residual seawater, chloride concentrations in ground water generally are a function of depth (table 3 ) but, to some extent, vary seasonally (table 4).

Much of the northernmost part of the northern Midlands (including the Corbett Wildlife Management Area) is greatly affected by residual seawater (fig. 2). Chloride concentrations were high at all depths near the southern border of the management area; water from well PB-1527 (20 $\mathrm{ft}$ deep) had chloride concentrations as high as $1,400 \mathrm{mg} / \mathrm{L}$, well PB-1558 (190 ft deep) as high as 3,000 mg/L, and well PB-1562 (250 ft deep) as high as 5,950 mg/L (tables 3 and 4). At the eastern perimeter, water from well PB-716 (15 ft deep) and well PB-1109A (128 ft deep) had chloride concentrations ranging from 22 to $960 \mathrm{mg} / \mathrm{L}$ (table 4), indicating that residual seawater has been flushed from only the uppermost part of the surficial aquifer system. East of the management area, water from well PB-1524 (22 ft deep) had chloride concentrations as high as $580 \mathrm{mg} / \mathrm{L}$, and water from adjacent well PB-1552 (100 ft deep) had chloride concentrations as high as $700 \mathrm{mg} / \mathrm{L}$ (table 4 ). Water samples collected at the 140-ft depth during drilling of well PB-1552 (backfilled and cased to $100 \mathrm{ft}$ ) contained a chloride concentration of 950 $\mathrm{mg} / \mathrm{L}$ (table 3).

In the vicinity of Loxahatchee Slough (fig. 2), deeper ground water contains residual seawater. Data from three wells adjacent to the C-18 Canal indicate that at depths greater than about 50 to $75 \mathrm{ft}$, chloride concentrations exceed the secondary drinking-water standard of $250 \mathrm{mg} / \mathrm{L}$ (Florida Department of Environmental Regulation 1989a; 1989b). Water from well PB-1607 (180 ft deep), drilled adjacent to the C-18 Canal, had chloride concentrations ranging from 270 $\mathrm{mg} / \mathrm{L}$ at $60 \mathrm{ft}$ to $1,950 \mathrm{mg} / \mathrm{L}$ at $180 \mathrm{ft}$ (table 3). About $3 \mathrm{mi}$ south, also along the canal, water from well PB-1084 (133 ft deep) had chloride concentrations as high as $1,550 \mathrm{mg} / \mathrm{L}$ (table 4). Water from well PB-1099, sampled during a previous study, had a chloride concentration of $1,100 \mathrm{mg} / \mathrm{L}$ at $88 \mathrm{ft}$ (Miller, 1988, p. 52).

Generally, in areas other than the northernmost part of the Midlands or near the Loxahatchee Slough, chloride concentrations from the water table to a depth of about $100 \mathrm{ft}$ ranged from 6 to $195 \mathrm{mg} / \mathrm{L}$ (tables 3 and 4). One exception was water from well PB-1540 (22 ft deep), which had chloride concentrations that ranged from 105 to $260 \mathrm{mg} / \mathrm{L}$. At depths ranging from 100 to $160 \mathrm{ft}$, water from six wells in these areas had chloride concentrations ranging from 30 to $360 \mathrm{mg} / \mathrm{L}$ (tables 3 and 4 ). Water from only two wells in these areas had chloride concentrations higher than $250 \mathrm{mg} / \mathrm{L}$; water from wells PB-1555 and PB-1564 had concentrations of $450 \mathrm{mg} / \mathrm{L}$ at $130 \mathrm{ft}$ (table 3 ). 
Table 3. Chloride concentrations in samples collected during test-well drilling in the northern Midlands [Concentrations shown in milligrams per liter; --, data not available]

\begin{tabular}{|c|c|c|}
\hline $\begin{array}{c}\text { Local well } \\
\text { number }\end{array}$ & $\begin{array}{c}\text { Well depth } \\
\text { (feet) }\end{array}$ & $\begin{array}{c}\text { Date of } \\
\text { collection }\end{array}$ \\
\hline $\begin{array}{l}P B-1546 \\
P B-1551 \\
P B-1552 \\
P B-1555 \\
P B-1558 \\
P B-1562 \\
P B-1564 \\
P B-1567 \\
P B-1583 \\
P B-1607\end{array}$ & $\begin{array}{l}140 \\
130 \\
140 \\
130 \\
190 \\
250 \\
130 \\
170 \\
170 \\
180\end{array}$ & $\begin{array}{l}6 / 15 / 86 \\
7 / 15 / 86 \\
7 / 17 / 86 \\
7 / 18 / 86 \\
7 / 22 / 86 \\
7 / 25 / 86 \\
7 / 30 / 86 \\
8 / 1 / 86 \\
10 / 21 / 86 \\
1 / 20 / 87\end{array}$ \\
\hline
\end{tabular}

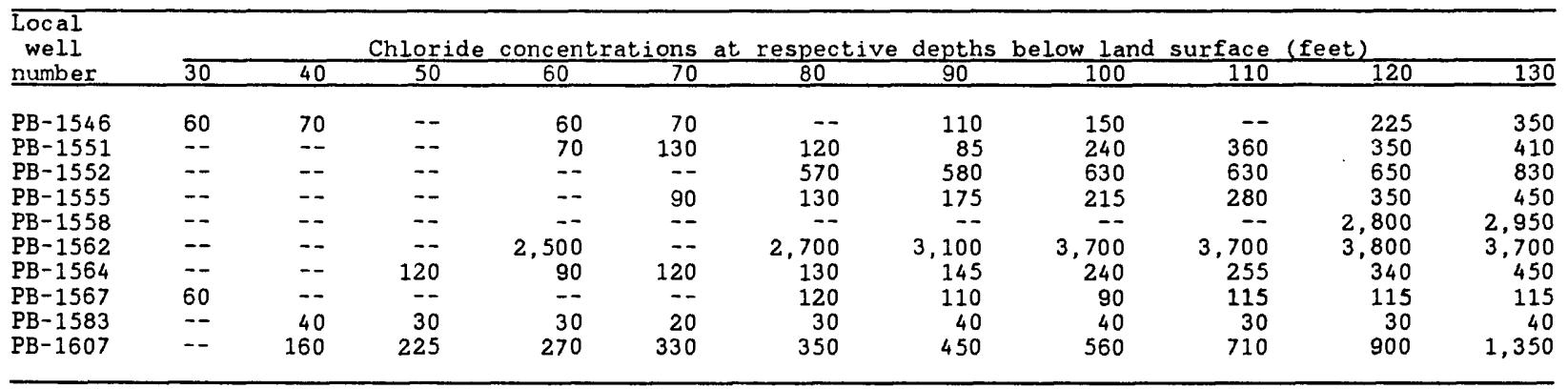

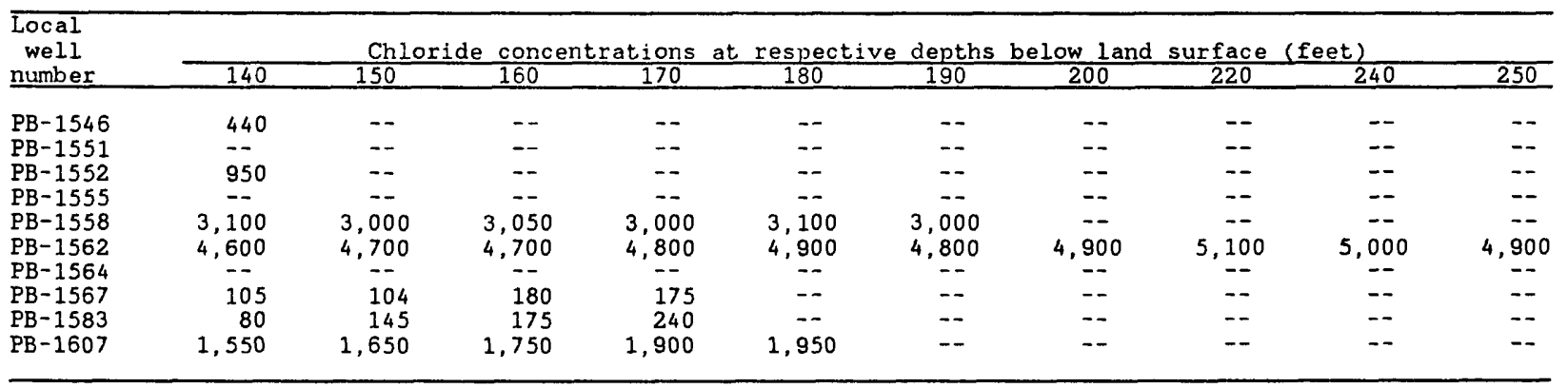

The distribution of chloride concentrations in ground water in the west-east profile A- $\mathrm{A}^{\prime}$ is shown in figure 9. Decreasing chloride concentrations toward the suburban eastern part of the area indicates the effect that canal drainage has on flushing highly mineralized water from shallow sediments. The relatively thick section of ground water with chloride concentrations less than $200 \mathrm{mg} / \mathrm{L}$ in the southern part of the area, as shown in north-south profile B-B' (fig. 10), probably is the result of drainage by the C-51 and M-1 Canals and subsequent flushing of residual seawater. Miller (1988, p. 22) concluded that mineralized water in the sediments was a result of residual seawater from the Pleistocene Epoch. Low permeability of sand and marl sediments has retarded flushing of poor quality ground water in recent geologic time. Permeability of the surficial aquifer system generally increases eastward, facilitating rainfall infiltration, a higher rate of ground-water movement, and dilution and flushing of residual seawater.

\section{Major Constituents and Characteristics}

Because of the diversity of ground-water quality due to patchy areas of residual seawater, three arrays of wells drilled to various depths were constructed in different areas of the northern Midlands (fig. 8) to characterize the water chemistry. Array 2 wells are about $120 \mathrm{ft}$ upgradient from septic-tank test site 2 in an area that is seemingly less affected by residual seawater (except possibly at depths much greater than $100 \mathrm{ft}$ ). Ground-water chloride concentrations at array 2 average less than $70 \mathrm{mg} / \mathrm{L}$. Array 3 wells are in the northern part of the study area, about 3 mi west of septic-tank test site 3 . Ground-water chloride concentrations at array 3 average about $550 \mathrm{mg} / \mathrm{L}$. Array 1 wells are about 3 mi upgradient from septic-tank test site 1 , in an area where ground water is affected by residual seawater and chloride concentrations are higher than 1,000 $\mathrm{mg} / \mathrm{L}$. 
Table 4. Chloride concentrations in water from selected wells in the northern Midlands [Concentrations in milligrams per liter; --, data not available; **, well destroyed]

\begin{tabular}{|c|c|c|c|c|c|c|}
\hline $\begin{array}{c}\text { Well } \\
\text { number }\end{array}$ & $\begin{array}{l}\text { Cased } \\
\text { depth } \\
\text { (feet) }\end{array}$ & $\begin{array}{c}\text { July } 24-25, \\
1986 \\
\end{array}$ & $\begin{array}{c}\text { Chloride conc } \\
\text { January 5-7. } \\
1987\end{array}$ & $\begin{array}{c}\text { ation on in } \\
\text { May } 12-19 \\
1987\end{array}$ & $\begin{array}{r}\text { ed sampling date } \\
\text { September } 2-4, \\
1987\end{array}$ & $\begin{array}{r}\text { December } \\
1987 \\
\end{array}$ \\
\hline$P B-685$ & 17 & -- & 16 & 10 & -- & 12 \\
\hline$P B-715$ & 67 & 100 & 95 & 80 & 100 & 95 \\
\hline $\mathrm{PB}-716$ & 15 & 31 & 26 & 22 & 22 & 24 \\
\hline PB-719 & 24 & -- & 10 & 6 & 12 & 10 \\
\hline$P B-875$ & 22 & 33 & 38 & 30 & 38 & 32 \\
\hline PB-876 & 41 & 40 & 28 & 30 & 50 & 42 \\
\hline PB- 1084 & 133 & -- & -- & - & 1,550 & 1,380 \\
\hline PB- 1089 & 135 & -- & 95 & 84 & 82 & 89 \\
\hline PB-1098 & 80 & 47 & 62 & 34 & 38 & 62 \\
\hline $\mathrm{PB}-1109 \mathrm{~A}$ & 128 & -- & 860 & 880 & 940 & 960 \\
\hline PB-1109B & 40 & 18 & 20 & 34 & 35 & 22 \\
\hline PB-1157 & 100 & -- & 14 & $* *$ & -- & -- \\
\hline$P B-1460$ & 30 & 48 & 78 & 110 & 105 & 100 \\
\hline PB- 1520 & 22 & 19 & 28 & 28 & 30 & 22 \\
\hline$P B-1521$ & 22 & -- & 34 & 34 & 18 & 19 \\
\hline$P B-1522$ & 22 & 42 & 42 & 40 & 44 & 38 \\
\hline PB- 1523 & 22 & 57 & $* *$ & -- & -- & -- \\
\hline$P B-1524$ & 22 & 500 & 540 & 580 & 550 & 560 \\
\hline$P B-1525$ & 22 & -- & 14 & 16 & 20 & 15 \\
\hline$P B-1526$ & 21 & -- & -- & -- & 11 & 11 \\
\hline PB- 1527 & 20 & 1,220 & 1,050 & 1,220 & 1,400 & -- \\
\hline PB- 1528 & 20 & 42 & 40 & 38 & 39 & 34 \\
\hline$P B-1529$ & 22 & 14 & 10 & 12 & 14 & 12 \\
\hline$P B-1530$ & 23 & -- & 18 & 20 & 21 & -- \\
\hline$P B-1531$ & 20 & 16 & 10 & 11 & 14 & 14 \\
\hline PB- 1532 & 22 & 14 & 10 & 13 & 14 & 16 \\
\hline PB- 1533 & 22 & 90 & 92 & 90 & 115 & 99 \\
\hline PB- 1534 & 22 & 90 & 112 & 90 & 105 & 90 \\
\hline PB-1535 & 22 & 58 & 50 & 50 & rev & -- \\
\hline PB- 1536 & 22 & 12 & 10 & 18 & 48 & 10 \\
\hline PB- 1537 & 22 & 21 & 16 & $* *$ & - & -- \\
\hline PB- 1538 & 22 & 10 & 6 & 6 & 10 & 8 \\
\hline PB-1539 & 22 & 195 & 180 & 185 & 195 & 170 \\
\hline PB- 1540 & 22 & -- & 110 & 260 & 115 & 105 \\
\hline PB-1541 & 20 & -- & 18 & 58 & -- & 40 \\
\hline PB- 1546 & 140 & -- & 54 & -- & -- & 275 \\
\hline PB- 1552 & 100 & - & 680 & 550 & 700 & 680 \\
\hline PB- 1553 & 37 & -- & 590 & 660 & 600 & 600 \\
\hline PB- 1554 & 40 & - & 33 & 26 & 29 & 26 \\
\hline PB- 1555 & 130 & -- & 360 & -- & 100 & 150 \\
\hline PB- 1560 & 56 & -- & 1,200 & 1,120 & 1,180 & 1,100 \\
\hline PB- 1561 & 163 & -- & -- & 2,300 & 2,600 & 2,350 \\
\hline РЬ -1562 & 250 & -- & -- & -- & 5,950 & $* *$ \\
\hline PB- 1583 & 160 & -- & 95 & 202 & 90 & 140 \\
\hline PB-1584 & 70 & -- & 28 & 28 & 28 & 26 \\
\hline PB- 1585 & 110 & -- & -- & 35 & 31 & 30 \\
\hline
\end{tabular}




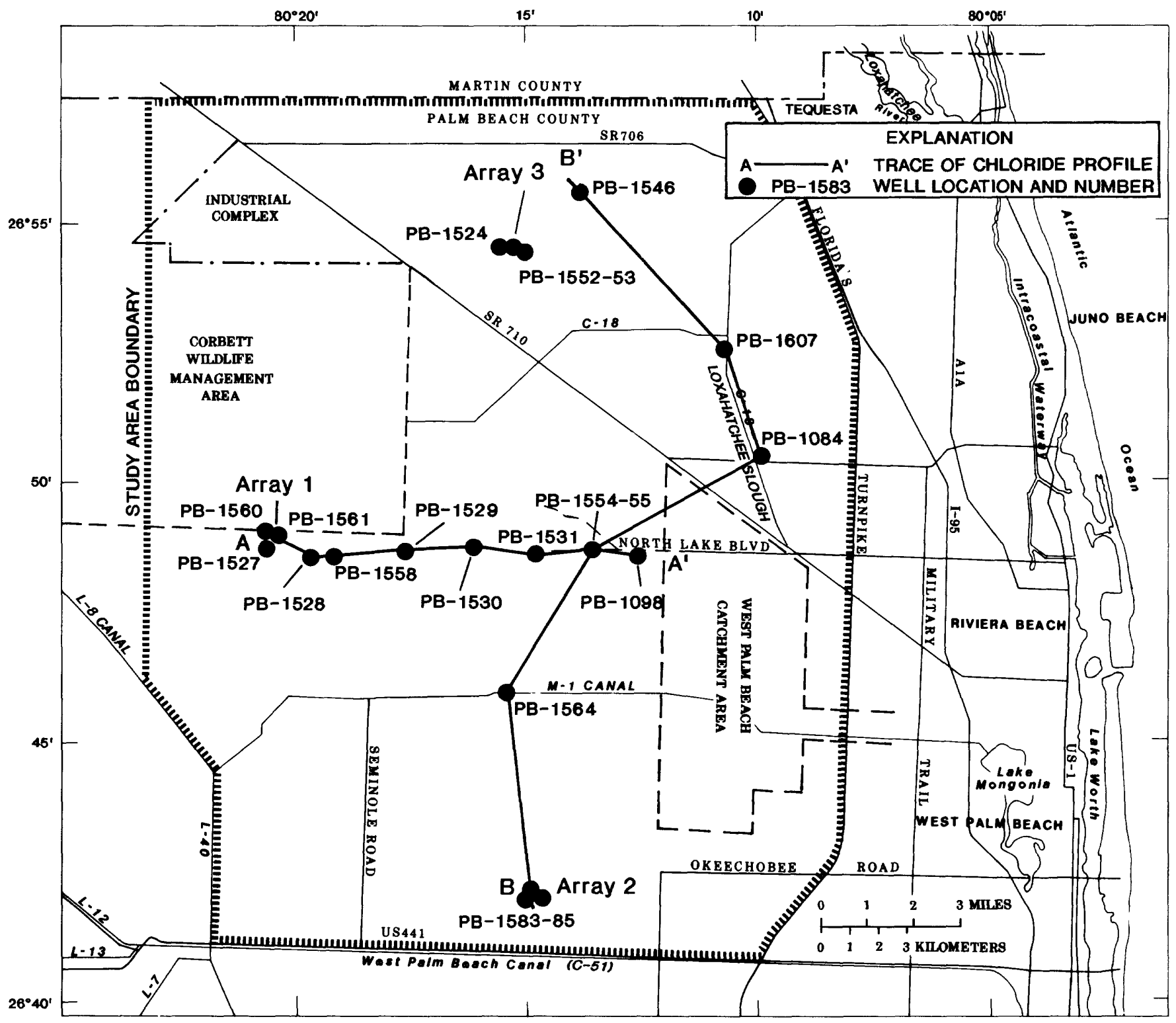

Figure 8. Location of chloride profiles $A-A^{\prime}$ and $B-B^{\prime}$ and arrays of quality-of-water wells in the northern Midlands. 


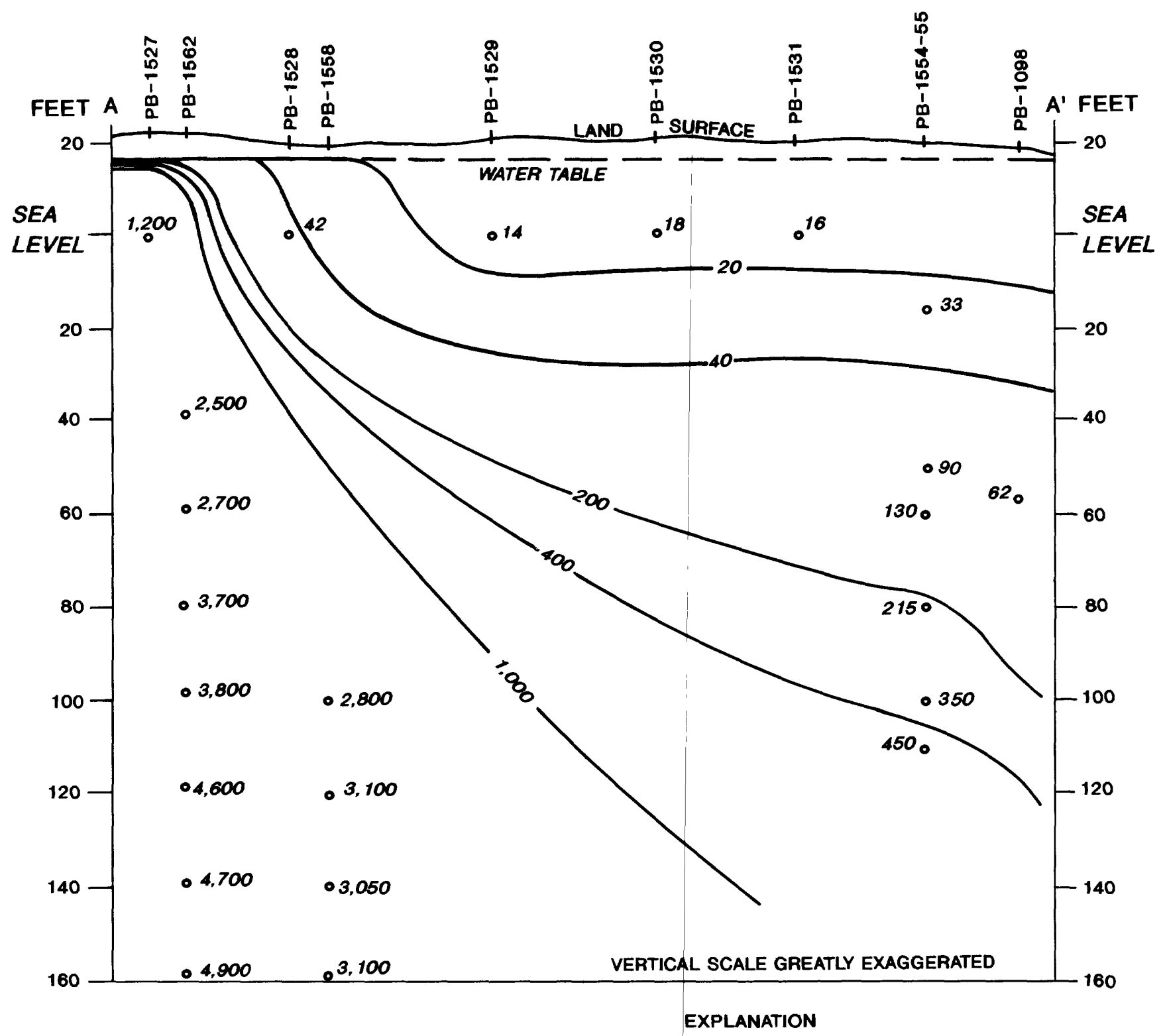

- 100 - LINE OF EQUAL ChLORIDE CONCENTRATION,

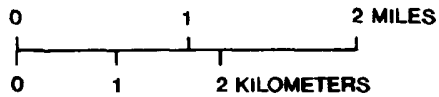

IN MILLIGRAMS PER LITER

- 2,800 POINT OF SAMPLING AND CHLORIDE CONCENTRATION

I PB-1528 TEST WELL AND NUMBER

Figure 9. Chloride concentrations along profile $A-A^{\prime}$ in the northern Midlands. 


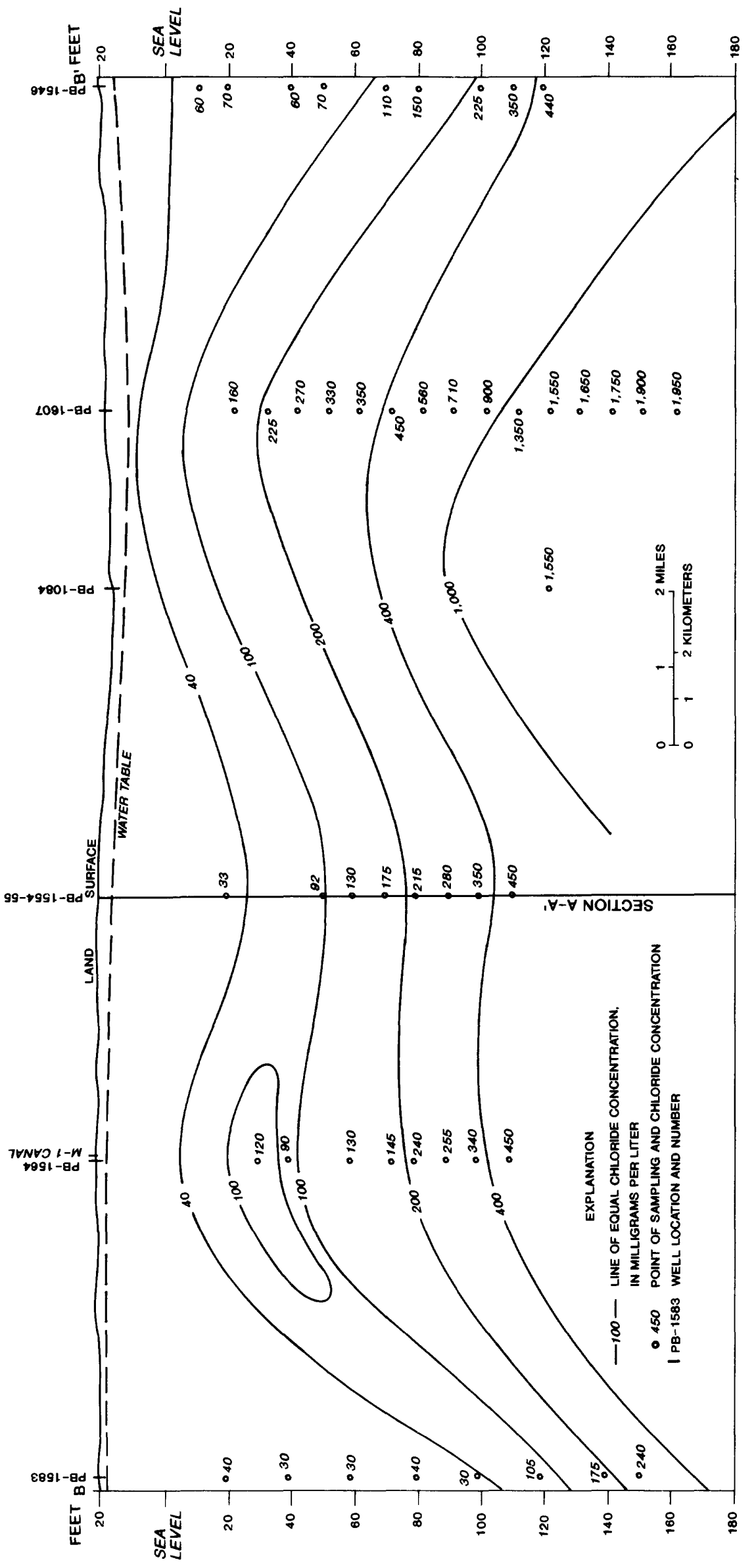

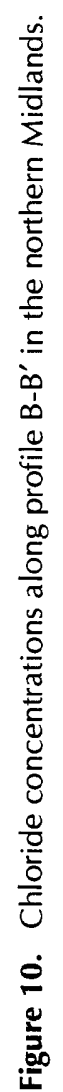


Water from each well was sampled three or four times between December 1986 and December 1987. The results of analyses of these samples (table 5-7) indicate a relation between chloride concentration, a measure of residual seawater content, and other major inorganic ions (calcium, magnesium, sodium, potassium, and sulfate). These constituents have highest concentrations in water samples from array 1 wells (table 5), in the area of greatest residual seawater effect; the lowest concentrations were in water samples from array 2 wells (table 6), in the area least affected by residual seawater.

Analytical results (table 5-7) indicate that nitrogen, phosphorus, ammonia, organic nitrogen, and organic carbon are not related to chloride concentrations. These constituent concentrations generally are similar at all three well arrays, regardless of depth and residual seawater content: ammonia plus organic nitrogen concentrations range from 1.0 to 2.2 $\mathrm{mg} / \mathrm{L}$, with a median of $1.6 \mathrm{mg} / \mathrm{L}$. Nitrite and nitrate concentrations are almost nonexistent because anaerobic conditions in the fine sand and marl of the surficial aquifer system limit oxidation reactions (Hem, 1985, p. 124). Total phosphorus, though in trace amounts, shows a wide range in concentration, from 0.02 to $0.36 \mathrm{mg} / \mathrm{L}$. Total organic carbon (TOC) concentrations had a median of about $14 \mathrm{mg} / \mathrm{L}$, and there seems to be no relation between TOC concentrations and concentrations of other constituents that were analyzed.

Several constituent concentrations listed in tables 5 to 7 exceed primary and secondary drinking-water standards of the Florida Department of Environmental Regulation (FDER). For comparison of values, the following is a list of constituents for which analyses were made during the study and for which there are standards established by the Florida Department of Environmental Regulation (1989a; 1989b). The Palm Beach County drinking-water standards are the same as those established by FDER for the inorganic constituents in the list. However, the County also has a primary drinking-water standard for nitrite $\left(\mathrm{NO}_{2}\right)$ of $1 \mathrm{mg} / \mathrm{L}$ and a different secondary drinking water-standard for $\mathrm{pH}$ of 6.9 to 9.5 (Alan Trefry, Palm Beach County Department of Environmental Regulation and Management, oral commun., 1989).

\begin{tabular}{lcc}
\hline Property or constituent & $\begin{array}{c}\text { FDER standards } \\
\text { Primary drinking- } \\
\text { water standard }\end{array}$ & $\begin{array}{c}\text { Secondary drinking- } \\
\text { water standard }\end{array}$ \\
\hline Nitrate $\left(\mathrm{NO}_{3}\right)$ as nitrogen, & 10 & \\
$\quad$ in $\mathrm{mg} / \mathrm{L}$ & 160 & 250 \\
Sodium $(\mathrm{Na})$, in $\mathrm{mg} / \mathrm{L}$ & & 250 \\
Chloride $(\mathrm{Cl})$, in $\mathrm{mg} / \mathrm{L}$ & 15 \\
Sulfate $\left(\mathrm{SO}_{4}\right)$, in mg/L & 500 \\
Color, in platinum-cobalt units & $6.5-8.5$ \\
Dissolved solids, in mg/L & \\
pH, in standard units &
\end{tabular}

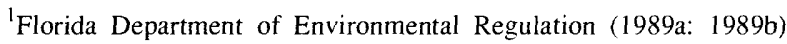
standards. The primary drinking-water standard is established for contamination which may cause adverse human health effects. The secondary drinkingwater standard is established for contamination that affects the esthetic quality of drinking water. At considerably higher concentrations, health implications may exist.
Water from array 1 wells were greatly influenced by residual seawater (table 5). Sodium concentrations $(760-1,400 \mathrm{mg} / \mathrm{L})$ greatly exceeded the primary drinkingwater standard $(160 \mathrm{mg} / \mathrm{L})$ of FDER. Chloride $(1,100-2,300$ $\mathrm{mg} / \mathrm{L})$, sulfate $(340-520 \mathrm{mg} / \mathrm{L})$, and dissolved solids $(2,850$ $5,200 \mathrm{mg} / \mathrm{L}$ ) concentrations in water from these wells greatly exceeded FDER secondary drinking-water standards. The concentrations increased with depth.

Water from array 2 wells PB-1584 and PB-1585 (70 and $110 \mathrm{ft}$ deep) had relatively low chloride concentrations (21-24 and $24-27 \mathrm{mg} / \mathrm{L}$ ), indicating the absence of residual seawater (table 6). Water from well PB-1583 (160 ft deep) had concentrations of 72 to $190 \mathrm{mg} / \mathrm{L}$ (table 6), less than the $250 \mathrm{mg} / \mathrm{L}$ secondary drinking-water standard but still an indication that flushing of highly mineralized residual seawater near the base of the surficial aquifer system was not complete in the area. None of the constituents for which standards exist exceeded drinking-water standards in water the three wells at array 2, except dissolved solids which exceeded the standards in two water samples (593 and $719 \mathrm{mg} / \mathrm{L}$ ) from well PB-1583.

Water from array 3 wells PB-1524, PB-1552, and PB1553 (22-100 ft deep) had chloride concentrations (440-670 $\mathrm{mg} / \mathrm{L}$ ) that were lower than those in water from array 1 wells, but which exceeded the FDER secondary drinking-water standard of $250 \mathrm{mg} / \mathrm{L}$ (tables 5 and 7). Concentrations of sodium (310-430 $\mathrm{mg} / \mathrm{L})$ and dissolved solids $(1,480-1,820$ $\mathrm{mg} / \mathrm{L}$ ) in ground water from array 3 wells were two or three times greater than the secondary drinking-water standards (table 7). The color of water in these wells, generally a physical indicator of organic material, also exceeded the FDER secondary drinking-water standard.

Water-quality data collected from the three well arrays (tables 5-7) along with chloride data from other wells (tables 3 and 4) indicate that, in some areas and at some depths, the surficial aquifer system in the northern Midlands contains mineralized water that is unsuitable for drinking. Use of water from the surficial aquifer system in these areas for domestic or public-water supply may not be feasible without extensive treatment.

\section{MIGRATION OF SEPTIC-TANK EFFLUENT}

Because of the frequency of flooding and the low permeability of surficial sedimentary material, many problems are associated with using septic tanks and drainfields in much of the northern Midlands (Canter and Knox, 1985 , p. 22). Fill is commonly used to elevate residential building sites above flood level, including the area in which septic tanks and drainfields are to be constructed. The matrix of the drainfield generally is composed of highly permeable material, such as gravel, shell, or coarse sand, to accept and transmit septic-tank effluent away from the septic-tank outlet.

Three rural residences, each served by a water-supply well and a septic tank and drainfield, were selected to 
Table 5. Concentrations of major constituents, nutrients, and related characteristics of water from wells PB-1560 and PB-1561 in array 1 in the northern Midlands

[All concentrations shown in milligrams per liter, except for $\mathrm{pH}$, in standard units; specific conductance, in microsiemens per centimeter, and color, in platinumcobalt units. <, less than the value; --, not determined]

\begin{tabular}{|c|c|c|c|c|c|c|c|}
\hline \multirow[b]{2}{*}{ Property or constituent } & \multicolumn{4}{|c|}{ Wel1 $\mathrm{PB}-1560$} & \multicolumn{3}{|c|}{ We11 $\mathrm{PB}-1561$} \\
\hline & $12 / 16 / 86$ & $5 / 15 / 87$ & $9 / 4 / 87$ & $12 / 4 / 87$ & $5 / 15 / 87$ & $9 / 4 / 87$ & $12 / 4 / 87$ \\
\hline $\mathrm{pH}$ & 7.5 & 8.0 & 7.4 & 8.2 & 7.4 & 7.4 & 8.0 \\
\hline Specific conductance & 4,850 & 4,740 & 4,750 & 4,650 & 8,440 & 8,370 & 8,310 \\
\hline Dissolved solids & 2,940 & 2,860 & 2,860 & 2,850 & 5,180 & 5,120 & 5,200 \\
\hline Fluoride & 0.4 & 0.4 & 0.3 & 0.3 & 0.4 & 0.4 & 0.3 \\
\hline Silica & 22 & 22 & 20 & 21 & 28 & 27 & 26 \\
\hline Calcium & 180 & 180 & 170 & 170 & 220 & 220 & 220 \\
\hline Magnesium & 52 & 52 & 52 & 52 & 100 & 100 & 100 \\
\hline Sodium & 790 & 770 & 770 & 760 & 1,400 & 1,400 & 1,400 \\
\hline Potassium & 24 & 24 & 25 & 24 & 61 & 2.0 & 61 \\
\hline Sulfate & 340 & 340 & 340 & 340 & 510 & 520 & 520 \\
\hline Chloride & 1,200 & 1,100 & 1,100 & 1,100 & 2,300 & 2,300 & 2,300 \\
\hline Color & 35 & 35 & 30 & 30 & 30 & 15 & 15 \\
\hline Nitrogen, total organic & 0.60 & 0.53 & 0.63 & 0.56 & 0.60 & 0.60 & 0.60 \\
\hline Nitrogen, total ammonia & 0.90 & 0.87 & 0.87 & 0.84 & 1.20 & 1.20 & 1.10 \\
\hline Nitrogen, total nitrite & $<0.01$ & $<0.01$ & $<0.01$ & $<0.01$ & $<0.01$ & $<0.01$ & $<0.01$ \\
\hline $\begin{array}{l}\text { Nitrogen, total ammonia } \\
\text { plus organic }\end{array}$ & 1.5 & 1.4 & 1.5 & 1.4 & 1.8 & 1.8 & 1.7 \\
\hline $\begin{array}{l}\text { Nitrogen, t, tal nitrite } \\
\text { plus nitral, }\end{array}$ & $<0.02$ & $<0.02$ & 0.02 & $<0.02$ & $<0.02$ & $<0.02$ & $<0.02$ \\
\hline $\begin{array}{l}\text { Phosphorus, total } \\
\text { orthophosphate }\end{array}$ & 0.04 & 0.02 & 0.02 & 0.02 & 0.01 & 0.01 & 0.01 \\
\hline Phosphorus, total & 0.22 & 0.14 & 0.09 & 0.15 & 0.10 & 0.04 & 0.08 \\
\hline Hardness noncarbonate & -- & 250 & 200 & 210 & 510 & 500 & 510 \\
\hline Carbon, total organic & 13 & 14 & 15 & -- & 13 & 15 & - \\
\hline
\end{tabular}

investigate migration of effluent from drainfields (fig. 2). The sites are widely separated--one is in the southwestern part of the study area (site 1), one is near the extreme southern boundary of the area (site 2), and the third is in the northeastern part of the area (site 3 ). Monitoring wells ranging in depth from 5 to $20 \mathrm{ft}$ below land surface were drilled at different distances immediately upgradient and downgradient (relative to the regional hydraulic gradient) of the septic tanks at sites 1 and 2 (table 2). Space limitations at site 3 (table 2) prevented drilling upgradient wells. Water levels in the monitoring wells were measured prior to collecting water-quality samples (tables 8-10) to determine local hydraulic gradients at the sites.

Most monitoring wells were sampled four times during 1986-87. Chemical analyses of these water samples were made for some constituents commonly associated with septic-tank effluent, including chloride, nitrogen, ammonia, and phosphorus (tables 11-13). Specific conductance, an indicator of the mineralization of ground water (and possible contaminant loading), was also determined for each well.

\section{Site 1}

Site 1 is in the southwestern part of the northern Midlands, about 0.5 mi north of the M-1 Canal (figs. 2 and 11). Fill material was used to elevate the house and drainfield above the flood plain as required by Palm Beach County building codes. The water-supply well (not shown) is near the northern side of the property and is completed at a depth of $35 \mathrm{ft}$ in the upper part of the surficial aquifer system. The drainfield is west of the residence, about $100 \mathrm{ft}$ southwest from the supply well and is in an area filled with locally obtained sand to a depth of about $2 \mathrm{ft}$ above preconstruction land surface. Shallow monitoring wells 
Table 6. Concentrations of major constituents, nutrients, and related characteristics of water from wells PB-1583, PB-1584, and PB-1585 in array 2 in the northern Midlands

[All concentrations shown in milligrams per liter, except for $\mathrm{pH}$, in standard units; specific conductance, in microsiemens per centimeter ; and color, in platinumcobalt units. <, less than the value; --, not determined]

\begin{tabular}{|c|c|c|c|c|c|c|c|c|c|c|c|}
\hline $\begin{array}{l}\text { Property or } \\
\text { constituent }\end{array}$ & $12116 / 86$ & $\frac{\text { Well PF }}{5 / 19 / 87}$ & $\frac{-1583}{912 / 87}$ & 1213187 & $1216 / 86$ & Well P & $\frac{B-1584}{0.2187}$ & 1212187 & $\frac{W_{\epsilon}}{5 / 19 / 87}$ & $\frac{11 \mathrm{~PB}-15}{912187}$ & 85 \\
\hline $\mathrm{pH}$ & 7.3 & 7.4 & 8.0 & 7.5 & 7.3 & 7.5 & 7.8 & 7.8 & 7.5 & 7.6 & 7.9 \\
\hline Specific conductance & 795 & 1,350 & 830 & 992 & 510 & 458 & 542 & 589 & 580 & 599 & 589 \\
\hline Dissolved solids & 487 & 719 & 471 & 593 & 349 & 364 & 372 & 363 & 367 & 376 & 360 \\
\hline Fluoride & 0.2 & 0.2 & 0.2 & 0.4 & 0.2 & 0.2 & 0.1 & 0.3 & 0.2 & 0.2 & 0.2 \\
\hline Silica & 18 & 19 & 17 & 18 & 23 & 20 & 19 & 17 & 18 & 17 & 17 \\
\hline Calcium & 110 & 120 & 110 & 110 & 96 & 110 & 100 & 100 & 110 & 110 & 110 \\
\hline Magnesium & 7.7 & 13 & 7.2 & 11 & 3.7 & 4.0 & 4.0 & 3.9 & 4.8 & 4.7 & 4.7 \\
\hline Sodium & 47 & 130 & 43 & 88 & 14 & 14 & 14 & 14 & 13 & 12 & 12 \\
\hline Potassium & 3.0 & 6.4 & 2.3 & 4.9 & 1.0 & 0.9 & 0.9 & 1.0 & 1.1 & 0.8 & 0.8 \\
\hline Sulfate & 10 & 19 & 6.5 & 16 & 2.5 & $<0.1$ & 0.4 & 1.0 & 1.6 & 0.4 & 1.6 \\
\hline Chloride & 80 & 190 & 72 & 140 & 24 & 22 & 24 & 21 & 25 & 27 & 24 \\
\hline Color & 25 & 40 & 20 & 30 & 40 & 40 & 20 & 30 & 30 & 25 & 30 \\
\hline $\begin{array}{l}\text { Nitrogen, total } \\
\text { organic }\end{array}$ & 0.58 & 0.32 & 0.47 & 0.54 & 0.50 & 0.48 & 0.70 & 0.70 & 0.32 & 0.50 & 0.49 \\
\hline $\begin{array}{l}\text { Nitrogen, total } \\
\text { ammonia }\end{array}$ & 0.62 & 0.68 & 0.63 & 0.66 & 1.40 & 0.36 & 1.50 & 1.50 & 0.78 & 0.80 & 0.81 \\
\hline $\begin{array}{l}\text { Nitrogen, total } \\
\text { nitrite }\end{array}$ & $<0.01$ & $<0.01$ & $<0.01$ & $<0.01$ & $<0.01$ & $<0.01$ & $<0.01$ & $<0.01$ & $<0.01$ & $<0.01$ & $<0.01$ \\
\hline $\begin{array}{l}\text { Nitrogen, total } \\
\text { ammonia + organic }\end{array}$ & 1.2 & 1.0 & 1.1 & 1.2 & 1.9 & 0.8 & 2.2 & 2.2 & 1.1 & 1.3 & 1.3 \\
\hline $\begin{array}{l}\text { Nitrogen, total } \\
\text { nitrite + nitrate }\end{array}$ & $<0.02$ & $<0.02$ & $<0.02$ & $<0.02$ & $<0.02$ & 0.65 & $<0.02$ & $<0.02$ & $<0.02$ & $<0.02$ & $<0.02$ \\
\hline $\begin{array}{l}\text { Phosphorus, total } \\
\text { orthophosphate }\end{array}$ & 0.03 & 0.01 & 0.01 & 0.01 & 0.04 & 0.04 & 0.05 & 0.07 & 0.02 & 0.02 & 0.03 \\
\hline Phosphorus, total & 0.20 & 0.04 & 0.03 & 0.02 & 0.18 & 0.12 & 0.15 & 0.27 & 0.04 & 0.04 & 0.05 \\
\hline Hardness noncarbonate & 0 & 10 & 0 & 4 & 0 & 98 & 24 & 0 & 23 & 10 & 29 \\
\hline $\begin{array}{l}\text { Carbon, total } \\
\text { organic }\end{array}$ & 7.5 & 11 & 11 & -- & 13 & 13 & 13 & -- & 11 & 11 & -- \\
\hline
\end{tabular}

(PB-1609A-H), completed 10 to $14 \mathrm{ft}$ below land surface, were installed upgradient and downgradient (relative to the regional ground-water gradient) of the drainfield (fig. 11). The wells penetrate the uppermost marl layer (fig. $7:$ and are completed in very fine sand that overlies a $15-\mathrm{ft}: \mathrm{t} \mathrm{mar}$ ? layer, 16 to $18 \mathrm{ft}$ below land surface.

During 1987, ground-water levels in each well were measured (tarlo,$\quad v r$ to the four water-quality sampling events to sround-water flow directions. Fill material building $10.5 \mathrm{a}$ a local hydraulic gradients and resulted in ground-.. aitr flows to the north and the south from the septic tank (fig. 11 and table 8). The regional gradient is to the southwest. Wells C and D on either side of the septic-tank outlet had nearly identical water levels during each of the four measurements. The greatest hydraulic gradient on the south side of the outlet where the drainfield is located was between wells D and $\mathrm{H}-1.06 \times 10^{-2}$ on both March 19,1987 , and May 19, 1987. The greatest gradient to the north was $1.84 \times$ $10^{-2}$ on May 19, 1987, between wells C and A.

Ground-water samples collected from well D (in the drainfield and $12 \mathrm{ft}$ from the septic-tank outlet) had the greatest specific conductance and concentrations of chloride, total nitrogen, nitrite plus nitrate, total phosphorus, and orthophosphate (table 11). Ground-water quality at wells C, E, F, and $\mathbf{G}(10-38 \mathrm{ft}$ from the outlet) was influenced by septic-tank effluent, with one or more constituents, including chloride, nitrogen, and ammonia having elevated concentrations (table 11). Water from wells A, B, and H (59-150 ft from the outlet) showed little, if any, effect from the effluent; water from well 
Table 7. Concentrations of major constituents, nutrients, and related characteristics of water from wells PB-1524, PB-1552, and PB-1553 in array 3 in the northern Midlands

[All concentrations shown in milligrams per liter, except for $\mathrm{pH}$, in standard units; specific conductance, in microsiemens per centimeter; and color, in platinum-cobalt units. <, less than the value; --, not determined]

\begin{tabular}{|c|c|c|c|c|c|c|c|c|c|c|c|c|}
\hline $\begin{array}{l}\text { Property or } \\
\text { constituent }\end{array}$ & 1211786 & Well & $\mathrm{PB}-1524$ & & 12117186 & Well P & -1552 & 501010 & \multicolumn{4}{|c|}{ We11 PB-1553 } \\
\hline $\mathrm{pH}$ & 7.1 & 7.2 & 7.4 & 7.5 & 7.2 & 7.4 & 7.5 & 8.0 & 7.7 & 7.1 & 7.4 & 7.5 \\
\hline $\begin{array}{l}\text { Specific con- } \\
\text { ductance }\end{array}$ & 2,460 & 2,580 & 2,590 & 2,600 & 3,040 & 2,720 & 3,050 & 2,990 & 2,640 & 3,050 & 2,720 & 2,730 \\
\hline Dissolved solids & 1,480 & 1,540 & 1,520 & 1,520 & 1,820 & 1,620 & 1,770 & 1,800 & 1,610 & 1,810 & 1,600 & 1,620 \\
\hline Fluoride & 0.3 & 0.3 & 0.3 & 0.5 & 0.3 & 0.4 & 0.4 & 0.6 & 0.3 & 0.3 & 0.3 & 0.5 \\
\hline Silica & 20 & 20 & 20 & 20 & 22 & 21 & 22 & 22 & 20 & 23 & 20 & 20 \\
\hline Calcium & 170 & 170 & 170 & 160 & 160 & 160 & 150 & 160 & 180 & 160 & 170 & 170 \\
\hline Magnesium & 24 & 23 & 23 & 23 & 37 & 24 & 37 & 36 & 26 & 35 & 26 & 26 \\
\hline Sodium & 310 & 320 & 330 & 340 & 430 & 350 & 420 & 430 & 350 & 430 & 360 & 370 \\
\hline Potassium & 7.3 & 8.4 & 7.9 & 9.9 & 16 & 9.4 & 18 & 18 & 8.3 & 17 & 9.8 & 11 \\
\hline Sulfate & 140 & 140 & 140 & 150 & 180 & 150 & 90 & 190 & 140 & 180 & 160 & 160 \\
\hline Chloride & 520 & 520 & 540 & 440 & 650 & 560 & 670 & 570 & 520 & 640 & 570 & 490 \\
\hline Color & 55 & 40 & 40 & 50 & 40 & 40 & 30 & 30 & 50 & 40 & 40 & 50 \\
\hline $\begin{array}{l}\text { Nitrogen, total } \\
\text { organic }\end{array}$ & 0.30 & 0.60 & 0.50 & 0.85 & 0.56 & 0.70 & 0.66 & 0.59 & 0.40 & 0.55 & 0.70 & 0.88 \\
\hline $\begin{array}{l}\text { Nitrogen, total } \\
\text { ammonia }\end{array}$ & 1.30 & 1.10 & 1.20 & 0.95 & 0.84 & 1.00 & 0.84 & 0.81 & 1.10 & 0.85 & 1.00 & 0.92 \\
\hline $\begin{array}{l}\text { Nitrogen, total } \\
\text { nitrite }\end{array}$ & $<0.01$ & $<0.01$ & $<0.01$ & $<0.01$ & $<0.01$ & $<0.01$ & $<0.01$ & $<0.01$ & $<0.01$ & $<0.01$ & $<0.01$ & $<0.01$ \\
\hline $\begin{array}{l}\text { Nitrogen, total } \\
\text { ammonia + organic }\end{array}$ & 1.6 & 1.7 & 1.7 & 1.8 & 1.4 & 1.7 & 1.5 & 1.4 & 1.5 & 1.4 & 1.7 & 1.8 \\
\hline $\begin{array}{l}\text { Nitrogen, total } \\
\text { nitrite + nitrate }\end{array}$ & $<0.02$ & $<0.02$ & $<0.02$ & $<0.02$ & $<0.02$ & $<0.02$ & $<0.02$ & $<0.02$ & $<0.02$ & $<0.02$ & $<0.02$ & $<0.02$ \\
\hline $\begin{array}{l}\text { Phosphorus, total } \\
\text { orthophosphate }\end{array}$ & 0.19 & 0.17 & 0.16 & 0.18 & 0.02 & 0.17 & 0.03 & 0.04 & 0.18 & 0.02 & 0.18 & 0.18 \\
\hline Phosphorus, total & 0.22 & 0.20 & 0.22 & 0.20 & 0.17 & 0.29 & -- & 0.09 & 0.23 & 0.15 & 0.36 & 0.21 \\
\hline $\begin{array}{l}\text { Hardness non- } \\
\text { carbonate }\end{array}$ & -- & 120 & 120 & 120 & -- & 90 & 110 & 200 & -- & 130 & 130 & 120 \\
\hline $\begin{array}{l}\text { Carbon, total } \\
\text { organic }\end{array}$ & 16 & 16 & 17 & -- & 13 & 17 & 16 & -- & 16 & 14 & 18 & -- \\
\hline
\end{tabular}

$\mathrm{B}$, with total phosphorus concentrations ranging from 0.44 to $0.98 \mathrm{mg} / \mathrm{L}$, may have been affected by effluent. Chloride concentrations in water from these three wells ranged from 9 to $20 \mathrm{mg} / \mathrm{L}$. Well A, the greatest distance upgradient from the outlet, was selected to represent background conditions. Trace amounts of other constituents at wells $\mathrm{B}$ and $\mathrm{H}$ were close to background levels. The maximum and minimum concentrations of ammonia plus organic nitrogen concentrations in water from each well are shown in figure 11. Concentrations of ammonia plus organic nitrogen were highest in water samples collected from wells C, D, E, and G.

\section{Site 2}

Site 2 is in the southern part of the study area where the water-table gradient is south toward the C-51 Canal (figs. 2 and 12). The septic tank and drainfield are installed in permeable fill material raised $1.5 \mathrm{ft}$ above preconstruction land surface. Fill was obtained from a borrow pond south of the site. Seven monitoring wells (PB-1590A-G), ranging in depth from 10 to $20 \mathrm{ft}$, were drilled through the uppermost marl layer that is about $5 \mathrm{ft}$ below land surface (fig. 7). Of these wells, six were south and southeast of the septic tank 
Table 8. Ground-water levels at septic-tank test site 1 in the northern Midlands prior to water-quality sampling

\begin{tabular}{lcccc}
\hline \multirow{2}{*}{$\begin{array}{l}\text { Well } \\
\text { number }\end{array}$} & March 19,1987 & Mayde of water, in feet above sea level \\
\cline { 2 - 5 } PB-1609A & 17.65 & 198.20 & September 2, 1987 & December 4, 1987 \\
PB-1609B & 18.19 & 17.76 & 15.95 & 17.27 \\
PB-1609C & 18.34 & 17.88 & 17.48 & 18.79 \\
PB-1609D & 18.30 & 17.88 & 17.52 & 18.89 \\
PB-1609E & 18.16 & 17.78 & 17.44 & 18.82 \\
PB-1609F & 18.16 & 17.86 & 17.50 & 18.71 \\
PB-1609G & 18.18 & 17.77 & 17.46 & 18.58 \\
PB-1609H & 16.71 & 16.29 & 15.95 & 18.70 \\
\hline
\end{tabular}

Table 9. Ground water levels at septic-tank test site 2 in the northern Midlands prior to water-quality sampling

\begin{tabular}{|c|c|c|c|c|}
\hline \multirow{2}{*}{$\begin{array}{l}\text { Well } \\
\text { number }\end{array}$} & \multicolumn{4}{|c|}{ Altitude of water, in feet above sea level } \\
\hline & December 16,1986 & May 12,1987 & September 2, 1987 & December 3, 1987 \\
\hline PB-1590A & 17.55 & 17.61 & 17.36 & 19.18 \\
\hline PB-1590B & 17.43 & 17.30 & 17.09 & 19.04 \\
\hline PB-1590C & 17.53 & 17.40 & 17.23 & 19.23 \\
\hline PB-1590D & 17.30 & 16.96 & 16.95 & 19.12 \\
\hline PB-1590E & 17.30 & 17.22 & 17.01 & 19.02 \\
\hline PB-1590F & 17.46 & 17.26 & 17.19 & 19.20 \\
\hline PB-1590G & 17.18 & 17.19 & 16.90 & 18.81 \\
\hline
\end{tabular}

Table 10. Ground-water levels at septic-tank test site 3 in the northern Midlands prior to water-quality sampling

\begin{tabular}{|c|c|c|c|c|c|}
\hline \multirow{2}{*}{$\begin{array}{l}\text { Well } \\
\text { number }\end{array}$} & \multicolumn{5}{|c|}{ Altitude of water, in feet above sea level } \\
\hline & Lo & $r^{-1} \operatorname{eer} 5,1986$ & May 12,1987 & September 8, 1987 & December 4, 1987 \\
\hline$\overline{\mathrm{PB}}-1589 \overline{\mathrm{A}}$ & & $\overline{1 t} \overline{26}$ & 14.61 & \begin{tabular}{|l|l|}
13.95 \\
\end{tabular} & 16.77 \\
\hline PB-1589B & & 15.27 & 13.62 & 12.97 & 15.73 \\
\hline PB- $1589 \mathrm{C}$ & & 15.44 & 13.52 & 12.94 & 15.64 \\
\hline PB-1589D & & 15.08 & 13.50 & 12.75 & 15.61 \\
\hline PB-1589E & & 15.07 & 13.41 & 12.74 & 14.91 \\
\hline PB-1589F & & 16.17 & 14.48 & 13.78 & 16.71 \\
\hline
\end{tabular}

and one was northwest of the tank (fig. 12). Each well is completed in silt and very fine sand of low permeability that lies above a relatively impermeable marl layer at a depth of about $20 \mathrm{ft}$.

At site 2, regional and local hydraulic gradients (fig. 12) are to the south. Water-level measurements made during 1986-87 (table 9) indicate that gradients across the site between wells $A$ and $\mathrm{G}$ ranged from $1.2 \times 10^{-3} 3$ to $1.5 \times 10^{-3}$. Between wells B (10 ft south of the septic-tank outlet) and C (just outside the drainfield), gradients were reversed to the north, ranging from $6.13 \times 10^{-3}$ to $3.23 \times 10^{-2}$ during sampling. However, between wells $\mathrm{C}$ and $\mathrm{D}$, gradients consistently were to the south. This apparent mounding is caused when ground water reaches the end of the drainfield, and low-permeability surficial materials impede downgradient flow.

Elevated concentrations of chloride, total nitrogen, organic nitrogen, ammonia, and total phosphorus in water from wells B, C, D, E, and F (table 12) indicate that effluent had migrated at least 92 feet laterally downgradient from the outlet. Total phosphorus concentrations of 1.5 to $3.2 \mathrm{mg} / \mathrm{L}$ (table 12) in water from well G ( $182 \mathrm{ft}$ from the outlet) may have been caused by a fertilizer spill found adjacent to the well or may have been from an undetected source. Because well $\mathrm{G}$ is relatively remote from the outlet and other analytical data do not indicate the effects of effluent, the elevated total phosphorus concentrations in water from well $G$ are not thought to be related to effluent. Water samples from well $D$ $(57 \mathrm{ft}$ from the outlet) generally contained higher concentrations of nitrogen and ammonia and occasionally had higher concentrations of total phosphorus than did samples from surrounding wells $\mathrm{C}, \mathrm{E}$, and $\mathrm{F}$. The fact that well $\mathrm{D} /(10 \mathrm{ft}$ deep $)$ is shallower than wells $\mathrm{C}, \mathrm{E}$, and $\mathrm{F}$ (15-18 $\mathrm{ft}$ deep) indicates that either constituents were more effectively attenuated during vertical migration than during lateral migration or there was little vertical migration. 


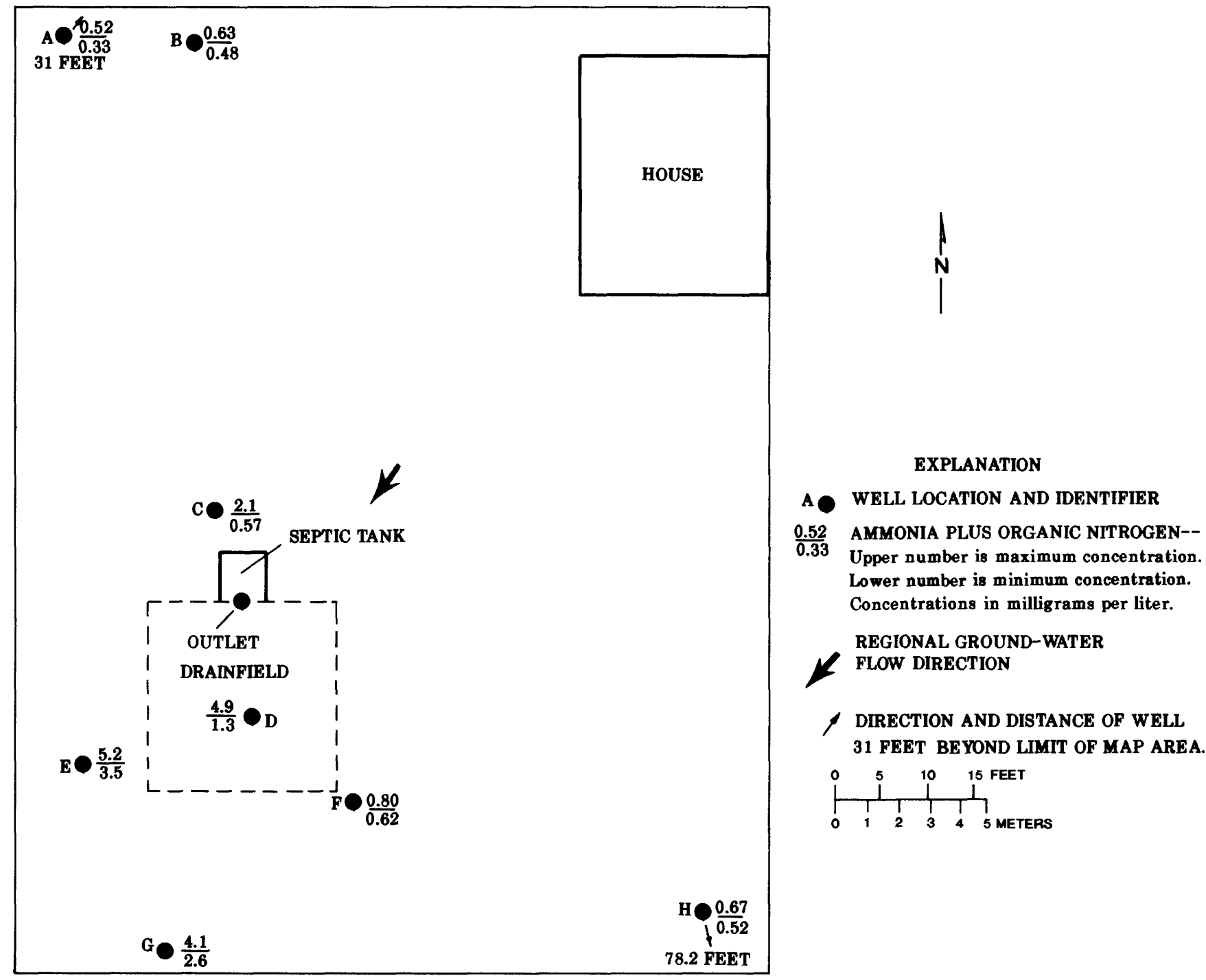

Figure 11. Septic-tank test site 1, location of nearby wells (PB-1609A-H), and minimum and maximum concentrations of ammonia plus organic nitrogen.

The maximum and minimum concentrations of ammonia plus organic nitrogen in water from each well are shown in figure 12. The maximum concentration of ammonia plus organic nitrogen in water from wells $\mathrm{C}, \mathrm{D}, \mathrm{E}$, and $\mathrm{F}$ equaled or exceeded the maximum concentration in water from well B within the drainfield.

Although the pond about $10 \mathrm{ft}$ south of well $\mathrm{F}$ was observed to periodically have heavy algal blooms during the study, water samples collected and analyzed by the Palm Beach County Health Department (Paul Davis, written commun., 1987) did not indicate that septic-tank effluent had entered the water.

\section{Site 3}

Site 3 is in the northeastern part of the study area, and its hydrology is influenced by the C-18 Canal (figs. 2 and 13). The drainfield area has not been raised by fill. Six monitoring wells (PB-1589A-F) were drilled south, east, and northeast of the septic tank to depths ranging from 5 to $20 \mathrm{ft}$ below land surface (fig. 13). Wells A, B, C, D, and E are completed in low-permeability marly sand, just above a relatively impermeable marl layer that occurs 5 to $10 \mathrm{ft}$ below land surface (fig. 7). Well $F$ is completed about $6 \mathrm{ft}$ below the marl layer. 
Table 11. Concentrations of selected constituents in ground water at septic-tank test site 1 in the northern Midlands, 1986-87 [All concentrations shown in milligrams per liter, except for specific conductance which is in microsiemens per centimeter. <, less than the value]

\begin{tabular}{|c|c|c|c|c|c|c|c|c|c|c|c|}
\hline $\begin{array}{l}\text { Well } \\
\text { number }\end{array}$ & $\begin{array}{l}\text { We11 } \\
\text { depth } \\
\text { (feet) }\end{array}$ & \begin{tabular}{l}
\multicolumn{1}{c}{ Dis $^{-}$} \\
tance \\
to tank \\
outlet \\
(feet)
\end{tabular} & $\begin{array}{l}\text { Date of } \\
\text { collec- } \\
\text { tion }\end{array}$ & $\begin{array}{l}\text { Specific } \\
\text { conductance }\end{array}$ & $\begin{array}{l}\text { Chlo- } \\
\text { ride }\end{array}$ & $\begin{array}{l}\text { Nitro- } \\
\text { gen, } \\
\text { total }\end{array}$ & $\begin{array}{c}\text { Nitro- } \\
\text { gen, } \\
\text { total } \\
\text { organic } \\
\end{array}$ & $\begin{array}{c}\text { Nitrogen, } \\
\text { total } \\
\text { ammonia } \\
\text { plus } \\
\text { organic } \\
\end{array}$ & $\begin{array}{c}\text { Nitrogen, } \\
\text { total } \\
\text { nitrite } \\
\text { plus } \\
\text { nitrate } \\
\end{array}$ & $\begin{array}{l}\text { Phos- } \\
\text { pho- } \\
\text { rus } \\
\text { total } \\
\end{array}$ & $\begin{array}{l}\text { Phos- } \\
\text { phorus, } \\
\text { total } \\
\text { ortho- } \\
\text { phosphate }\end{array}$ \\
\hline$P B-1609 A$ & 13 & 92 & $\begin{array}{l}03-17-87 \\
05-19-87 \\
09-02-87 \\
12-08-87\end{array}$ & $\begin{array}{l}642 \\
656 \\
625 \\
488\end{array}$ & $\begin{array}{l}13 \\
10 \\
17 \\
11\end{array}$ & $\begin{array}{l}-- \\
-- \\
--\end{array}$ & $\begin{array}{r}0.13 \\
.34 \\
.19 \\
.27\end{array}$ & $\begin{array}{r}0.33 \\
.52 \\
.40 \\
.47\end{array}$ & $\begin{array}{l}<0.02 \\
<.02 \\
<.02 \\
<.02\end{array}$ & $\begin{array}{l}0.10 \\
.13 \\
.10 \\
.05\end{array}$ & $\begin{array}{r}0.01 \\
.02 \\
.01 \\
<.01\end{array}$ \\
\hline$P B-1609 B$ & 13 & 59 & $\begin{array}{l}03-17-87 \\
05-19-87 \\
09-02-87 \\
12-08-87\end{array}$ & $\begin{array}{l}872 \\
720 \\
892 \\
754\end{array}$ & $\begin{array}{l}15 \\
11 \\
20 \\
15\end{array}$ & $\begin{array}{l}-- \\
-- \\
-- \\
--\end{array}$ & $\begin{array}{l}.38 \\
.45 \\
.28 \\
.37\end{array}$ & $\begin{array}{l}.57 \\
.63 \\
.48 \\
.55\end{array}$ & $\begin{array}{l}<.02 \\
<.02 \\
<.02 \\
<.02\end{array}$ & $\begin{array}{l}.98 \\
.78 \\
.44 \\
.73\end{array}$ & $\begin{array}{l}.01 \\
.02 \\
.01 \\
.01\end{array}$ \\
\hline$P B-1609 C$ & 10 & 10 & $\begin{array}{l}03-17-87 \\
05-19-87 \\
09-02-87 \\
12-08-87\end{array}$ & $\begin{array}{r}877 \\
902 \\
769 \\
1,130\end{array}$ & $\begin{array}{r}30 \\
33 \\
18 \\
110\end{array}$ & $\begin{array}{r}1.2 \\
--- \\
--\end{array}$ & $\begin{array}{r}.84 \\
.75 \\
1.46 \\
1.6\end{array}$ & $\begin{array}{l}1.2 \\
1.0 \\
.57 \\
2.1\end{array}$ & $\begin{array}{r}.02 \\
<.02 \\
<.02 \\
<.02\end{array}$ & $\begin{array}{l}.11 \\
.11 \\
.08 \\
.07\end{array}$ & $\begin{array}{l}.02 \\
.04 \\
.01 \\
.01\end{array}$ \\
\hline PB-1609D & 10 & 12 & $\begin{array}{l}03-17-87 \\
05-19-87 \\
09-02-87 \\
12-08-87\end{array}$ & $\begin{array}{l}1,270 \\
1,420 \\
1,370 \\
1,380\end{array}$ & $\begin{array}{l}130 \\
150 \\
150 \\
160\end{array}$ & $\begin{array}{r}20 \\
32 \\
29 \\
3.0\end{array}$ & $\begin{array}{r}.90 \\
.80 \\
.75 \\
1.0\end{array}$ & $\begin{array}{l}4.9 \\
3.0 \\
1.3 \\
1.8\end{array}$ & $\begin{array}{r}15.0 \\
29.0 \\
28.0 \\
1.2\end{array}$ & $\begin{array}{r}3.8 \\
6.7 \\
6.2 \\
15.0\end{array}$ & $\begin{array}{r}3.4 \\
3.9 \\
4.8 \\
11.0\end{array}$ \\
\hline PB - 1609E & 12 & 24 & $\begin{array}{l}03-17-87 \\
05-19-87 \\
09-02-87 \\
12-08-87\end{array}$ & $\begin{array}{l}920 \\
936 \\
828 \\
964\end{array}$ & $\begin{array}{l}54 \\
51 \\
75 \\
65\end{array}$ & $\begin{array}{r}4.3 \\
3.8 \\
5.2 \\
--\end{array}$ & $\begin{array}{l}1.3 \\
1.2 \\
2.0 \\
1.3\end{array}$ & $\begin{array}{l}4.3 \\
3.8 \\
5.2 \\
3.5\end{array}$ & $\begin{array}{r}.03 \\
.02 \\
.02 \\
<.02\end{array}$ & $\begin{array}{l}.21 \\
.10 \\
.10 \\
.05\end{array}$ & $\begin{array}{l}.14 \\
.03 \\
.02 \\
.02\end{array}$ \\
\hline$P B-1609 F$ & 14 & 24 & $\begin{array}{l}03-17-87 \\
05-19-87 \\
09-02-87 \\
12-08-87\end{array}$ & $\begin{array}{l}1,040 \\
957 \\
1,060 \\
1,170\end{array}$ & $\begin{array}{r}95 \\
94 \\
100 \\
140\end{array}$ & $\begin{array}{l}-- \\
.82 \\
--\end{array}$ & $\begin{array}{l}.35 \\
.60 \\
.48 \\
.43\end{array}$ & $\begin{array}{l}.62 \\
.80 \\
.68 \\
.68\end{array}$ & $\begin{array}{r}<.02 \\
.02 \\
<.02 \\
<.02\end{array}$ & $\begin{array}{l}.14 \\
.12 \\
.14 \\
.05\end{array}$ & $\begin{array}{r}.01 \\
.03 \\
.02 \\
<.01\end{array}$ \\
\hline$P B-1609 G$ & 12 & 38 & $\begin{array}{l}03-17-87 \\
05-19-87 \\
09-02-87 \\
12-08-87\end{array}$ & $\begin{array}{l}571 \\
522 \\
506 \\
615\end{array}$ & $\begin{array}{l}18 \\
20 \\
19 \\
47\end{array}$ & $\begin{array}{r}-- \\
3.3 \\
4.1 \\
--\end{array}$ & $\begin{array}{r}.80 \\
1.90 \\
1.7 \\
.60\end{array}$ & $\begin{array}{l}3.2 \\
3.3 \\
4.1 \\
2.6\end{array}$ & $\begin{array}{r}<.02 \\
.04 \\
.03 \\
<.02\end{array}$ & $\begin{array}{l}.31 \\
.31 \\
.26 \\
.08\end{array}$ & $\begin{array}{l}.03 \\
.09 \\
.05 \\
.02\end{array}$ \\
\hline $\mathrm{PB}-1609 \mathrm{H}$ & 11 & 150 & $\begin{array}{l}03-17-87 \\
05-19-87 \\
09-02-87 \\
12-08-87\end{array}$ & $\begin{array}{l}625 \\
632 \\
451 \\
463\end{array}$ & $\begin{array}{r}14 \\
20 \\
9 \\
9\end{array}$ & $\begin{array}{l}-- \\
-- \\
--\end{array}$ & $\begin{array}{l}.39 \\
.55 \\
.51 \\
.43\end{array}$ & $\begin{array}{l}.52 \\
.67 \\
.63 \\
.52\end{array}$ & $\begin{array}{l}<.02 \\
<.02 \\
<.02 \\
<.02\end{array}$ & $\begin{array}{l}.08 \\
.06 \\
.07 \\
.05\end{array}$ & $\begin{array}{l}<.01 \\
.02 \\
.02 \\
.01\end{array}$ \\
\hline
\end{tabular}

During 1986-87, ground-water levels in the monitoring wells were measured (table 10 ) prior to water-quality sampling to determine ground-water flow directions. The direction of regional ground-water flow is to the east in the vicinity of site 3 (fig. 13). The local gradient across the site between wells $\mathrm{A}$ and $\mathrm{D}$ during sampling was also east, ranging from $1.90 \times 10^{-2}$ to $1.98 \times 10^{-2}$. Water levels in well $\mathrm{F}$ were consistently above those in the shallower monitoring wells at the site. At well $\mathrm{F}$, and possibly at other sites, higher heads below the marl layer effectively prevent the downward migration of ground water through the marl.

Water from well A, closest to the outlet $(6 \mathrm{ft})$, had the highest concentrations of chloride, total nitrogen, nitrite plus nitrate, total phosphorus, and orthophosphate (table 13). Concentrations of constituents commonly associated with septic-tank effluent in water from other wells generally decreased with distance from the outlet. The exception to this was well C ( $5 \mathrm{ft}$ deep), which was shallower than the other wells $(8-20 \mathrm{ft}$ deep). As at site 2 , either there is greater attenuation of effluent with vertical migration than with lateral migration or little downward flow occurs. At site 3, well $\mathrm{D}$ ( $67 \mathrm{ft}$ from the outlet) is affected by effluent. Water samples collected December 16, 1986 (table 13), indicate that septic-tank effluent may have reached wells E or F (102 and $176 \mathrm{ft}$ from the outlet). However, subsequent analyses were inconclusive, and higher heads at well $\mathrm{F}$ completed below the marl layer make it unlikely that septic-tank effluent had affected that well. The cause of the anomalous concentration is unknown. The maximum and minimum concentrations of ammonia plus organic nitrogen in water from each well are shown in figure 13. The maximum concentration of ammonia plus organic nitrogen in water samples collected at site 3 was in a sample from well C, the shallowest well at the site. 


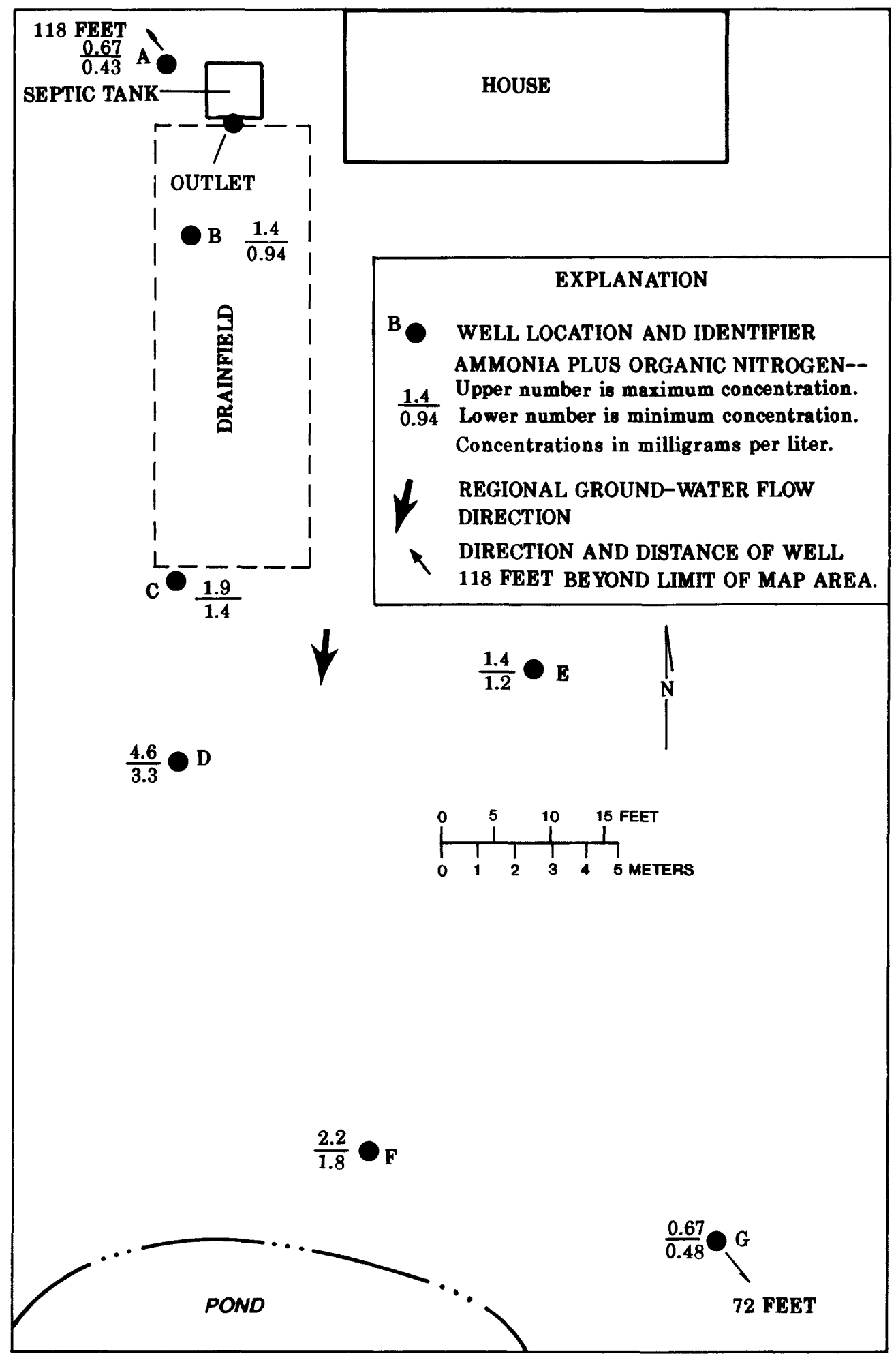

Figure 12. Septic-tank test site 2, location of nearby wells (PB-1590A-G), and minimum and maximum concentrations of ammonia plus organic nitrogen. 
Table 12. Concentrations of selected constituents in ground water at septic-tank test site 2 in the northern Midlands, 1986-87 [All concentrations shown in milligrams per liter, except for specific oonductance which is in microsiemens per centimeter. $<$, less than the value]

\begin{tabular}{|c|c|c|c|c|c|c|c|c|c|c|c|}
\hline $\begin{array}{l}\text { Well } \\
\text { number }\end{array}$ & $\begin{array}{l}\text { Well } \\
\text { depth } \\
\text { (feet) }\end{array}$ & $\begin{array}{l}\text { Dis- } \\
\text { tance } \\
\text { to tank } \\
\text { outlet } \\
\text { (feet) }\end{array}$ & $\begin{array}{l}\text { Date of } \\
\text { collec- } \\
\text { tion }\end{array}$ & $\begin{array}{l}\text { Specific } \\
\text { conductance }\end{array}$ & $\begin{array}{l}\text { Chlo- } \\
\text { ride }\end{array}$ & $\begin{array}{l}\text { Nitro- } \\
\text { gen, } \\
\text { total }\end{array}$ & $\begin{array}{c}\text { Nitro- } \\
\text { gen, } \\
\text { total } \\
\text { organic }\end{array}$ & $\begin{array}{c}\text { Nitrogen, } \\
\text { total } \\
\text { ammonia } \\
\text { plus } \\
\text { organic } \\
\end{array}$ & $\begin{array}{c}\text { Nitrogen, } \\
\text { total } \\
\text { nitrite } \\
\text { plus } \\
\text { nitrate } \\
\end{array}$ & $\begin{array}{l}\text { Phos- } \\
\text { pho- } \\
\text { rus } \\
\text { total } \\
\end{array}$ & $\begin{array}{l}\text { Phos- } \\
\text { phorus, } \\
\text { total } \\
\text { ortho- } \\
\text { phosphate }\end{array}$ \\
\hline PB- $1590 A$ & 20 & 126 & $\begin{array}{l}12-16-86 \\
05-12-87 \\
09-02-87 \\
12-03-87\end{array}$ & $\begin{array}{l}596 \\
663 \\
595 \\
616\end{array}$ & $\begin{array}{l}20 \\
32 \\
20 \\
16\end{array}$ & $\begin{array}{l}-- \\
.69 \\
-- \\
--\end{array}$ & $\begin{array}{r}0.43 \\
.56 \\
.37 \\
.33\end{array}$ & $\begin{array}{r}0.53 \\
.67 \\
.46 \\
.43\end{array}$ & $\begin{array}{l}<0.02 \\
.02 \\
<.02 \\
<.02\end{array}$ & $\begin{array}{r}1.2 \\
.85 \\
.18 \\
.26\end{array}$ & $\begin{array}{l}0.05 \\
.04 \\
.03 \\
.02\end{array}$ \\
\hline PB-1590B & 15 & 10 & $\begin{array}{l}12-16-86 \\
05-12-87 \\
09-02-87 \\
12-03-87\end{array}$ & $\begin{array}{l}1,020 \\
1,040 \\
1,650 \\
1,570\end{array}$ & $\begin{array}{l}110 \\
120 \\
260 \\
220\end{array}$ & $\begin{array}{l}1.2 \\
.96 \\
1.3 \\
--\end{array}$ & $\begin{array}{l}.85 \\
.71 \\
.90 \\
.99\end{array}$ & $\begin{array}{l}1.2 \\
.94 \\
1.3 \\
1.4\end{array}$ & $\begin{array}{r}.03 \\
.02 \\
.03 \\
<.02\end{array}$ & $\begin{array}{l}6.6 \\
1.0 \\
2.0 \\
.66\end{array}$ & $\begin{array}{l}.12 \\
.04 \\
.10 \\
.04\end{array}$ \\
\hline PB-1590C & 18 & 39 & $\begin{array}{l}12-16-86 \\
05-12-87 \\
09-02-87 \\
12-03-87\end{array}$ & $\begin{array}{l}1,690 \\
1,710 \\
1,240 \\
1,440\end{array}$ & $\begin{array}{l}260 \\
280 \\
170 \\
210\end{array}$ & $\begin{array}{l}-- \\
-- \\
--\end{array}$ & $\begin{array}{l}.82 \\
.98 \\
.89 \\
.87\end{array}$ & $\begin{array}{l}1.7 \\
1.9 \\
1.4 \\
1.6\end{array}$ & $\begin{array}{l}<.02 \\
<.02 \\
<.02 \\
<.02\end{array}$ & $\begin{array}{l}.63 \\
.28 \\
.24 \\
.15\end{array}$ & $\begin{array}{l}.03 \\
.03 \\
.03 \\
.03\end{array}$ \\
\hline$P B-1590 D$ & 10 & 57 & $\begin{array}{l}12-16-86 \\
05-12-87 \\
09-02-87 \\
12-03-87\end{array}$ & $\begin{array}{l}1,770 \\
1,840 \\
1,510 \\
1,110\end{array}$ & $\begin{array}{l}280 \\
280 \\
220 \\
140\end{array}$ & $\begin{array}{r}-- \\
3.4 \\
--\end{array}$ & $\begin{array}{l}1.5 \\
1.3 \\
2.1 \\
1.1\end{array}$ & $\begin{array}{l}4.0 \\
3.4 \\
4.6 \\
3.3\end{array}$ & $\begin{array}{r}<.02 \\
.02 \\
<.02 \\
<.02\end{array}$ & $\begin{array}{r}5.0 \\
.88 \\
.78 \\
1.7\end{array}$ & $\begin{array}{l}.03 \\
.08 \\
.09 \\
.11\end{array}$ \\
\hline $\mathrm{PB}-1590 \mathrm{E}$ & 15 & 57 & $\begin{array}{l}12-06-86 \\
05-12-87 \\
09-02-87 \\
12-03-87\end{array}$ & $\begin{array}{l}1,550 \\
1,790 \\
1,630 \\
1,640\end{array}$ & $\begin{array}{l}220 \\
280 \\
250 \\
240\end{array}$ & $\begin{array}{r}-- \\
1.2 \\
1.4 \\
--\end{array}$ & $\begin{array}{l}.83 \\
.91 \\
.98 \\
.77\end{array}$ & $\begin{array}{l}1.3 \\
1.2 \\
1.4 \\
1.2\end{array}$ & $\begin{array}{r}<.02 \\
.02 \\
.02 \\
<.02\end{array}$ & $\begin{array}{c}1.5 \\
.68 \\
1.6 \\
.39\end{array}$ & $\begin{array}{l}.05 \\
.04 \\
.07 \\
.03\end{array}$ \\
\hline $\mathrm{PB}-1590 \mathrm{~F}$ & 15 & 92 & $\begin{array}{l}12-16-86 \\
05-12-87 \\
09-02-87 \\
12-03-87\end{array}$ & $\begin{array}{r}907 \\
951 \\
1,030 \\
976\end{array}$ & $\begin{array}{r}84 \\
96 \\
110 \\
96\end{array}$ & $\begin{array}{r}-- \\
1.9 \\
2.2 \\
--\end{array}$ & $\begin{array}{r}.60 \\
.70 \\
1.0 \\
.60\end{array}$ & $\begin{array}{l}2.0 \\
1.9 \\
2.2 \\
1.8\end{array}$ & $\begin{array}{r}<.02 \\
.02 \\
.02 \\
<.02\end{array}$ & $\begin{array}{l}3.2 \\
3.2 \\
2.56 \\
.80\end{array}$ & $\begin{array}{l}.06 \\
.05 \\
.08 \\
.03\end{array}$ \\
\hline PB-1590G & 20 & 182 & $\begin{array}{l}12-16-86 \\
05-12-87 \\
09-02-87 \\
12-03-87\end{array}$ & $\begin{array}{l}584 \\
637 \\
666 \\
562\end{array}$ & $\begin{array}{l}13 \\
13 \\
16 \\
15\end{array}$ & $\begin{array}{l}-- \\
.69 \\
.61 \\
-.\end{array}$ & $\begin{array}{l}.28 \\
.48 \\
.40 \\
.41\end{array}$ & $\begin{array}{l}.48 \\
.67 \\
.59 \\
.60\end{array}$ & $\begin{array}{r}<.02 \\
.02 \\
.02 \\
<.02\end{array}$ & $\begin{array}{l}3.2 \\
2.4 \\
3.2 \\
1.5\end{array}$ & $\begin{array}{l}.04 \\
.05 \\
.07 \\
.04\end{array}$ \\
\hline
\end{tabular}

\section{SUMMARY}

The northern Midlands, a sparsely developed area of northeastern Palm Beach County, is undergoing increased pressures for construction of single- family residences. As many as 20,000 new homes are expected to be built in the area by the year 2000 . The area has low-topographic relief and is often inundated because of heavy rainfall, poor drainage, and the occurrence of near-surface marls that retard infiltration. No public-water supplies and sewer services are currently planned for the northern Midlands. Homes in the area are, and will probably continue to be, served by domestic wells completed in the surficial aquifer system and by septic-tank systems. The possible effects of the use of a large number of individual septic tanks and wells on ground-water quality and water levels are major concerns for the area.

The uppermost part of the surficial aquifer system is primarily composed of unconsolidated sand and marl, with localized lenses of shell and shelly limestone. Marl layers extend throughout the northern Midlands at various depths in the upper 50 feet of sediments. The shallowest of these marl layers is a 4- to 10 -foot thick unit that generally exists at depths of less than 10 feet below land surface. The marl is of very low permeability and greatly retards infiltration of rain and surface water. Deeper marl layers further retard infiltration. Ground-water levels in the northern Midlands during the study were seldom more than 5 feet below land surface. The water table was highest, about 22 feet above sea level in the northwestern part of the area. Regional directions of ground-water flow were from this water-table high, east toward the Atlantic Ocean, southwest toward the L-8 Canal, and south toward the C-51 Canal.

Ground-water quality in the northern Midlands is primarily influenced by residual seawater that was emplaced during the Pleistocene Epoch. Chloride and dissolved-solids concentrations that exceed secondary drinking-water standards exist at depths ranging from near land surface to the base of the surficial aquifer system mainly in the northern and western parts of the study area. Chloride concentrations in water from the upper 100 feet of the aquifer ranged from 


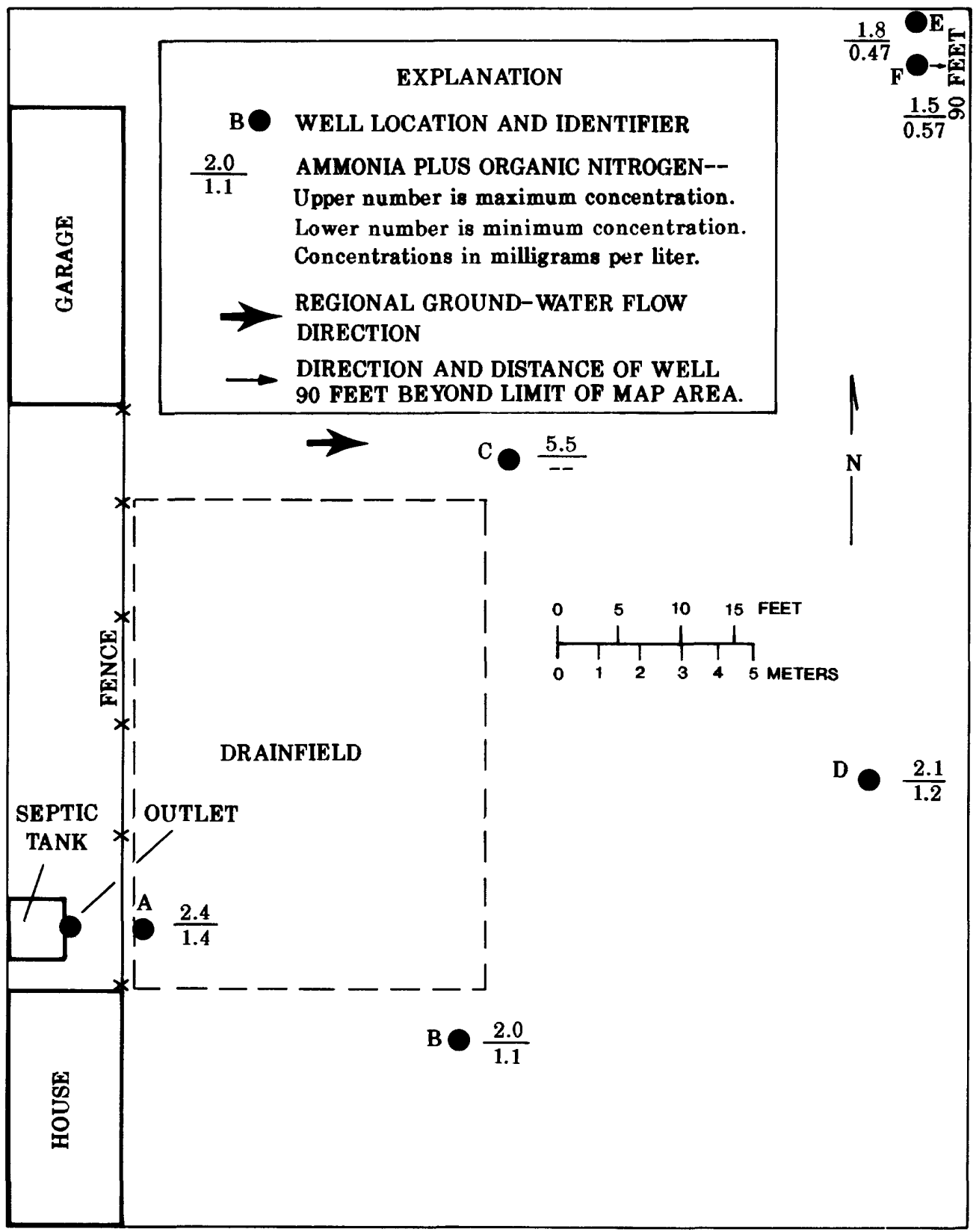

Figure 13. Septic-tank test site 3 , location of nearby wells (PB-1589A-F), and minimum and maximum concentrations of ammonia plus organic nitrogen. 
Table 13. Concentrations of selected constituents in ground water at septic-tank test site 3 in the northern Midlands, $1986-87$ [All concentrations shown in milligrams per liter, except for specific conductance which is in microsiemens per centimeter. <, less than the value]

\begin{tabular}{|c|c|c|c|c|c|c|c|c|c|c|c|}
\hline $\begin{array}{c}\text { Well } \\
\text { number }\end{array}$ & $\begin{array}{l}\text { Well } \\
\text { depth } \\
\text { (feet) }\end{array}$ & $\begin{array}{l}\text { Dis- } \\
\text { tance } \\
\text { to tank } \\
\text { outlet } \\
\text { (feet) }\end{array}$ & $\begin{array}{l}\text { Date of } \\
\text { collec- } \\
\text { tion }\end{array}$ & $\begin{array}{l}\text { Specific } \\
\text { conductance }\end{array}$ & $\begin{array}{l}\text { Chlo- } \\
\text { ride }\end{array}$ & $\begin{array}{l}\text { Nitro- } \\
\text { gen, } \\
\text { total }\end{array}$ & $\begin{array}{c}\text { Nitro- } \\
\text { gen, } \\
\text { total } \\
\text { organic }\end{array}$ & $\begin{array}{c}\text { Nitrogen, } \\
\text { total } \\
\text { ammonia } \\
\text { plus } \\
\text { organic } \\
\end{array}$ & $\begin{array}{c}\text { Nitrogen, } \\
\text { total } \\
\text { nitrite } \\
\text { plus } \\
\text { nitrate } \\
\end{array}$ & $\begin{array}{c}\text { Phos- } \\
\text { pho- } \\
\text { rus } \\
\text { total } \\
\end{array}$ & $\begin{array}{l}\text { Phos- } \\
\text { phorus, } \\
\text { total } \\
\text { ortho- } \\
\text { phosphate }\end{array}$ \\
\hline$P B-1589 A$ & 8 & 6 & $\begin{array}{l}12-16-86 \\
05-14-87 \\
09-08-87 \\
12-04-87\end{array}$ & $\begin{array}{r}941 \\
741 \\
2,300 \\
706\end{array}$ & $\begin{array}{r}48 \\
65 \\
240 \\
26\end{array}$ & $\begin{array}{r}15 \\
11 \\
2.6 \\
8.4\end{array}$ & $\begin{array}{l}1.1 \\
1.4 \\
1.9 \\
.93\end{array}$ & $\begin{array}{l}1.4 \\
2.2 \\
2.4 \\
1.9\end{array}$ & $\begin{array}{c}14 \\
8.8 \\
.21 \\
6.5\end{array}$ & $\begin{array}{l}4.0 \\
3.8 \\
2.4 \\
2.1\end{array}$ & $\begin{array}{r}0.74 \\
.25 \\
.04 \\
.55\end{array}$ \\
\hline PB-1589B & 8 & 33 & $\begin{array}{l}12-16-86 \\
05-14-87 \\
09-08-87\end{array}$ & $\begin{array}{r}1,220 \\
1,110 \\
799\end{array}$ & $\begin{array}{l}67 \\
67 \\
82\end{array}$ & $\begin{array}{r}4.6 \\
3.1 \\
--\end{array}$ & $\begin{array}{l}1.6 \\
1.0 \\
.74\end{array}$ & $\begin{array}{l}2.0 \\
1.5 \\
1.1\end{array}$ & $\begin{array}{l}2.6 \\
1.6 \\
<.02\end{array}$ & $\begin{array}{l}1.3 \\
.90 \\
.24\end{array}$ & $\begin{array}{l}.07 \\
.03 \\
.02\end{array}$ \\
\hline$F B-1589 C$ & 5 & 52 & $\begin{array}{l}12-16-86 \\
05-14-87\end{array}$ & $\begin{array}{l}804 \\
878\end{array}$ & $\begin{array}{l}64 \\
58\end{array}$ & $\begin{array}{r}6.0 \\
--\end{array}$ & 5.2 & 5.5 & $\begin{array}{l}.45 \\
--\end{array}$ & 1.1 & .02 \\
\hline$P B-1589 D$ & 8 & 67 & $\begin{array}{l}12-16-86 \\
05-14-87 \\
09-08-87 \\
12-04-87\end{array}$ & $\begin{array}{r}653 \\
573 \\
718 \\
1,020\end{array}$ & $\begin{array}{l}44 \\
50 \\
78 \\
65\end{array}$ & $\begin{array}{r}2.2 \\
1.2 \\
-. \\
--\end{array}$ & $\begin{array}{r}1.8 \\
1.0 \\
.87 \\
.86\end{array}$ & $\begin{array}{l}2.1 \\
1.2 \\
1.2 \\
1.2\end{array}$ & $\begin{array}{r}.08 \\
.03 \\
<.02 \\
<.02\end{array}$ & $\begin{array}{l}.43 \\
.18 \\
.20 \\
.23\end{array}$ & $\begin{array}{r}<.01 \\
.01 \\
<.01 \\
.01\end{array}$ \\
\hline$P B-1589 E$ & 10 & 102 & $\begin{array}{l}12-16-86 \\
05-14-87 \\
09-08-87 \\
12-04-87\end{array}$ & $\begin{array}{l}677 \\
516 \\
549 \\
575\end{array}$ & $\begin{array}{l}20 \\
27 \\
36 \\
24\end{array}$ & $\begin{array}{c}1.8 \\
.04 \\
-- \\
--\end{array}$ & $\begin{array}{l}1.6 \\
.76 \\
.55 \\
.34\end{array}$ & $\begin{array}{l}1.8 \\
.88 \\
.79 \\
.47\end{array}$ & $\begin{array}{r}.02 \\
.06 \\
<.02 \\
<.02\end{array}$ & $\begin{array}{l}.31 \\
.19 \\
.14 \\
.05\end{array}$ & $\begin{array}{r}<.01 \\
.01 \\
<.01 \\
<.01\end{array}$ \\
\hline$P B-1589 F$ & 20 & 176 & $\begin{array}{l}12-16-86 \\
05-14-87 \\
09-08-87 \\
12-04-87\end{array}$ & $\begin{array}{r}509 \\
307 \\
289 \\
1,690\end{array}$ & $\begin{array}{l}47 \\
26 \\
10 \\
99\end{array}$ & $\begin{array}{l}1.5 \\
-- \\
-- \\
--\end{array}$ & $\begin{array}{r}1.3 \\
.50 \\
.40 \\
.30\end{array}$ & $\begin{array}{r}1.5 \\
.64 \\
.60 \\
.57\end{array}$ & $\begin{array}{r}.04 \\
<.02 \\
<.02 \\
<.02\end{array}$ & $\begin{array}{l}.25 \\
.10 \\
.10 \\
.05\end{array}$ & $\begin{array}{r}.01 \\
.01 \\
>.01 \\
>.01\end{array}$ \\
\hline
\end{tabular}

$6 \mathrm{mg} / \mathrm{L}$ (milligrams per liter) in well PB-1538 to $3,700 \mathrm{mg} / \mathrm{L}$ in well PB-1562, and all water samples from depths greater than 100 feet contained chloride concentrations higher than $500 \mathrm{mg} / \mathrm{L}$, except in well PB-1546. Wells in arrays 1 and 3, in the western part of the study area, yielded water that exceeded secondary drinking-water standards for chloride and dissolved-solids concentrations at all depths sampled during drilling operations or during subsequent pumping of the completed wells.

In the eastern and southeastern parts of the study area, higher permeabilities of sediments in the surficial aquifer system have allowed more effective flushing and dilution of residual seawater. With the exception of wells in the area of Loxahatchee Slough, chloride concentrations in water from wells in these parts of the study area were less than $250 \mathrm{mg} / \mathrm{L}$. Water samples collected from wells in the area of Loxahatchee Slough, during (and periodically after) drilling operations, had chloride concentrations that exceeded 250 $\mathrm{mg} / \mathrm{L}$ at depths greater than about 60 feet. The chloride concentration in water from well PB-1607, which is 180 feet deep, was $1,950 \mathrm{mg} / \mathrm{L}$.

Three residential sites representative of hydrogeologic conditions in the northern Midlands were selected to study the migration of septic-tank effluent. All three sites are characterized by near-surface marl layers and fine silty sands that retard vertical migration of effluent and ground water. In the vicinity of the septic-tank drainfields, migration of effluent was controlled by the local water-table gradient within the drainfield fill material on which the house and drainfield were constructed. Once away from the groundwater mound, within the fill material, the effluent flowed in the direction of regional ground-water movement or toward a local hydrologic feature, such as a pond, canal, or pumping well.

Water from the shallowest wells nearest the septic-tank outlet contained the highest concentrations of chloride, nitrogen, and phosphorus associated with the effluent. Concentrations of these constituents in the ground water attenuated with distance and depth from the drainfield. Sampled ground water (5-20 feet deep) contained elevated concentrations of these constituents as far as 38 feet from the outlet at site 1,92 feet from the outlet at site 2 , and 67 feet from the outlet at site 3 -all in the direction of regional ground-water flow. The Florida Department of Environmental Regulation drinkingwater standard of $10 \mathrm{mg} / \mathrm{L}$ maximum concentration for nitrate plus nitrite was exceeded in ground water at two sites: 29 $\mathrm{mg} / \mathrm{L}$ at site 1 and $14 \mathrm{mg} / \mathrm{L}$ at site 3 .

The northern Midlands is an area of flat topography, frequent flooding, and low permeability of surficial sedimentary materials that retard percolation of ground water and promote surface flow. These factors need to be considered when septic-tank disposal systems are constructed in the area. 


\section{SELECTED REFERENCES}

Canter, L.W., and Knox, R.C., 1985, Septic tank system effects on ground water quality: Chelsea, Mich., Lewis Publishers, Inc., $336 \mathrm{p}$.

Fischer, F.J., 1980, Evaluation of a cavity-riddled zone of the shallow aquifer near Riviera Beach, Palm Beach County, Florida: U.S. Geological Survey Water-Resources Investigations Report 80-60, $39 \mathrm{p}$.

Florida Department of Environmental Regulation, 1989a, Waterquality standards: Chapter 17-3 in Florida Administrative Code.

---- 1989b, Drinking water standards: Chapter 17-1550 in Florida Administrative Code.

Hem, J.D., 1985, Study and interpretation of the chemical characteristics of natural water ( $3 \mathrm{~d}$ ed.): U.S. Geological Survey WaterSupply Paper 2254, 263 p.

Land, L.F., Rodis, H.G., and Schneider, J.J., 1973, Appraisal of the water resources of eastern Palm Beach County, Florida: Florida Bureau of Geology Report of Investigations 67, $64 \mathrm{p}$.

Miller, W.L., 1985a, Altitude of water table, surficial aquifer, Palm Beach County, Florida, April 24-26, 1984: U.S. Geological Survey Open-File Report 85-336, 1 sheet.

-.-- 1985b, Altitude of water table, surficial aquifer, Palm Beach County, Florida, November 9-14, 1984: U.S. Geological Survey Open-File Report 85-637, 1 sheet.

---- 1986, Lithology and base of the surficial aquifer system, Palm Beach County, Florida: U.S. Geological Survey WaterResources Investigations Report 86-4067, 1 sheet.

-.-. 1988, Description and evaluation of the effects of urban and agricultural development on the surficial aquifer system, Palm Beach County, Florida: U.S. Geological Survey WaterResources Investigations Report 88-4056, 58 p.

Miller, W.L., and Alvarez, J.A., 1984, Public supply water use, Palm Beach County, Florida, 1978-82: U.S. Geological Survey Open-File Report 84-240, 14 p.

Miller, W.L., and Lietz, A.C., 1976, Quality-of-water data, Palm Beach County, Florida, 1970-75: U.S. Geological Survey Open-File Report 76-784, 100 p.
Olhoeft, R., 1984, Applications and limitations of ground penetrating radar: in Expanded Abstracts, 54th Annual International Meeting Exposition, December 2-6, 1984, Atlanta, Ga., p. 147-148.

Palm Beach County Department of Planning, Building, and Zoning, 1980: Comprehensive Plan, 83 p.

Parker, G.G., Ferguson, G.E., Love, S.K., and others, 1955, Water resources of southeastern Florida, with special reference to geology and ground water of the Miami area: U.S. Geological Survey Water-Supply Paper 1255, 965 p.

Peterson, C.J., 1988, Direct-current resistivity data from 94 sites in northeastern Palm Beach County, Florida: U.S. Geological Survey Open-File Report 88-464, 101 p.

Rodis, H.G., and Land, L.F., 1976, The shallow aquifer--a prime freshwater resource in eastern Palm Beach County, Florida: U.S. Geological Survey Water-Resources Investigations Report 76-21, 12 p.

Schneider, J.J., 1977, Water-table contours in Palm Beach County, Florida, October 5-6, 1976: U.S. Geological Survey Open-File Report 77-364, 1 sheet.

Schroeder, M.C., Milliken, D.L., and Love, S.K., 1954, Water resources of Palm Beach County, Florida: Florida Geological Survey Report of Investiga- tions 13,63 p.

Scott, W.B., 1977, Hydraulic conductivity and water quality of the shallow aquifer, Palm Beach County, Florida: U.S. Geological Survey Water-Resources Investigations 76-119, 22 p.

Shiffman, Arnold, 1989, Cleanup of polluted ground water--a solution in search of the right problem: Ground Water Monitoring Review, v. 9, no. 1, p. 5-10.

Swayze, L.J., and Miller, W.L., 1984, Hydrogeology of a zone of secondary permeability in the surficial aquifer of eastern Palm Beach County, Florida: U.S. Geological Survey WaterResources Investigations 83-4249, 39 p.

Zohdy, A.A.R., Eaton, G.P., and Mabey, D.R., 1974, Application of surface geophysics to ground-water investigations: U.S. Geological Survey Techniques of Water-Resources Investigations, book 2, chap. D1, $116 \mathrm{p}$. 
Appendix: Description of lithologic logs 
Lat $26^{\circ} 25^{\prime} 50^{\prime \prime}$, long $80^{\circ} 08^{\prime} 39^{\prime \prime}$

Sec. 22, T. 41 S., R. 42 E.

\begin{tabular}{|c|c|c|}
\hline $\begin{array}{l}\text { Thick- } \\
\text { ness } \\
\text { (feet) }\end{array}$ & $\begin{array}{l}\text { Depth below } \\
\text { land surface } \\
\text { (feet) }\end{array}$ & Description \\
\hline 5 & $0-5$ & Sand, brownish-gray; fine grained; 10 percent shell fragments. \\
\hline 5 & $5-10$ & Sand, brown; fine grained; some black organics; marl at 8 feet. \\
\hline 5 & $10-15$ & $\begin{array}{l}\text { Sand, light-gray; quartzose, fine to very fine, } 10 \text { to } 15 \text { percent heavy minerals; } 35 \\
\text { to } 40 \text { percent sheil fragments. }\end{array}$ \\
\hline 5 & $15-20$ & $\begin{array}{l}\text { Sand, light-gray; quartzose as above; } 5 \text { to } 10 \text { percent heavy minerals; } 30 \text { to } 35 \text { per- } \\
\text { cent shell fragments; streaks of marl. }\end{array}$ \\
\hline 2 & $20-22$ & $\begin{array}{l}\text { Sand, grayish-brown; quartzose, fine to very fine; } 5 \text { to } 10 \text { percent heavy minerals; } 3 \\
\text { to } 5 \text { shell fragments; } 5 \text { percent dark-gray silt and clay nodules. }\end{array}$ \\
\hline
\end{tabular}

\section{We11 PB-1522}

Lat $26^{\circ} 54^{\prime} 17^{\prime \prime}$, long $80^{\circ} 13^{\prime} 03^{\prime \prime}$

Sec. 14, T. 41 S., R. 41 E.

\begin{tabular}{|c|c|c|}
\hline $\begin{array}{l}\text { Thick- } \\
\text { ness } \\
\text { (feet) }\end{array}$ & $\begin{array}{l}\text { Depth below } \\
\text { land surface } \\
\text { (feet) }\end{array}$ & Description \\
\hline 5 & $0-5$ & $\begin{array}{l}\text { Sand, light-brown to dark-brown; quartzose, fine to very fine; } 5 \text { to } 10 \text { percent heavy } \\
\text { minerals; } 5 \text { percent shell fragments. }\end{array}$ \\
\hline 5 & $5-10$ & $\begin{array}{l}\text { Sand, light-gray; quartzose, fine to very fine; } 1 \text { to } 3 \text { percent heavy minerals; } 40 \\
\text { percent shell fragments, bivalves, gastropods, bryozoans; interbedded with limestone } \\
\text { rock fragments; marl at } 10 \text { feet. }\end{array}$ \\
\hline 5 & $10-15$ & $\begin{array}{l}\text { Sand, light-gray to medium-gray; quartzose, fine to very fine; } 10 \text { to } 15 \text { percent heavy } \\
\text { minerals; about } 15 \text { percent shell fragments; } 10 \text { percent marl. }\end{array}$ \\
\hline 5 & $15-20$ & $\begin{array}{l}\text { Sand, brownish-gray; quartzose, fine to very fine; } 5 \text { to } 10 \text { percent heavy minerals; } \\
\text { black organics; } 5 \text { to } 10 \text { percent silt-size particles. }\end{array}$ \\
\hline 2 & $20-22$ & Sand as in 15 to 20 feet. \\
\hline
\end{tabular}

We11 PB-1523

Lat $26^{\circ} 54^{\prime} 45^{\prime \prime}$, long $80^{\circ} 14^{\prime} 03^{\prime \prime}$

Sec. 14, T. 41 S., R. 41 E.

\begin{tabular}{|c|c|c|}
\hline $\begin{array}{c}\text { Thick- } \\
\text { ness } \\
\text { (feet) }\end{array}$ & $\begin{array}{c}\text { Depth below } \\
\text { land surface } \\
\text { (feet) }\end{array}$ & Description \\
\hline 5 & $0-5$ & $\begin{array}{l}\text { Sand, grayish-brown; quartzose, fine to very fine; some organics; } 15 \text { to } 20 \text { percent } \\
\text { heavy minerals. }\end{array}$ \\
\hline 5 & $5-10$ & Sand, dark-brown; as above; 20 percent shell fragments; marl at 8 feet. \\
\hline 5 & $10-15$ & $\begin{array}{l}\text { Sand, light-brown; quartzose, very fine; } 10 \text { to } 15 \text { percent heavy minerals; } 30 \\
\text { marl; } 20 \text { percent shell; some mud and organics. }\end{array}$ \\
\hline 5 & $15-20$ & $\begin{array}{l}\text { Sand, grayish-brown; quartzose, fine to|very fine; } 5 \text { to } 10 \text { percent heavy minerals; } \\
\text { percent shell; } 20 \text { percent marl. }\end{array}$ \\
\hline 2 & $20-22$ & $\begin{array}{l}\text { Sand, grayish-brown to greenish-gray; quartzose, very fine; } 3 \text { to } 5 \text { percent heavy min- } \\
\text { erals. }\end{array}$ \\
\hline
\end{tabular}


Well PB-1524

Lat $26^{\circ} 54^{\prime} 43^{\prime \prime}$, long $80^{\circ} 15^{\prime} 20^{\prime \prime}$

Sec. 16, T. 41 S., R. $41 \mathrm{E}$.

\begin{tabular}{|c|c|c|}
\hline $\begin{array}{l}\text { Thick- } \\
\text { ness } \\
\text { (feet) }\end{array}$ & $\begin{array}{c}\text { Depth below } \\
\text { land surface } \\
\text { (feet) }\end{array}$ & Description \\
\hline 5 & $0-5$ & $\begin{array}{l}\text { Sand, brownish-gray; quartzose, fine to very fine, well sorted; } 3 \text { to } 5 \text { percent heavy } \\
\text { minerals. }\end{array}$ \\
\hline 5 & $5-10$ & $\begin{array}{l}\text { Sand, brownish-gray to dark-brown; as above; } 5 \text { to } 10 \text { percent heavy minerals; abundant } \\
\text { organics; marl layers. }\end{array}$ \\
\hline 5 & $10-15$ & $\begin{array}{l}\text { Sand, grayish-green; quartzose, very fine; } 3 \text { to } 5 \text { percent heavy minerals; } 15 \text { to } 20 \\
\text { percent shell fragments. }\end{array}$ \\
\hline 5 & $15-20$ & Sand, light-gray; same as above. \\
\hline
\end{tabular}

Wel1 PB-1525

Lat $26^{\circ} 52^{\prime} 56^{\prime \prime}$, long $80^{\circ} 12^{\prime} 32^{\prime \prime}$

Sec. 24, T. 41 S., R. 41 E.

\begin{tabular}{ccl}
$\begin{array}{c}\text { Thick- } \\
\text { ness } \\
\text { (feet) }\end{array}$ & $\begin{array}{c}\text { Depth below } \\
\text { land surface } \\
\text { (feet) }\end{array}$ & Description \\
5 & $0-5$ & $\begin{array}{l}\text { Mud, brownish-gray to black; organic mud and marl; } 20 \text { percent quartzose, very fine to } \\
\text { silt. }\end{array}$ \\
5 & $5-10$ & $\begin{array}{l}\text { Mud, brownish-gray to black; organic mud; } 50 \text { percent quartzose, greenish-gray, very } \\
\text { fine to silt. }\end{array}$ \\
5 & $10-15$ & $\begin{array}{l}\text { Sand, light-brown to light-gray; quartzose, very fine, well sorted; } 20 \text { percent organ- } \\
\text { ics, black. }\end{array}$ \\
5 & $15-20$ & Sand, light-brown to tan; same as above; 5 to 10 percent heavy minerals. \\
\hline
\end{tabular}

We11 PB-1526

Lat $26^{\circ} 50^{\prime} 17^{\prime \prime}$, long $80^{\circ} 17^{\prime} 32^{\prime \prime}$

Sec. 7, T. 42 S., R. 41 E.

\begin{tabular}{|c|c|c|}
\hline $\begin{array}{l}\text { Thick- } \\
\text { ness } \\
\text { (feet) }\end{array}$ & $\begin{array}{c}\text { Depth below } \\
\text { land surface } \\
\text { (feet) }\end{array}$ & Description \\
\hline 5 & $0-5$ & $\begin{array}{l}\text { Sand, brownish-gray to grayish-green; quartzose, very fine; } 5 \text { to } 10 \text { percent heavy } \\
\text { minerals; } 30 \text { percent marl. }\end{array}$ \\
\hline 5 & $5-10$ & $\begin{array}{l}\text { Marl, greenish-gray to light-brown; silt and clay-size particles; } 30 \text { percent quartz- } \\
\text { ose, very fine; } 3 \text { to } 5 \text { percent heavy minerals. }\end{array}$ \\
\hline 2 & $10-12$ & Marl as above; 10 percent quartzose as above. \\
\hline 3 & $12-15$ & $\begin{array}{l}\text { Sandy shell; brownish-gray to greenish-gray; } 40 \text { percent quartzose, very fine to fine, } \\
10 \text { to } 15 \text { percent heavy minerals. }\end{array}$ \\
\hline 5 & $15-20$ & $\begin{array}{l}\text { Sandy shell, brownish-gray to } 8 \text { reenish-8ray; } 40 \text { percent quartzose, medium to fine; } 10 \\
\text { to } 15 \text { percent heavy minerals; } 10 \text { to } 15 \text { percent marl. }\end{array}$ \\
\hline
\end{tabular}


We11 PB-1527

Lat $26^{\circ} 48^{\prime} 56^{\prime \prime}$, long $80^{\circ} 20^{\prime} 37^{\prime \prime}$

Sec. 15, T. 42 S., R. $40 \mathrm{E}$.

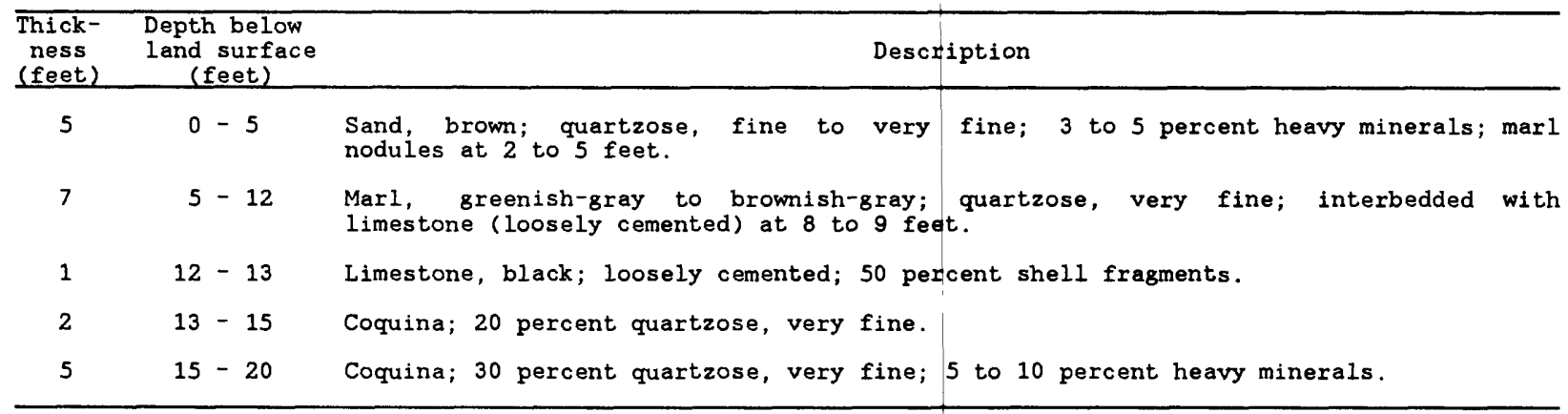

We11 PB-1528

Lat $26^{\circ} 48^{\prime} 34^{\prime \prime}$, long $80^{\circ} 12^{\prime} 34^{\prime \prime}$

Sec. 14 , T. 42 S. . R. 40 E.

\begin{tabular}{|c|c|c|}
\hline $\begin{array}{l}\text { Thick- } \\
\text { ness } \\
\text { (feet) }\end{array}$ & $\begin{array}{l}\text { Depth below } \\
\text { land surface } \\
\text { (feet) }\end{array}$ & Description \\
\hline 4 & $0-4$ & Sand, brownish-tan; quartzose, fine to very fine; 5 to 10 percent heavy minerals. \\
\hline 1 & $4-5$ & Marl, medium-gray; clay and silt size; quartzose, very fine. \\
\hline 5 & $5-10$ & Marl, same as above; interbedded with limestone and 30 percent shell at 8 to 10 feet. \\
\hline 5 & $10-15$ & $\begin{array}{l}\text { Sand; quartzose, fine to very fine; } 5 \text { to } 10 \text { percent heavy minerals; } 10 \text { to } 15 \text { percent } \\
\text { sheli. }\end{array}$ \\
\hline 5 & $15-20$ & $\begin{array}{l}\text { Sand, medium-gray; quartzose, fine to very fine; } 15 \text { to } 20 \text { percent shell; } 10 \text { to } 15 \\
\text { percent heavy minerals. }\end{array}$ \\
\hline
\end{tabular}

We11 PB-1529

Lat $26^{\circ} 48^{\prime} 32^{\prime \prime}$, long $80^{\circ} 17^{\prime} 33^{\prime \prime}$

Sec. 13, T. 42 S., R. $40 \mathrm{E}$.

\begin{tabular}{|c|c|c|}
\hline $\begin{array}{l}\text { Thick- } \\
\text { ness } \\
\text { (feet) }\end{array}$ & $\begin{array}{l}\text { Depth below } \\
\text { land surface } \\
\text { (feet) }\end{array}$ & Description \\
\hline 5 & $0-5$ & $\begin{array}{l}\text { Sandy marl, pink-gray to brownish-gray; silt and clay; } 30 \text { percent quartzose, fine to } \\
\text { very fine; } 3 \text { to } 5 \text { percent heavy minerals; } 15 \text { to } 20 \text { percent shell fragments at } 4 \text { to } 5 \\
\text { feet. }\end{array}$ \\
\hline 2 & $5-7$ & $\begin{array}{l}\text { Limestone or sandstone, greenish-gray to brownish-gray; quartzose, fine to very fine, } \\
\text { poorly cemented; } 20 \text { to } 30 \text { percent shell fragments; } 5 \text { to } 10 \text { percent heavy minerals. }\end{array}$ \\
\hline 3 & $7-10$ & Sandy marl, grayish-green; clay and silt; quartzose, fine to very fine. \\
\hline 5 & $10-15$ & $\begin{array}{l}\text { Marl, same as above; with sand increasing to } 50 \text { percent at } 9 \text { to } 10 \text { feet; } 3 \text { to } 5 \text { per- } \\
\text { cent heavy minerals. }\end{array}$ \\
\hline 5 & $15-20$ & $\begin{array}{l}\text { Sand, grayish-green to brownish-gray; quartzose, fine to very fine; } 5 \text { to } 10 \text { percent } \\
\text { heavy minerals; some marl } 15 \text { to } 18 \text { feet; } 25 \text { to } 30 \text { percent organics at } 18 \text { to } 20 \text { feet; } \\
\text { brown sandstone nodules at } 18 \text { feet. }\end{array}$ \\
\hline
\end{tabular}


We11 PB-1531

Lat $26^{\circ} 48^{\prime} 41^{\prime \prime}$, long $80^{\circ} 14^{\prime} 42^{\prime \prime}$

Sec. 16, T. 42 S., R. 41 E.

\begin{tabular}{|c|c|c|}
\hline $\begin{array}{l}\text { Thick- } \\
\text { ness } \\
\text { (feet) }\end{array}$ & $\begin{array}{l}\text { Depth below } \\
\text { land surface } \\
\text { (feet) }\end{array}$ & Description \\
\hline 5 & $0-5$ & $\begin{array}{l}\text { Sandy shell, grayish-brown to brownish-tan; } 30 \text { to } 35 \text { percent quartzose, fine to very } \\
\text { fine; } 5 \text { to } 10 \text { percent heavy minerals; abundant bivalvia. }\end{array}$ \\
\hline 2 & $5-7$ & $\begin{array}{l}\text { Sandy marl, grayish-green to medium-gray; quartzose, very fine; } 3 \text { to } 5 \text { percent heavy } \\
\text { minerals; } 20 \text { to } 30 \text { percent shell fragments. }\end{array}$ \\
\hline 3 & $7-10$ & $\begin{array}{l}\text { Sandy marl, greenish-gray; clay and silt; quartzose, very fine; } 3 \text { to } 5 \text { percent heavy } \\
\text { minerals. }\end{array}$ \\
\hline 5 & $10-15$ & $\begin{array}{l}\text { Sand, greenish-gray to brownish-gray; quartzose, fine to very fine; } 5 \text { to } 10 \text { percent } \\
\text { heavy minerals; } 20 \text { percent shell fragments; marl, increasing to } 30 \text { percent from } 12 \text { to } \\
15 \text { feet. }\end{array}$ \\
\hline 5 & $15-20$ & $\begin{array}{l}\text { Sand, grayish-green to greenish-gray; quartzose, very fine; } 10 \text { to } 20 \text { percent heavy } \\
\text { minerals; shell fragments at } 18 \text { to } 20 \text { feet. }\end{array}$ \\
\hline
\end{tabular}

Well PB-1532

Lat $26^{\circ} 48^{\prime} 33^{\prime \prime}$, long $80^{\circ} 17^{\prime} 34^{\prime \prime}$

Sec. 24, T. 42 S., R. 40 E.

\begin{tabular}{|c|c|c|}
\hline $\begin{array}{c}\text { Thick- } \\
\text { ness } \\
\text { (feet) }\end{array}$ & $\begin{array}{c}\text { Depth below } \\
\text { land surface } \\
\text { (feet) }\end{array}$ & Description \\
\hline 5 & $0-5$ & $\begin{array}{l}\text { Sand, greenish-gray to brownish-gray; quartzose, fine to very fine; } 5 \text { to } 10 \text { percent } \\
\text { heavy minerals; } 30 \text { percent organics; marl layer at } 4 \text { to } 5 \text { feet. }\end{array}$ \\
\hline 5 & $5-10$ & $\begin{array}{l}\text { Sandy marl, greenish-gray; clay and silt; quartzose, very fine; } 3 \text { to } 5 \text { percent heavy } \\
\text { minerals; } 3 \text { to } 5 \text { percent shell fragments. }\end{array}$ \\
\hline 5 & $10-15$ & $\begin{array}{l}\text { Sandy marl, greenish-gray to grayish-brown; silt and clay; quartzose, very fine; } 3 \text { to } \\
5 \text { percent heavy minerals; } 5 \text { to } 10 \text { percent shell fragments. }\end{array}$ \\
\hline 5 & $15-20$ & $\begin{array}{l}\text { Sand, grayish-brown to greenish-gray; quartzose, medium to very fine; } 0 \text { to } 3 \text { percent } \\
\text { heavy minerals; streaks of marl. }\end{array}$ \\
\hline
\end{tabular}

We11 PB-1533

Lat $26^{\circ} 45^{\prime} 55^{\prime \prime}$, long $80^{\circ} 20^{\prime} 34^{\prime \prime}$

Sec. 34, T. 42 S., R. 40 E.

\begin{tabular}{|c|c|c|}
\hline $\begin{array}{l}\text { Thick- } \\
\text { ness } \\
\text { (feet) }\end{array}$ & $\begin{array}{l}\text { Depth below } \\
\text { land surface } \\
\text { (feet) }\end{array}$ & Description \\
\hline 5 & $0-5$ & $\begin{array}{l}\text { Sand, grayish-tan to yellowish-brown; quartzose, fine to very fine; } 5 \text { to } 10 \text { percent } \\
\text { heavy minerals; } 10 \text { to } 15 \text { percent shell fragments; } 5 \text { to } 10 \text { percent marl; } 5 \text { percent } \\
\text { sandstone nodules. }\end{array}$ \\
\hline 5 & $5-10$ & $\begin{array}{l}\text { Sand, grayish-tan to greenish-gray; quartzose, medium to fine, } 35 \text { to } 40 \text { percent shell } \\
\text { fragments; } 3 \text { to } 5 \text { percent heavy minerals; marl layer at } 8 \text { to } 10 \text { feet; some organics. }\end{array}$ \\
\hline 5 & $10-15$ & $\begin{array}{l}\text { Sandy marl, greenish-gray; clay and silt; quartzose, very fine; } 1 \text { to } 3 \text { percent heavy } \\
\text { minerals; } 15 \text { to } 20 \text { percent shell fragments from } 10 \text { to } 12 \text { feet, increasing to } 40 \text { per- } \\
\text { cent from } 12 \text { to } 15 \text { feet; some organics. }\end{array}$ \\
\hline 5 & $15-20$ & $\begin{array}{l}\text { Sandy marl, greenish-gray; clay and silt; quartzose, very fine to fine; } 5 \text { to } 10 \text { per- } \\
\text { cent heavy minerals; bivalvia, gastropoda, Iurritella, coral; } 10 \text { to } 15 \text { percent rock } \\
\text { fragments. }\end{array}$ \\
\hline
\end{tabular}


Wel1 PB-1534

Lat $26^{\circ} 45^{\prime} 53^{\prime \prime}$, long $80^{\circ} 16^{\prime} 17^{\prime \prime}$

Sec. 32 , T. 42 S., R. 41 E.

$\begin{array}{ccl}\begin{array}{c}\text { Thick- } \\ \text { ness } \\ \text { (feet) }\end{array} & \begin{array}{c}\text { Depth below } \\ \text { land surface } \\ \text { (feet) }\end{array} & \text { Description } \\ 5 & 0-5 & \begin{array}{l}\text { Sand, yellowish-brown; quartzose, fine to very fine; } 5 \text { to } 10 \text { percent heavy minerals; } \\ 5 \text { to } 10 \text { percent shell fragments; } 15 \text { to } 20 \text { percent organics; } 40 \text { percent marl at } 4 \text { to } 5 \\ \text { feet. }\end{array} \\ 5 & 5-10 & \begin{array}{l}\text { Sand, grayish-tan to medium-gray; quartzose, medium to very fine; } 5 \text { to } 10 \text { percent } \\ \text { heavy minerals; } 10 \text { to } 15 \text { percent shell fragments; } 5 \text { to } 10 \text { percent streaks of clay or } \\ \text { silt. }\end{array} \\ 5 & 10-15 & \begin{array}{l}\text { Sand, pale-gray to beige; quartzose, medium to very fine; } 3 \text { to } 5 \text { percent heavy miner- } \\ \text { als; } 3 \text { to } 5 \text { percent sheli fragments. } \\ \text { Sand, grayish-brown to yellowish-brown; quartzose, same as above; } 3 \text { to } 5 \text { percent } \\ \text { heavy minerals; } 5 \text { to } 10 \text { percent organics; about } 5 \text { percent rock fragments. }\end{array}\end{array}$

\section{We11 PB-1535 \\ Lat $26^{\circ} 45^{\prime} 54^{\prime \prime}$, long $80^{\circ} 14^{\prime} 48^{\prime \prime}$ \\ Sec. 3, T. 43 S., R. 41 E.}

\begin{tabular}{|c|c|c|}
\hline $\begin{array}{l}\text { Thick- } \\
\text { ness } \\
\text { (feet) }\end{array}$ & $\begin{array}{l}\text { Depth below } \\
\text { land surface } \\
\text { (feet) }\end{array}$ & Description \\
\hline 3 & $0-3$ & $\begin{array}{l}\text { Sand, grayish-tan to dark-brown; quartzose, fine to very fine; } 40 \text { to } 45 \text { percent or- } \\
\text { ganics; } 5 \text { to } 10 \text { percent heavy minerals. }\end{array}$ \\
\hline 2 & $3-5$ & $\begin{array}{l}\text { Marl, yellowish-brown to reddish-brown; clay and silt; quartzose, very fine; } 5 \text { to } 10 \\
\text { percent shell fragments; } 15 \text { to } 20 \text { percent organics. }\end{array}$ \\
\hline 2 & $5-7$ & $\begin{array}{l}\text { Sandstone, reddish-brown to light-gray; quartzose, medium to fine; } 5 \text { to } 10 \text { percent } \\
\text { heavy minerals; } 10 \text { to } 15 \text { percent shell fragments; poorly cemented. }\end{array}$ \\
\hline 3 & $7-10$ & $\begin{array}{l}\text { Sand, white to light-gray; quartzose, fine to very fine; } 3 \text { to } 5 \text { percent heavy miner- } \\
\text { als. }\end{array}$ \\
\hline 5 & $10-15$ & Sand, light-gray to grayish-tan; same as above. \\
\hline 5 & $15-20$ & $\begin{array}{l}\text { Sand, light-gray to grayish-tan; quartzose, medium to fine; } 0 \text { to } 3 \text { percent heavy min- } \\
\text { erals; } 15 \text { to } 20 \text { percent sandstone; loosely cemented. }\end{array}$ \\
\hline 2 & $20-22$ & $\begin{array}{l}\text { Sand, light-gray to grayish-tan; quartzose, fine to very fine; } 5 \text { to } 10 \text { percent heavy } \\
\text { minerals; } 15 \text { to } 20 \text { percent marl. }\end{array}$ \\
\hline
\end{tabular}

\section{We11 PB-1536}

Lat $26^{\circ} 45^{\prime} 55^{\prime \prime}$, long $80^{\circ} 13^{\prime} 22^{\prime \prime}$

Sec. 35, T. 42 S., R. 41 E.

\begin{tabular}{|c|c|c|}
\hline $\begin{array}{l}\text { Thick- } \\
\text { ness } \\
\text { (feet) }\end{array}$ & $\begin{array}{l}\text { Depth below } \\
\text { land surface } \\
\text { (feet) }\end{array}$ & Description \\
\hline 3 & $0-3$ & $\begin{array}{l}\text { Sand, brownish-gray to reddish-brown; quartzose, fine to very fine; } 3 \text { to } 5 \text { percent } \\
\text { heavy minerals. }\end{array}$ \\
\hline 2 & $3-5$ & $\begin{array}{l}\text { Marl, greenish-brownish-gray; silt; quartzose, very fine; interbedded with calcite } \\
\text { and dolomite gravel-size rock fragment. }\end{array}$ \\
\hline 3 & $5-8$ & $\begin{array}{l}\text { Sandy shel1, brownish-gray; } 25 \text { to } 30 \text { percent quartzose, fine to very fine; } 5 \text { to } 10 \\
\text { percent heavy minerals; abundant bivalvia; interbedded with limestone rock fragments. }\end{array}$ \\
\hline 2 & $8-10$ & $\begin{array}{l}\text { Sand, white to olive-gray; quartzose, fine to very fine; } 3 \text { to } 5 \text { percent heavy miner- } \\
\text { als. }\end{array}$ \\
\hline 4 & $10-14$ & $\begin{array}{l}\text { Sand, white to olive-gray; quartzose, fine to very fine; } 3 \text { to } 5 \text { percent heavy miner- } \\
\text { als; } 10 \text { to } 15 \text { percent sheli fragments; interbedded with } 5 \text { to } 10 \text { percent limestone } \\
\text { rock fragments. }\end{array}$ \\
\hline 6 & $14-20$ & Sand, dark-brown; quartzose, fine to very fine. \\
\hline
\end{tabular}


We11 $P B-1537$

Lat $26^{\circ} 45^{\prime} 47^{\prime \prime}$, long $80^{\circ} 12^{\prime} 53^{\prime \prime}$

Sec. 35, T. 42 S., R. 41 E.

$\begin{array}{ccc}\begin{array}{c}\text { Thick- } \\ \text { ness } \\ \text { (feet) }\end{array} & \begin{array}{c}\text { Depth below } \\ \text { land surface } \\ \text { (feet) }\end{array} & \text { Description } \\ 5 & 0-5 & \text { Road fill. } \\ 5 & 5-10 \quad \begin{array}{l}\text { Sandy mar1, medium-gray to brownish-gray; quartzose, fine to very fine; } 5 \text { to } 10 \text { per- } \\ \text { cent heavy minerals; } 20 \text { to } 30 \text { percent she11 fragments, decreasing to } 5 \text { to } 10 \text { percent } \\ \text { at } 10 \text { feet. }\end{array} \\ 5 & 10-15 \quad \begin{array}{l}\text { Sand, light-gray to blue-gray; } 30 \text { to } 35 \text { percent quartzose, fine to very fine; } 1 \text { to } \\ \text { 3 percent heavy minerals; } 20 \text { to } 25 \text { percent shell fragments; } 20 \text { to } 25 \text { percent marl, } \\ \text { blue-gray; clay and silt; } 10 \text { to } 15 \text { percent dolomite, orange, weathered. } \\ \text { Sand, dark-brown to grayish-tan; quartzose, coarse to very fine; } 1 \text { to } 3 \text { percent heavy } \\ \text { minerals. }\end{array} \\ 5 & 15-20 & \end{array}$

We11 PB-1538

Lat $26^{\circ} 44^{\prime} 20^{\prime \prime}$, long $80^{\circ} 19^{\prime} 43^{\prime \prime}$

Sec. 11, T. 43 S., R. 40 E.

\begin{tabular}{|c|c|c|}
\hline $\begin{array}{l}\text { Thick- } \\
\text { ness } \\
\text { (feet) }\end{array}$ & $\begin{array}{l}\text { Depth below } \\
\text { land surface } \\
\text { (feet) }\end{array}$ & Description \\
\hline 5 & $0-5$ & $\begin{array}{l}\text { Sand, medium-brown to dark-brown; quartzose, fine to very fine; } 1 \text { to } 3 \text { percent heavy } \\
\text { minerals; abundant organic materials; mar1 at } 4 \text { to } 5 \text { feet. }\end{array}$ \\
\hline 5 & $5-10$ & $\begin{array}{l}\text { Marly sand, brownish-tan to medium-brown; quartzose, fine to very fine; silt; } 1 \text { to } 3 \\
\text { percent heavy minerals. }\end{array}$ \\
\hline 3 & $10-13$ & $\begin{array}{l}\text { Sand, white to light-gray; quartzose, fine to very fine; } 5 \text { to } 10 \text { percent heavy miner- } \\
\text { als. }\end{array}$ \\
\hline 2 & $13-15$ & $\begin{array}{l}\text { Shell, white to light-gray; } 80 \text { percent shell fragments; interbedded with about } 20 \\
\text { percent limestone, black. }\end{array}$ \\
\hline 5 & $15-20$ & Shell interbedded with limestone, same as above. \\
\hline 2 & $20-22$ & $\begin{array}{l}\text { Calcareous sand, light-gray to grayish-tan; quartzose, fine to very fine; } 5 \text { to } 10 \\
\text { percent heavy minerals; } 35 \text { percent shell fragments. }\end{array}$ \\
\hline
\end{tabular}

\section{Well PB-1539}

Lat $26^{\circ} 42^{\prime} 24^{\prime \prime}$, long $80^{\circ} 16^{\prime} 55^{\prime \prime}$

Sec. 19, T. 43 S., R. 41 E.

\begin{tabular}{|c|c|c|}
\hline $\begin{array}{l}\text { Thick- } \\
\text { ness } \\
\text { (feet) } \\
\end{array}$ & $\begin{array}{c}\text { Depth below } \\
\text { land surface } \\
\text { (feet) }\end{array}$ & Description \\
\hline 5 & $0-5$ & Road fill. \\
\hline 5 & $5-10$ & $\begin{array}{l}\text { Sand, white to light-gray to grayish-tan; quartzose, fine to very fine; } 5 \text { to } 10 \text { per- } \\
\text { cent heavy minerals; about } 10 \text { percent organics at } 5 \text { to } 6 \text { feet. }\end{array}$ \\
\hline 10 & $10-20$ & Sand, white to light-gray to gray-tan; quartzose, coarse to very fine, well rounded. \\
\hline
\end{tabular}




\begin{tabular}{|c|c|c|}
\hline $\begin{array}{l}\text { Thick- } \\
\text { ness } \\
\text { (feet) }\end{array}$ & $\begin{array}{l}\text { Depth below } \\
\text { land surface } \\
\text { (feet) }\end{array}$ & Description \\
\hline 5 & $0-5$ & Road fill. \\
\hline 5 & $5-10$ & $\begin{array}{l}\text { Sand, greenish-gray; quartzose, fine to very fine; } 5 \text { to } 10 \text { percent heavy minerals; } 10 \\
\text { to } 15 \text { percent shell fragments; interbedded with } 5 \text { to } 10 \text { percent limestone. }\end{array}$ \\
\hline 5 & $10-15$ & $\begin{array}{l}\text { Sand, white to light-gray to greenish-gray; quartzose, fine to very fine; } 5 \text { to } 10 \\
\text { percent heavy minerals; } 20 \text { to } 25 \text { percent shell fragments; } 5 \text { to } 10 \text { percent marl; } 20 \text { to } \\
25 \text { percent limestone rock fragments. }\end{array}$ \\
\hline 3 & $15-18$ & Sand, greenish-gray; interbedded with limestone as above. \\
\hline 2 & $18-20$ & $\begin{array}{l}\text { Sand, blue-gray; quartzose, fine to very fine; } 5 \text { to } 10 \text { percent heavy minerals; } 25 \text { to } \\
30 \text { percent shell fragments; } 15 \text { to } 20 \text { percent marl, clay and silt (blue-gray). }\end{array}$ \\
\hline 2 & $20-22$ & $\begin{array}{l}\text { Sand, blue-gray to grayish-tan; quartzose, fine to very fine; marl to } 21 \text { feet; shells } \\
\text { increase to } 50 \text { percent at } 22 \text { feet. Turritella. }\end{array}$ \\
\hline
\end{tabular}

\section{Wel1 PB-1541}

Lat $26^{\circ} 51^{\prime} 45^{\prime \prime}$, long $80^{\circ} 15^{\prime} 27^{\prime \prime}$

Sec. 33, T. 41 S., R. 41 E.

\begin{tabular}{|c|c|c|}
\hline $\begin{array}{l}\text { Thick- } \\
\text { ness } \\
\text { (feet) }\end{array}$ & $\begin{array}{c}\text { Depth below } \\
\text { land surface } \\
\text { (feet) }\end{array}$ & Description \\
\hline 4 & $0-4$ & $\begin{array}{l}\text { Sand, yellowish-brown to light-gray; quartzose, fine to very fine; } 3 \text { to } 5 \text { percent } \\
\text { heavy minerals; } 3 \text { to } 5 \text { percent sheli fragments. }\end{array}$ \\
\hline 2 & $4-6$ & Sandy marl, brownish-gray to olive-gray; silt and very fine quartzose. \\
\hline 2 & $6-8$ & $\begin{array}{l}\text { Sandy shell, olive-gray; quartzose, medium to fine; abundant bivalvia; } 15 \text { to } 20 \text { per- } \\
\text { cent limestone rock fragments. }\end{array}$ \\
\hline 2 & $8-10$ & $\begin{array}{l}\text { Sandy marl, olive-gray; silt; quartzose, very fine; } 3 \text { to } 5 \text { percent heavy minerals; } 15 \\
\text { to } 20 \text { percent limestone rock fragments. }\end{array}$ \\
\hline 5 & $10-15$ & $\begin{array}{l}\text { Sand, white to light-gray; quartzose, fine to very fine; } 3 \text { to } 5 \text { percent heavy miner- } \\
\text { als; } 20 \text { to } 25 \text { percent marl, greenish-gray, clay and silt. }\end{array}$ \\
\hline 5 & $15-20$ & $\begin{array}{l}\text { Sand, white to light-gray; quartzose, fine to very fine; } 5 \text { to } 10 \text { percent heavy miner- } \\
\text { als; } 15 \text { to } 20 \text { percent shel1 fragments; } 10 \text { to } 15 \text { percent marl, same as above. }\end{array}$ \\
\hline
\end{tabular}




\section{We11 PB-1546}

Lat $26^{\circ} 56^{\prime} 06^{\prime \prime}$, long $80^{\circ} 13^{\prime} 55^{\prime \prime}$

Sec. 3, T. 41 S, R. $41 \mathrm{E}$

\begin{tabular}{|c|c|c|}
\hline $\begin{array}{l}\text { Thick- } \\
\text { ness } \\
\text { (feet) }\end{array}$ & $\begin{array}{l}\text { Depth below } \\
\text { land surface } \\
\text { (feet) }\end{array}$ & Description \\
\hline 5 & $0-5$ & $\begin{array}{l}\text { Sand, dark-brown to medium-brown; } 40 \text { to } 45 \text { percent quartzose, moderately sorted, me- } \\
\text { dium to coarse, subrounded to subangular; } 1 \text { to } 3 \text { percent heavy minerals, fine to very } \\
\text { fine, subrounded to rounded, well sorted; } 5 \text { to } 10 \text { percent shell fragments; } 10 \text { to } 15 \\
\text { percent organics; } 20 \text { to } 25 \text { percent calcite; grades down to lime mud marl. }\end{array}$ \\
\hline 5 & $5-10$ & $\begin{array}{l}\text { Mar1, bluish-gray; } 20 \text { to } 25 \text { percent quartzose, fine to very fine, moderately sorted, } \\
\text { subrounded to rounded; } 10 \text { to } 15 \text { percent shell fragments, abundant bivalvia, Venus; } 1 \\
\text { to } 3 \text { percent heavy minerals, fine to very fine, rounded to subrounded, well sorted; } \\
45 \text { to } 50 \text { percent calcite crystals and lime mud; semi-impermeable. }\end{array}$ \\
\hline 3 & $10-13$ & $\begin{array}{l}\text { Marl, bluish-gray to brownish-gray; quartzose, silt to very fine, moderately sorted, } \\
\text { subrounded to rounded; } 5 \text { to } 10 \text { percent shell fragments; } 1 \text { to } 3 \text { percent heavy minerals } \\
\text { as above; } 20 \text { to } 25 \text { percent carbonates; semi-impermeable. }\end{array}$ \\
\hline 5 & $13-18$ & $\begin{array}{l}\text { Sandy marl, brownish-gray to bluish-gray; quartzose, very fine to fine, well sorted, } \\
\text { subrounded to rounded; } 3 \text { to } 5 \text { percent heavy minerals, very fine, subrounded to } \\
\text { subangular, well sorted; } 1 \text { to } 3 \text { shell fragments; } 5 \text { to } 10 \text { percent carbonates; semi- } \\
\text { impermeable. }\end{array}$ \\
\hline 2 & $18-20$ & $\begin{array}{l}\text { Shelly sand, brownish-gray; quartzose, fine to very fine, moderately sorted, sub- } \\
\text { rounded to rounded; } 1 \text { to } 3 \text { percent heavy minerals, very fine, well sorted subrounded } \\
\text { to rounded; } 40 \text { to } 45 \text { percent shells, abundant bivalvia. }\end{array}$ \\
\hline 3 & $20-23$ & $\begin{array}{l}\text { Carbonate sand, brownish-gray; } 45 \text { to } 50 \text { percent detrital carbonates, fine to very } \\
\text { fine, subangular to angular, moderately sorted; } 10 \text { to } 15 \text { percent heavy minerals, very } \\
\text { fine, well sorted, rounded; } 25 \text { to } 30 \text { percent shell fagments, abundant bivalvia; } \\
\text { interbedded with } 10 \text { to } 15 \text { percent limestone, brownish-gray to bluish-gray; packed } \\
\text { biomicrite to sparse biosparite. }\end{array}$ \\
\hline 3 & $23-26$ & $\begin{array}{l}\text { Limestone, dark-brownish-gray to medium-brownish-gray; fossiliferous intramicrite; } 1 \\
\text { to } 3 \text { percent bivalvia; } 5 \text { to } 10 \text { percent calcite intraclast, fine to very fine, moder- } \\
\text { ately sorted, subrounded to subangular; } 3 \text { to } 5 \text { percent heavy minerals, fine to very } \\
\text { fine, well sorted, subrounded to rounded; very well cemented; very porous. }\end{array}$ \\
\hline 4 & $26-30$ & $\begin{array}{l}\text { Carbonate sand, medium-brownish-gray; detrital calcite crystals, medium to fine, sub- } \\
\text { rounded to angular, poorly sorted; } 30 \text { to } 35 \text { percent shell fragments; } 10 \text { to } 15 \text { percent } \\
\text { heavy minerals, fine to very fine, subangular to rounded, poorly sorted. }\end{array}$ \\
\hline 6 & $30-36$ & $\begin{array}{l}\text { Carbonate sand, medium-brownish-gray; detrital calcite crystals as above; } 40 \text { to } 45 \\
\text { percent shell fragments, abundant bivalvia; } 10 \text { to } 15 \text { percent heavy minerals as above. }\end{array}$ \\
\hline 7 & $36-43$ & $\begin{array}{l}\text { Carbonate sand, dark-gray to medium-gray; detrital carbonates, coarse to fine, angu- } \\
\text { lar to rounded, poorly sorted; } 40 \text { to } 45 \text { percent shell fragments as above; } 10 \text { to } 15 \\
\text { percent heavy minerals as above. }\end{array}$ \\
\hline 3 & $43-46$ & $\begin{array}{l}\text { Carbonate sand, dark-gray to medium-gray; detrital carbonates, very fine to medium, } \\
\text { angular to subrounded, poorly sorted; } 40 \text { to } 45 \text { percent shell fragments, bivalvia; } 5 \\
\text { to } 10 \text { percent heavy minerals, fine to very fine, rounded, well sorted. }\end{array}$ \\
\hline 4 & $46-50$ & Carbonate sand, same as above; Galeodea. \\
\hline 3 & $50-53$ & $\begin{array}{l}\text { Carbonate sand, dark-gray to medium-gray; detrital carbonates, very fine to medium, } \\
\text { subangular to subrounded, poorly sorted; } 3 \text { to } 5 \text { percent heavy minerals, fine to very } \\
\text { fine, rounded to subrounded, moderately sorted; } 35 \text { to } 40 \text { percent sheil fragments, } \\
\text { bivalvia, Mya. }\end{array}$ \\
\hline 3 & $53-56$ & $\begin{array}{l}\text { Carbonate sand, dark-gray to medium-gray; detrital carbonates, fine to very fine, } \\
\text { subrounded to subangular, moderately sorted; } 5 \text { to } 10 \text { percent heavy minerals as above; } \\
35 \text { to } 40 \text { percent shell fragments, Mya, Anadora, gastropods. }\end{array}$ \\
\hline 4 & $56-60$ & $\begin{array}{l}\text { Carbonate sand, dark-gray to medium-gray to grayish-brown; detrital carbonates, very } \\
\text { fine to medium, subrounded to subangular, moderately sorted; } 3 \text { to } 5 \text { percent heavy } \\
\text { minerals, fine to very fine, rounded to subrounded; } 40 \text { to } 45 \text { percent shell fragments, } \\
\text { Turritelia, Anadora, Mya, Glycymeris, worms, others; about } 20 \text { to } 30 \text { percent cemented } \\
\text { into sandstone and limestone nodules, quartzose, fine to very fine, subrounded to } \\
\text { rounded, moderately sorted. }\end{array}$ \\
\hline 3 & $60-63$ & $\begin{array}{l}\text { Carbonate sand interbedded with } 25 \text { percent limestone, dark-gray to medium-gray to } \\
\text { grayish-brown; detrital carbonate, very fine to very coarse, angular to rounded, } \\
\text { poorly sorted; } 40 \text { to } 45 \text { percent shell fragments, gastropods, viviporus, bivalves as } \\
\text { above, barnacles, worms; fossiliferous limestone; poorly washed biosparite to sorted } \\
\text { biosparite; quartzose, fine to very fine, rounded to subrounded; carbonates as above; } \\
10 \text { to } 15 \text { percent heavy minerals, fine to very fine, rounded to subrounded; abundant } \\
\text { gastropod molds; very porous. }\end{array}$ \\
\hline
\end{tabular}


We11 PB-1546--Continued

\begin{tabular}{ccc}
\hline $\begin{array}{c}\text { Thick- } \\
\text { ness } \\
\text { (feet) }\end{array}$ & $\begin{array}{c}\text { Depth below } \\
\text { land surface } \\
\text { (feet) }\end{array}$ & Description \\
\hline
\end{tabular}

$763-70$ Carbonate sand interbedded with 10 percent limestone, medium-gray to grayish-green. detrital carbonates, fine to very fine, subrounded to rounded, well sorted; 25 to 30 percent microscopic shell fragments; 5 to 10 percent heavy minerals, fine to very fine, rounded to subrounded, well sorted; cemented in places to intrasparite limestone; semi-impermeable.

$370-73$ Carbonate sand with interbedded limestone, medium-gray to brownish-gray; about 50 percent detrital carbonates and shell fragments, bivalves, gastropods, barnacles; 10 to 15 percent heavy minerals, fine to very fine, rounded to subrounded, some phosphates and elongate gypsum crystals; 25 to 30 percent limestone; intrasparite to sparse biosparite.

$3 \quad 73-76 \quad$ Carbonate sand with interbedded sandy limestone; medium-gray to brownish-gray; detrital carbonates and shell fragments as above; 10 to 15 percent heavy minerals as above; about 5 to 10 percent sandy limestone, intrasparite; 25 to 30 percent quartzose, fine to very fine.

$476-80$

Sandy limestone, medium-gray to brownish-gray; poorly washed biosparite; 25 to 30 percent quartzose, fine to medium, subrounded to subangular; 10 to 15 percent heavy mineraj.s, fine to very fine, rounded to subrounded; 25 to 30 percent shell fragments, Anadora, others, gastropods; moldic, vugs, very porous; about 25 to 30 percent loose detrital carbonate and shell fragments.

$380-83$

Sandy, calcareous limestone; packed biosparite; medium-gray to brownish-gray; quartzose as above; 5 to 10 percent heavy minerals, very fine, rounded, we11 sorted; 35 to 40 percent shell fragments, scallops, other bivalves, gastropods, Turritella; moldic, vugs, very porous; moderately cemented; 25 to 30 percent loose detrital carbonates and shell fragments.

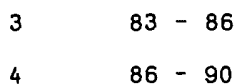

Sandy, calcareous limestone as above, medium-gray to olive-gray to browmish-gray.

Sandy, calcareous limestone, medium-gray; packed biosparite to coquina in places; 20 to 25 percent quartzose, fine to very fine, subangular to subrounded, well sorted; 3 to 5 percent heavy minerals, very fine, rounded, well sorted; abundant bivalvia, scallops; moldic, vugs; moderately cemented; porous; 25 to 30 percent 100 se detrital carbonates and shell fragments.

$390-93$

Carbonate sand interbedded with limestone, medium-gray to browmish-gray; 20 to 25 percent quartzose, fine to very fine, subanguiar to subrounded, well sorted; 5 to 10 percent heavy minerals and phosphates, very fine to medium, well rounded, well sorted (fine); 30 to 35 percent shell fragments, abundant bivalvia, gastropods; about 10 to 15 percent limestone; sandy, packed biosparite; moldic, vugs; poorly to moderately cemented; porous.

Calcareous sand, medium-gray to brownish-gray; 10 to 15 percent quartzose as above; 5 to 10 percent heavy minerals as above; 45 to 50 percent shell fragments, Neptunea, Terebra, Glycymeris; about 5 to 10 percent loosely cemented nodules.

Sandy shell, medium-gray to brownish-gray; 20 to 25 percent detrital carbonates, fine to coarse, angular to rounded, poorly sorted; 5 to 10 percent heavy minerals as above; abundant gastropods, Turritella, Conus, Terebra, Olivella, Clathrodrilla, bivalvia, Cerastroderma, Lirophora, scallops, Chlorophyta (algae).

Sandy shell as above, dark-gray to medium-gray; Cypraea and other shell fragments as above; 5 to 10 percent cemented as nodules.

Sandy shel1, dark-gray to medium-gray to brownish-gray; 10 to 15 percent quartzose, very fine to medium, subrounded to angular, pooriy sorted; 3 to 5 percent heavy minerals, very fine, rounded, well sorted; 25 to 30 percent detrital carbonates; shell fragments, Turritella (abundant), other gastropods and bivalves, barnacles, algae.

Sandy shell as above; shell fragments, abundant Turritella, Oliva, Cypraea, oysters, and clams, Glycymeris bryozoan, Conopeum.

$3 \quad 110-113$

Sandy shell, dark-gray to medium-gray; 20 to 25 percent quartzose, fine to medium, subrounded to angular, moderately sorted; 3 to 5 percent heavy minerals, very fine to medium, rounded to subangular, moderately sorted; 5 to 10 percent cemented as coquina; shell fragments as above, coral, Septastrea.

$3 \quad 113-116$ Sandy she11 as above; not cemented.

$4116-120$

Sandy shell, dark-gray to medium-gray to brownish-gray; 15 to 20 percent quartzose, very fine to medium, subrounded to angular, poorly sorted; 3 to 5 percent heavy minerals, rounded to subrounded, fine to very fine, moderately sorted; 20 to 25 percent detrital carbonates; shell fragments, abundant gastropods, Turritella, Conus, oliva, Chione, coral. 
Well PB-1546--Continued

\begin{tabular}{|c|c|c|}
\hline $\begin{array}{l}\text { Thick- } \\
\text { ness } \\
\text { (feet) }\end{array}$ & $\begin{array}{l}\text { Depth below } \\
\text { land surface } \\
\text { (feet) }\end{array}$ & Description \\
\hline 3 & $120-123$ & Sandy shell as above; about 5 to 10 percent partially cemented. \\
\hline 3 & $123-126$ & $\begin{array}{l}\text { Shelly sand, medium-gray to beige-gray; quartzose, very fine to medium, moderately } \\
\text { sorted, subrounded to angular; } 5 \text { to } 10 \text { percent heavy minerals, very fine to fine, } \\
\text { rounded to subrounded, well sorted, } 40 \text { to } 45 \text { percent detrital carbonates and sheil } \\
\text { fragments; } 5 \text { to } 10 \text { percent loosely cemented as coquina. }\end{array}$ \\
\hline 4 & $126-130$ & $\begin{array}{l}\text { Shelly sand interbedded with coquina, medium-gray to beige-gray; quartzose, very fine } \\
\text { to coarse, subrounded to angular, poorly sorted; } 3 \text { to } 5 \text { percent heavy minerals and } \\
\text { phosphates, very fine to fine, rounded to subrounded, well sorted; } 40 \text { to } 45 \text { percent } \\
\text { detrital carbonates and shell fragments; interbedded with } 20 \text { to } 25 \text { percent coquina. }\end{array}$ \\
\hline 3 & $130-133$ & $\begin{array}{l}\text { Shelly sand, medium-gray to beige-gray; quartzose, fine to coarse, subrounded to an- } \\
\text { gular, poorly sorted; } 5 \text { to } 10 \text { percent heavy minerals, very fine to medium, rounded to } \\
\text { subangular, poorly sorted; } 40 \text { to } 45 \text { percent detrital carbonates and shell fragments, } \\
\text { bivalvia, barnacles, worms, spines; loosely consolidated. }\end{array}$ \\
\hline 3 & $133-136$ & $\begin{array}{l}\text { Shelly sand with interbedded limestone, medium-gray to beige-gray; quartzose, very } \\
\text { fine to medium, angular to subrounded, moderately sorted; } 5 \text { to } 10 \text { percent heavy min- } \\
\text { erals, very fine to fine, rounded to subrounded, moderately sorted; } 30 \text { to } 35 \text { percent } \\
\text { shell fragments and detrital carbonates; } 20 \text { to } 25 \text { percent loosely cemented limestone; } \\
\text { sparse biosparite. }\end{array}$ \\
\hline 7 & $136-143$ & $\begin{array}{l}\text { Sand, medium-gray to light-gray; quartzose, fine to medium, subangular to angular, } \\
\text { well sorted; } 3 \text { to } 5 \text { percent heavy minerals, fine to very fine, rounded to subrounded, } \\
\text { moderately sorted; } 5 \text { to } 10 \text { percent detrital carbonates and shell fragments. }\end{array}$ \\
\hline 3 & $143-146$ & $\begin{array}{l}\text { Sand, medium-gray to light-gray; quartzose, fine to medium, subrounded to angular, } \\
\text { moderately sorted; } 5 \text { to } 10 \text { percent heavy minerals as in } 135 \text { to } 140 \text { feet; } 1 \text { to } 3 \text { per- } \\
\text { cent phosphates; } 5 \text { to } 10 \text { percent detrital carbonates and shell fragments. }\end{array}$ \\
\hline 4 & $146-150$ & $\begin{array}{l}\text { Sand, medium-gray to light-gray; quartzose, fine to medium, subrounded to angular, } \\
\text { moderately sorted; } 5 \text { to } 10 \text { percent heavy minerals, rounded to subrounded, well } \\
\text { sorted, } 1 \text { to } 3 \text { percent phosphates; } 3 \text { to } 5 \text { percent detrital carbonates and shell } \\
\text { fragments. }\end{array}$ \\
\hline 6 & $150-156$ & $\begin{array}{l}\text { Sand interbedded with sandstone, medium-gray to grayish-green; quartzose, fine to } \\
\text { very fine, angular to subrounded, moderately sorted; } 5 \text { to } 10 \text { percent heavy minerals, } \\
\text { fine to very fine, rounded to angular, moderately sorted; } 1 \text { to } 3 \text { percent detrital } \\
\text { carbonates; } 1 \text { to } 3 \text { percent phosphates; } 5 \text { to } 10 \text { percent loosely cemented quartz sand- } \\
\text { stone. }\end{array}$ \\
\hline 4 & $156-160$ & $\begin{array}{l}\text { Sand, grayish-green to olive-green; quartzose, silt size to fine, subrounded to angu- } \\
\text { lar, well sorted; } 3 \text { to } 5 \text { percent heavy minerals, fine to very fine, rounded to sub- } \\
\text { rounded, well sorted; } 3 \text { to } 5 \text { percent phosphates; } 1 \text { to } 3 \text { percent detrital carbonates. }\end{array}$ \\
\hline 3 & $160-163$ & $\begin{array}{l}\text { Sand interbedded with sandstone, grayish-green to olive-green; quartzose as above; } 5 \\
\text { to } 10 \text { percent heavy minerals, fine to very fine, rounded to subrounded, well sorted; } \\
5 \text { to } 10 \text { percent phosphates; } 5 \text { to } 10 \text { percent loosely cemented sandstone with micritic } \\
\text { matrix. }\end{array}$ \\
\hline 3 & $163-166$ & $\begin{array}{l}\text { Sand, olive-green; quartzose, very fine to fine, subrounded to angular, moderately } \\
\text { sorted; } 3 \text { to } 5 \text { percent heavy minerals as above; } 5 \text { to } 10 \text { percent phosphate; } 3 \text { to } 5 \\
\text { percent detrital carbonates. }\end{array}$ \\
\hline 4 & $166-170$ & $\begin{array}{l}\text { Sand, dark-greenish-gray to olive-green; quartzose, silt size to fine, rounded to } \\
\text { subrounded, well sorted; } 3 \text { to } 5 \text { percent heavy minerals, rounded to subangular, silt } \\
\text { to fine; } 5 \text { to } 10 \text { percent phosphates; } 10 \text { to } 15 \text { percent detrital carbonates and mi- } \\
\text { critic mud. }\end{array}$ \\
\hline
\end{tabular}


We11 PB-1550

Lat $26^{\circ} 51^{\prime} 34^{\prime \prime}$, long $80^{\circ} 17^{\prime} 27^{\prime \prime}$

Sec. 6, T. 42 S., R. 41 E.

\begin{tabular}{ccc}
\hline $\begin{array}{c}\text { Thick- } \\
\text { ness } \\
\text { (feet) }\end{array}$ & $\begin{array}{l}\text { Depth below } \\
\text { land surface } \\
\text { (feet) }\end{array}$ & Description \\
\hline
\end{tabular}

$50-$

$5 \quad 5-10$

$6 \quad 10-16$

$4 \quad 16-20$

$320-23$

$3 \quad 23-26$

$426-30$

$3 \quad 30-33$

$3 \quad 33-36$

$436-40$

$340-43$

$343-46$

$446-50$

$350-53$

$353-56$

$7 \quad 56-63$

Sand, pale-yellowish-brown ( 10 YR 6/2) to light-olive-gray ( $5 \mathrm{Y} 6 / 1$ ), medium to coarse, rounded to subrounded, moderately sorted; 1 to 3 percent heavy minerals, fine to very fine, rounded to subrounded, well sorted; 1 to 3 percent detrital carbonates.

Sandy mar1, grayish-brown ( 5 YR 3/2) to olive-gray (5 Y $4 / 1$ ); 40 to 45 percent quartzose, clay size to coarse, rounded to angular, poorly sorted; 3 to 5 percent heavy minerals, fine to very fine, rounded to subrounded, well sorted; 10 to 15 percent organics, micritic mud; 5 to 10 percent detrital shell fragments.

Sandy, shelly marl, yellowish-gray ( 5 Y 8/1) to light-olive-gray ( 5 Y 6/1); 20 to 25 percent quartzose, clay size to medium, rounded to subangular, poorly sorted; 5 to 10 percent heavy minerals, fine to very fine, rounded to subrounded, well sorted; micritic mud with 25 to 30 percent detrital carbonate and shell fragments; 5 to 10 percent organics.

Shelly sand, light-gray (N 7) to yellowish-gray ( $5 \mathrm{Y} 8 / 1$ ); quartzose, silt size to fine, rounded to subangular, well sorted; 10 to 15 percent heavy minerals, very fine to medium, rounded to subangular, moderately sorted; 35 to 40 percent shell fragments and detrital carbonates.

Muddy sand, light-olive-gray ( $5 \mathrm{Y} 6 / 1)$; quartzose, silt size to very fine, rounded to subrounded, well sorted; 5 to 10 percent heavy minerals, very fine to fine, well sorted, rounded to subrounded; micritic lime mud; 10 to 15 percent shell fragments, Chione, Pitar, Cardita, Cardium.

Muddy sand as above; Diplodonta.

Muddy sand, light-olive-gray ( 5 Y 6/1) to olive-gray ( 5 Y 4/1); quartzose, silt size to very fine, subrounded to angular; moderately sorted; 10 to 15 percent heavy minerals, very fine to fine, rounded to subrounded, well sorted; micritic mud; 5 to 10 percent shell fragments, Chione, Mya, Olivella, Terebra, Cerithium, Calliostoma.

Sandy lime mud with rock fragments, medium-gray (N 5) to light-olive-gray (5 Y 6/1); micrite; 30 to 35 percent quartzose, silt size to fine, angular to subrounded, moderately sorted; 5 to 10 percent heavy minerals as above; 5 to 10 percent shell fragments, Busycon, Chione; 5 to 10 percent partially cemented, sandy, sparse biosparite.

Sandy lime mud with rock fragments; micrite; 30 to 35 percent quartzose as above; 5 to 10 percent heavy minerals as above; 10 to 15 percent detrital carbonates and shell fragments, Chione, Oliva, Cardita; 10 to 15 percent limestone; poorly washed biosparite; 30 to 35 percent quartzose as above.

Carbonate sand, light-olive-gray ( 5 Y $6 / 1$ ) to light-bluish-gray ( $5 \mathrm{~B} 7 / 1)$; 20 to 25 percent quartzose, fine to very fine, angular to subrounded, poorly sorted; 5 to 10 percent heavy minerals, very fine to fine, rounded to subrounded, well sorted; detrital carbonates and shell fragments. Chione, limpets, Olivella; 5 to 10 percent rock fragments; poorly washed biosparite; 20 to 25 percent quartzose as above.

Carbonate sand as above; Cypraea, Chione, Calliostoma, Terebra.

Carbonate sand, color as above; 30 to 35 percent quartzose, very fine to medium, angular to subrounded, poorly sorted; 5 to 10 percent heavy minerals, very fine to coarse, rounded to subrounded, poorly sorted; detrital carbonates and shell fragments, Chione, Cypraea, Oliva, limpet, Crepidula, Cardita.

Carbonate sand as above; Anadara, Strombus, Conus.

Sandy shell, yellowish-gray ( 5 Y $8 / 1)$ to medium-bluish-gray ( 5 B 5/1); 30 to 35 percent quartzose as above; 5 to 10 percent heavy minerals, very fine to coarse, rounded to subrounded, poorly sorted; 1 to 3 percent heavy minerals; detrital carbonates and shell fragments, abundant bivalvia, Chione, oysters.

Sandy shell, medium-gray (N 5) to yellowish-gray ( 5 Y 8/1); 15 to 20 percent quartzose, very fine to medium, angular to subrounded, moderately sorted; 3 to 5 percent heavy minerals, very fine to medium, rounded to subrounded, moderately sorted; detrital carbonates and shell fragments, oysters, Chione, Cypraea, Cerithium.

Shelly sand, yellowish-gray ( 5 Y 8/1) to medium-gray (N 5); quartzose, angular to subrounded, very fine to medium moderately sorted; 3 to 5 percent heavy minerals, very fine to medium, rounded to subrounded, moderately, moderately sorted; 35 to 40 percent detrital carbonates and shell fragments, abundant bivalvia, oysters, Anadara. 


\begin{tabular}{cll}
\hline $\begin{array}{c}\text { Thick- } \\
\text { ness } \\
\text { (feet) }\end{array}$ & $\begin{array}{c}\text { Depth below } \\
\text { land surface } \\
\text { (feet) }\end{array}$ & Description \\
\hline
\end{tabular}

$363-66$

$466-70$

$3 \quad 70-73$

$3 \quad 73-76$

$476-80$

$3 \quad 80-83$

$3 \quad 83-86$

$86-90$

$390-93$

$3 \quad 93-96$

$496-100$

$3100-103$

$3 \quad 103-106$

$4106-110$

$3 \quad 110-113$

Sandy limestone, yellowish-gray $(5 Y 7 / 2)$ to medium-gray (N 5); intramicrite; 20 to 25 percent quartz, very fine to medium, rounded to subangular, moderately sorted; 15 to 20 percent shell fragments, worm colony, molds; 15 to 20 percent detrital carbonates; very porous, vugs; interbedded with sand; quartzose, very fine to fine, angular to subrounded, well sorted; 3 to 5 percent heavy minerals, very fine to fine, rounded to subangular, moderately sorted; 3 to 5 percent phosphates; 35 to 40 percent detrital carbonates and shell fragments, Chione.

Sandy shell, medium-gray (N 5) to yellowish-gray ( 5 Y 8/1); detrital carbonates and shell fragments, Conus, Cerastoderma, Oliva, Anadara: 30 to 35 percent quartzose very fine to fine, rounded to subrounded, well sorted; 5 to 10 percent phosphates: about 5 to 10 percent partly cemented as packed biosparite.

Sandy shell as above; Chione, limpets, Oliva; algae, barnacles, abundant bivalvia.

Sandy shell, medium-1ight-gray (N 6) to yellowish-gray (5 Y 8/1); detrital carbonates and shell fragments, Chione, Terebra, bivalves and gastropods abundant; 25 to 30 percent quartzose, very fine to medium, angular to subangular, moderately sorted; 3 to 5 percent heavy minerals, fine to very fine, well sorted, rounded to subrounded; 5 to 10 percent phosphates, rounded to subrounded, very fine to medium, moderately sorted.

Sandy shell as above; 30 to 35 percent quartzose, Conus, Cancellaria.

Sandy shell, yellowish-gray ( 5 Y 8/1) to medium-light-gray (N 6); detrital carbonates and shell fragments, Chione, Crepidula, Cancellaria, oysters; quartzose, very fine to medium, angular to subangular, moderately sorted; 5 to 10 percent heavy minerals as above; 3 to 5 percent phosphates as above.

Sandy shell as above; 35 to 40 percent quartzose.

Sandy shell, partially cemented, yellowish-gray ( 5 Y 8/1) to medium-gray (N 5); detrital carbonates and shell fragments, Terebra, Crepidula, oysters, scallops, barnacles: 30 to 35 percent quartzose as above; 5 to 10 percent heavy minerals, very fine to medium, rounded to subrounded, moderately sorted; 5 to 10 percent phosphates; interbedded with 10 to 15 percent limestone; packed biosparite; moldic, vugs, very porous; loosely cemented.

Sandy shell; interbedded with limestone, medium-gray (N 5) to yellowish-gray (5 Y 8/1); detrital carbonates and shell fragments, Conus, Turritella, Olivella, Chione, barnacles, worm tubes, algae; 20 to 25 percent quartzose, very fine to medium, angular to subrounded, moderately sorted; 3 to 5 percent heavy minerals, very fine to medium, rounded to subrounded, moderately sorted; 3 to 5 percent phosphates; interbedded with limestone, dark-gray; packed biosparite; 20 to 25 percent quartz as above; 40 to 45 percent shell fragments; very porous, moldic, vugs; loosely cemented.

Sandy shell; interbedded with limestone nodules as above; Chione, Turritella, barnacles, abundant bivalves, Conus.

Sandy shell; interbedded with limestone nodules; detrital carbonates and shell fragments, Conus, Turritella, Chione, Murex, Cancellaria, Arca, abundant bivalvia, barnacles, worm tubes, Conopeum; 15 to 20 percent quartzose, very fine to medium, subrounded to angular, poorly sorted; 3 to 5 percent heavy minerals, very fine to fine, rounded to subrounded, well sorted; 1 to 3 percent phosphates; interbedded with limestone nodules; packed biosparite; quartz and heavy minerals as above; moldic, vugs, very porous; loosely cemented.

Sandy limestone, yellowish-gray ( 5 Y $8 / 1$ ) to medium-gray (N 5); packed biosparite, barnacles, Conopeum, abundant bivalvia, worm tubes; 10 to 15 percent quartz, very fine to medium, rounded to subrounded, moderately sorted; 3 to 5 percent heavy minerals, rounded to subrounded, fine to very fine, moderately sorted; interbedded with about 45 to 50 percent loose sand and detrital carbonates and sheil fragments; Conus, Chione, Turritella, Olivella, Cardita, Terebra, Cypraea, abundant bivalvia; 15 to 20 percent quartzose, angular to subrounded, very fine to medium, moderately sorted; 3 to 5 percent heavy minerals as above; 3 to 5 percent phosphates.

Sandy she11; interbedded with limestone, yellowish-gray ( 5 Y $8 / 1)$ to medium-gray (N 5); detrital carbonates and shell fragments, Turritella, Clavilithes, abundant gastropods, Cancellaria, Glycymeris, abundant bivalvia, clathrodrillia; 15 to 20 percent quartzose, very fine to medium, angular to subangular, moderately sorted; 5 to 10 percent heavy minerals, rounded to subrounded, very fine to fine, moderately sorted; 1 to 3 percent phosphates; interbedded with 5 to 10 percent limestone; packed biosparite; very porous, moldic, vugs; loosely cemented.

Sandy shell; interbedded with limestone as above; 20 to 25 percent quartzose; Turritella, Clathrodrilla, Glycymeris, Conus, Fusinus.

Sandy shell, yellowish-gray ( 5 Y $8 / 1$ ); detrital carbonates and shell fragments, Chione, Turritella, Conus. Cypraea, Lirophora; 15 to 20 percent quartzose, very fine to medium, angular to subangular, moderately sorted; 5 to 10 percent heavy minerals and phosphates, very fine to fine, rounded to subrounded, moderately sorted. 


\begin{tabular}{|c|c|c|}
\hline $\begin{array}{l}\text { Thick- } \\
\text { ness } \\
\text { (feet) }\end{array}$ & $\begin{array}{l}\text { Depth below } \\
\text { land surface } \\
\text { (feet) }\end{array}$ & Description \\
\hline 3 & $113-116$ & $\begin{array}{l}\text { Sandy shell as above; interbedded with loosely cemented limestone rock fragments; } \\
\text { packed biosparite, Turritella, Chione, abundant bivalvia. }\end{array}$ \\
\hline 7 & $116-123$ & $\begin{array}{l}\text { Sandy shell, yellowish-gray ( } 5 \text { Y } 8 / 1) \text { to medium-gray (N } 5) \text {; detrital carbonates and } \\
\text { shell fragments, Oliva, Glycymeris, Fusinus, Architectonica, Turritella; } 25 \text { to } 30 \\
\text { percent quartzose, very fine to medium, subrounded to angular, moderately sorted; } \\
5 \text { to } 10 \text { percent heavy minerals and phosphates, rounded to subrounded, very fine to } \\
\text { fine, moderately sorted. }\end{array}$ \\
\hline 3 & $123-126$ & $\begin{array}{l}\text { Sandy shell, yellowish-gray ( } 5 \text { Y } 8 / 1) \text { to light-gray (N } 7) \text {; detrital carbonates and } \\
\text { shell fragments, } \text { Turritella, abundant gastropods, abundant bivalvia, scallops, } \\
\text { barnacles; } 15 \text { to } 20 \text { percent quartzose, vefy fine to coarse, subrounded to angular, } \\
\text { poorly sorted; } 3 \text { to } 5 \text { percent heavy minerals and phosphates, very fine to medium, } \\
\text { rounded to subrounded, moderately sorted; loosely cemented in places. }\end{array}$ \\
\hline 4 & $126-130$ & $\begin{array}{l}\text { Sandy limestone, light-gray (N } 7) \text { to yellowish-gray ( } 5 \text { Y } 8 / 1 \text { ) changes to light-olive- } \\
\text { gray ( } 5 \text { Y } 5 / 2 \text { ) when wet with water; packed biosparite, abundant bivalvia; } 20 \text { to } 25 \\
\text { percent quartzose, fine to coarse, subrounded to subangular, moderately sorted; } 3 \text { to } \\
5 \text { percent heavy minerals, fine to coarse, moderately sorted; moderately cemented; } \\
\text { moldic, vugs, very porous; interbedded with sandy shell as in } 123 \text { to } 126 \text { feet. }\end{array}$ \\
\hline 6 & $130-136$ & $\begin{array}{l}\text { Sandy shell, yellowish-gray }(5 \mathrm{Y} 8 / 1) \text { to 1ight-gray }(\mathrm{N} 7) \text {; quartzose, very fine to } \\
\text { medium, angular to subrounded, poorly sorted; } 5 \text { to } 10 \text { percent heavy minerals, fine to } \\
\text { very fine, rounded to subrounded, moderately sorted; } 15 \text { to } 20 \text { percent detrital car } \\
\text { bonates and shell fragments, echinoid plates and spines; about } 3 \text { to } 5 \text { percent ce- } \\
\text { mented as sandstone with carbonate cement. }\end{array}$ \\
\hline 4 & $136-140$ & $\begin{array}{l}\text { Sand, very light gray }(\mathrm{N} 8) \text { to yellowish-gray }(5 \mathrm{Y} 8 / 1) \text {; quartzose, very fine to } \\
\text { medium, rounded to subangular, moderately sorted; } 5 \text { to } 10 \text { percent heavy minerals and } \\
\text { phosphates, very fine to fine, rounded to subrounded, well sorted; } 15 \text { to } 20 \text { percent } \\
\text { detrital carbonates and shell fragments. }\end{array}$ \\
\hline 3 & $140-143$ & $\begin{array}{l}\text { Sand, very light gray ( } \mathrm{N} 8 \text { ); quartzose as above; } 5 \text { to } 10 \text { percent heavy minerals and } \\
\text { phosphates as above; } 10 \text { to } 15 \text { percent detrital carbonates and shell fragments; about } \\
3 \text { to } 5 \text { percent sandstone as in } 130 \text { to } 133 \text { feet; } 5 \text { to } 10 \text { percent silt nodules, light- } \\
\text { olive-gray ( } 5 \mathrm{Y} 6 / 1 \text { ). }\end{array}$ \\
\hline 3 & $143-146$ & $\begin{array}{l}\text { Sand, very light gray (N } 8) \text {; quartzose, very fine to medium, subrounded to suban- } \\
\text { gular; moderately cemented; } 5 \text { to } 10 \text { percent heavy minerals and phosphates, very fine } \\
\text { to medium, rounded to subrounded, moderately sorted; } 10 \text { to } 15 \text { percent detrital car- } \\
\text { bonates and shell fragments; } 10 \text { percent silt nodules as above. }\end{array}$ \\
\hline 4 & $146-150$ & $\begin{array}{l}\text { Silty sand, light-olive-gray }(5 \mathrm{Y} 6 / 1) \text { changing to light-olive-gray }(5 \mathrm{Y} 5 / 2) \text { when } \\
\text { wet; quartzose, silt size to medium, rounded to subangular, moderately sorted; } 15 \text { to } \\
20 \text { percent heavy minerals and phosphates, very fine to medium, rounded to subrounded, } \\
\text { moderately sorted; } 20 \text { to } 25 \text { percent detrital carbonates and shell fragments; about } 5 \\
\text { to } 10 \text { percent steaks of olive-green clay. }\end{array}$ \\
\hline 3 & $150-153$ & $\begin{array}{l}\text { Sand with clay streaks, light-olive-gray }(5 \mathrm{Y} 6 / 1) \text {; quartzose, silt size to medium, } \\
\text { rounded to subangular, moderately sorted; } 15 \text { to } 20 \text { percent heavy minerals and phos- } \\
\text { phates, very fine to fine, rounded to subfounded, well sorted; } 5 \text { to } 10 \text { percent detri- } \\
\text { tal carbonates and shell fragments; } 10 \text { to } 15 \text { percent globs of olive-green clay. }\end{array}$ \\
\hline 7 & $153-160$ & $\begin{array}{l}\text { Clayey sand, light-olive-gray ( } 5 \text { Y } 5 / 2 \text { ); quartzose, very fine to fine, subrounded to } \\
\text { subangular, well sorted; } 35 \text { to } 40 \text { percent olive-green silt and clay-size particles; } \\
5 \text { to } 10 \text { percent heavy minerals and phosphates, very fine to fine, rounded to sub- } \\
\text { rounded, well sorted; } 1 \text { to } 3 \text { percent detrital carbonates. }\end{array}$ \\
\hline 3 & $160-163$ & $\begin{array}{l}\text { Sandy clay, light-olive-gray ( } 5 \text { Y } 5 / 2 \text { ); clay and silt-size particles; } 35 \text { to } 40 \text { per- } \\
\text { cent quartzose, very fine to fine, subrounded to angular, well sorted; } 10 \text { to } 15 \text { per- } \\
\text { cent heavy minerals and phosphates as above. }\end{array}$ \\
\hline 3 & $163-166$ & Sandy clay as above; 1 to 3 percent shell fragments. \\
\hline 4 & $166-170$ & $\begin{array}{l}\text { Sandy clay, light-olive-gray }(5 \mathrm{Y} 5 / 2) \text {; clay, silt, and micrite; } 20 \text { to } 25 \text { percent } \\
\text { quartzose, silt size to very fine, subfounded to subangular, well sorted; } 10 \text { to } 15 \\
\text { percent heavy minerals and phosphates, fine to silt, rounded to subrounded, well } \\
\text { sorted. }\end{array}$ \\
\hline 3 & $170-173$ & Sandy clay, light-olive-gray ( 5 Y $5 / 2$ ). \\
\hline 3 & $173-176$ & $\begin{array}{l}\text { Clay, light-olive-gray }(5 \mathrm{Y} 5 / 2) \text {; clay and silt-size particles; } 15 \text { to } 20 \text { percent } \\
\text { quartzose, very fine, subrounded to subangular, well sorted; } 5 \text { to } 10 \text { percent heavy } \\
\text { minerals and phosphates, silt to very fine, rounded to subrounded, well sorted. }\end{array}$ \\
\hline 4 & $176-180$ & $\begin{array}{l}\text { Clay, light-olive-gray ( } 5 \text { y } 5 / 2) \text {; clay and silt-size particles; } 10 \text { to } 15 \text { percent } \\
\text { heavy minerals and phosphates as above. }\end{array}$ \\
\hline
\end{tabular}




\begin{tabular}{ccc}
\hline $\begin{array}{c}\text { Thick- } \\
\text { ness } \\
\text { (feet) }\end{array}$ & $\begin{array}{c}\text { Depth below } \\
\text { land surface } \\
\text { (feet) }\end{array}$ & Description \\
\hline
\end{tabular}

$\begin{array}{ll}3 & 0-3 \\ 2 & 3-5 \\ 5 & 5-10 \\ 14 & 10-24 \\ & \\ 3 & 24-27 \\ 4 & 27-30 \\ 4 & 30-34\end{array}$

Road fill.

Sand, dusky-brown ( 5 YR 2/2); quartzose, medium to very fine, moderately sorted,
subangular to subrounded; about i percent carbonates; 20 to 25 percent organic mud, clay and silt size.

Sand, dark-yellowish-brown ( 10 YR 4/2); quartzose as above; 20 to 25 percent micritic mud; about 3 to 5 percent organic fragments; 5 to 10 percent detrital carbonates and shell fragments; Chione, Tellina.

Sand, dark-yellowish-brown (10 YR 4/2); quartzose, medium to very fine, moderately sorted, subrounded to rounded; about 1 percent heavy minerals, fine to very fine, subrounded to rounded; about 1 percent detrital carbonates; about 5 to 10 percent mud, clay and silt size.

$3 \quad 34-37$

Sand, light-olive-gray ( 5 Y 5/2); as above; 1 to 3 percent mud, clay and silt size.

Sand as above.

Sand, light-gray (N 7) to yellowish-gray ( 5 Y 7/2); quartzose, medium to very fine, moderately sorted, subangular to subrounded; 1 to 3 percent heavy minerals, fine to very fine, moderately sorted, subangular to rounded; 3 to 5 percent detrital carbonates and shell fragments, Chione, Cardita, other bivalves.

Sand, light-gray (N 7 ) to yellowish-gray ( $5 \mathrm{Y} 8 / 1$ ); quartzose, medium to very fine, moderately sorted, angular to subrounded; 1 to 3 percent heavy minerals as above; 30 to 35 percent detrital carbonates and shell fragments, Chione, Ostrea, Cardita Limopsis, Donat, Cerithium, Crepidula, Prunum, Olivella, Philippia, Chlamys.

$\begin{array}{ll}3 & 37-40 \\ 4 & 40-44 \\ 3 & 44-47 \\ 7 & 47-54\end{array}$

Sand, light-olive-gray $(5 \mathrm{Y} 6 / 1)$ to yellowish-gray $(5 \mathrm{Y} 8 / 1)$; as above; 3 to 5 percent heavy minerals.

Sand; as above; about 1 to 3 percent rock fragments.

Sand; as above; 35 to 40 percent detrital carbonates and shell fragments, Busycon.

Sand, olive-gray ( 5 Y 4/1); quartzose, medium to very fine, moderately sorted, angular to subrounded; 5 to 10 percent heavy minerals and phosphates, fine to very fine, moderately sorted, subangular to rounded; 30 to 35 percent detrital carbonates and shell fragments.

$3 \quad 54-57$

Sand, olive-gray (5 Y 4/1); quartzose, fine to very fine, well sorted, subangular to subrounded; 5 to 10 percent heavy minerals and phosphates, fine to very fine, well sorted, subangular to rounded; 35 to 40 percent detrital carbonates and sheli fragments.

$35-60$
$4 \quad 60-64$

Sand; as above; interbedded with 10 percent limestone and claystone, light-olive-gray ( 5 Y $5 / 2)$; micrite and clay.

Sand, olive-gray ( $5 \mathrm{Y} 4 / 1$ ); quartzose, fine to very fine, well sorted, angular to subrounded; 3 to 5 percent heavy minerals and phosphates, fine to very fine, well sorted, subangular to rounded; 35 to 40 percent detrital carbonates and sheli fragments.

$6 \quad 64-70$

$470-74$

Sand, light-olive-gray ( 5 Y 5/2); as above.

Sand, light-olive-gray ( 5 Y $6 / 1$ ); as above; quartzose, medium to very fine, angular to subrounded.

$3 \quad 74-77$

Sand, light-olive-gray ( 5 Y $6 / 1$ ); quartzose, fine to very fine, well sorted, angular to subrounded; 5 to 10 percent heavy minerals and phosphates, fine to very fine, well sorted, subangular to rounded; 1 to 3 percent micrite; 35 to 40 percent detrital carbonates and shell fragments.

Sand, olive-gray ( 5 Y 4/1);/ detrital carbonates and shell fragments; 25 to 30 percent quartzose, very fine, well sorted, angular to subrounded; 5 to 10 percent heavy minerals and phosphates, fine to very fine, well sorted, subangular to rounded; about 5 percent micrite.

$4 \quad 80-84$

Sand, light-olive-gray ( 5 Y $6 / 1)$; as above.

$6 \quad 84-90$

Sand, light-olive-gray ( 5 Y 6/1); quartzose, fine to very fine, well sorted, angular to subrounded; 5 to 10 percent heavy minerals and phosphate as above; 35 to 40 percent detrital carbonates and shell fragments, Terebra.

Sand, olive-gray ( 5 Y 4/1); quartzose, fine to very fine, angular to subrounded, well sorted; 5 to 10 percent heavy minerals and phosphates, fine to very fine, moderately sorted, subrounded to rounded; 35 to 40 percent detrital carbonates and shell fragments. 


\begin{tabular}{|c|c|c|}
\hline $\begin{array}{l}\text { Thick- } \\
\text { ness } \\
\text { (feet) }\end{array}$ & $\begin{array}{l}\text { Depth below } \\
\text { land surface } \\
\text { (feet) }\end{array}$ & Description \\
\hline 3 & $97-100$ & $\begin{array}{l}\text { Sand, olive-gray }(5 \text { Y } 4 / 1) \text { to medium-dark } 7 \text { ray }(\mathrm{N} 4) \text {; quartzose, medium to very fine, } \\
\text { moderately sorted, angular to subrounded; } 3 \text { to } 5 \text { percent heavy minerals, fine to very } \\
\text { fine, well sorted, subrounded to rounded; } 20 \text { to } 25 \text { percent detrital carbonates and } \\
\text { phosphates, very coarse to very fine; } 20 \text { to } 25 \text { percent shells and shell fragments, } \\
\text { Turritella, Chione, echinoid plates, Crucibulum, Tellina, Anadora. }\end{array}$ \\
\hline 4 & $100-104$ & $\begin{array}{l}\text { Sand, olive-gray ( } 5 \text { Y } 4 / 1) \text {; as above; interbedded with about } 20 \text { percent fossiliferous } \\
\text { limestone, light-olive-gray ( } 5 \text { Y } 6 / 1 \text { ), packed biosparite, bivalves; } 15 \text { to } 20 \text { percent } \\
\text { quartz, medium to very fine, subangular to subrounded; poorly cemented; very porous. }\end{array}$ \\
\hline 3 & $104-107$ & $\begin{array}{l}\text { Sand, light-olive-gray }(5 \mathrm{Y} 6 / 1) \text {; quartzose, medium to very fine, moderately sorted, } \\
\text { subangular to subrounded; } 5 \text { to } 10 \text { percent heavy minerals and phosphates, medium to } \\
\text { very fine, moderately sorted, subrounded to rounded; } 35 \text { to } 40 \text { percent detrital car- } \\
\text { bonates and shell fragments; interbedded with about } 10 \text { percent limestone, packed } \\
\text { biosparite; } 20 \text { percent quartz, medium to very fine, subangular to subrounded; } 3 \text { to } \\
5 \text { percent heavy minerals and phosphates, fine to very fine, subrounded to rounded; } \\
\text { poorly cemented; very porous. }\end{array}$ \\
\hline \multirow[t]{2}{*}{3} & $107-110$ & Sand, interbedded with about 10 percent limestone as above. \\
\hline & $110-114$ & $\begin{array}{l}\text { Sand, light-olive-gray }(5 \mathrm{Y} 6 / 1) \text {; quartzose, fine to very fine, well sorted, suban- } \\
\text { gular to subrounded; } 5 \text { to } 10 \text { percent heavy minerals and phosphates, fine to very } \\
\text { fine, well sorted, subrounded to rounded; } 30 \text { to } 35 \text { percent detrital carbonates and } \\
\text { sheli fragments; lost circulation at } 113 \text { feet. }\end{array}$ \\
\hline 3 & $114-117$ & Marl, yellowish-gray ( 5 Y $8 / 1$ ); clay and micrite; impermeable. \\
\hline 3 & $117-120$ & $\begin{array}{l}\text { Sand, light-olive-gray ( } 5 \text { Y } 6 / 1) \text {; quartzose, medium to very fine, moderately sorted, } \\
\text { angular to subrounded; } 3 \text { to } 5 \text { percent heavy minerals and phosphates, fine to very } \\
\text { fine, well sorted, subangular to subrounded; } 25 \text { to } 30 \text { percent detrital carbonates and } \\
\text { sheli fragments, abundant bivalve fragments; interbedded with about } 20 \text { percent marl } \\
\text { as above. }\end{array}$ \\
\hline 4 & $120-124$ & $\begin{array}{l}\text { Sand, yellowish-gray }(5 \mathrm{Y} 8 / 1) \text {; detrital carbonates and shell fragments, bivalve } \\
\text { fragments; } 35 \text { to } 40 \text { percent quartzose, fine to very fine, well sorted, angular to } \\
\text { subrounded; } 3 \text { to } 5 \text { percent heavy minefals and phosphates, fine to very fine, well } \\
\text { sorted, subrounded to rounded; interbedded with about } 10 \text { percent limestone, packed } \\
\text { biosparite; } 10 \text { percent quartz, fine to very fine, subangular to subrounded; } 3 \text { to } 5 \\
\text { percent heavy minerals and phosphates, fine to very fine, subrounded to rounded; } \\
\text { poorly cemented; very porous, moldic. }\end{array}$ \\
\hline 3 & $124-127$ & $\begin{array}{l}\text { Sand; as above; quartzose, medium to very fine, moderately sorted, angular to sub- } \\
\text { rounded; interbedded with } 20 \text { percent limestone, light-olive-gray }(5 \mathrm{Y} 6 / 1) \text {; sandy, } \\
\text { sparse biosparite; } 20 \text { to } 25 \text { percent quartz, medium to very fine, subangular to sub- } \\
\text { rounded; } 3 \text { to } 5 \text { percent heavy minerals and phosphates, fine to very fine, subrounded } \\
\text { to rounded; poorly cemented; very porous, moldic. }\end{array}$ \\
\hline 7 & $127-134$ & $\begin{array}{l}\text { Sand, very light gray (N } 8) \text { to yellowi\$h-gray }(5 \mathrm{Y} 8 / 1) \text {; quartzose, medium to silt } \\
\text { size, moderately sorted, angular to subrounded; } 3 \text { to } 5 \text { percent heavy minerals and } \\
\text { phosphates, fine to very fine, well sorted, subrounded to rounded; } 15 \text { to } 20 \text { percent } \\
\text { detrital carbonates and shell fragments. }\end{array}$ \\
\hline 6 & $134-140$ & $\begin{array}{l}\text { Sand, very light gray }(\mathrm{N} 8) \text { to yellowish-gray }(5 \mathrm{Y} 8 / 1) \text {; quartzose, fine to very } \\
\text { fine, well sorted, subangular to subrounded; } 1 \text { to } 3 \text { percent detrital carbonates, } \\
\text { coarse to very fine; } 1 \text { to } 3 \text { percent heavy minerals and phosphates, fine to very fine, } \\
\text { well sorted, subrounded to rounded; } 5 \text { to } 10 \text { percent sandstone nodules, micritic ma- } \\
\text { trix; very poorly cemented. }\end{array}$ \\
\hline 4 & $140-144$ & Sand as above; quartzose, medium to very fine. \\
\hline 6 & $144-150$ & $\begin{array}{l}\text { Clayey sand, light-olive-gray }(5 \text { Y } 5 / 2) \text {; quartzose, fine to very fine, well sorted, } \\
\text { subangular to subrounded; } 3 \text { to } 5 \text { percent heavy minerals and phosphates as above; } 1 \text { to } \\
3 \text { percent detrital carbonates; } 15 \text { to } 20 \text { percent marl, micritic, clay and silt. }\end{array}$ \\
\hline 4 & $150-154$ & Sand as above; 20 to 25 percent clay and silt. \\
\hline 3 & $154-157$ & $\begin{array}{l}\text { Clayey sand, light-olive-gray ( } 5 \text { Y } 5 / 2) \text {; quartzose, fine to very fine, well sorted, } \\
\text { angular to subrounded; } 3 \text { to } 5 \text { percent heavy minerals and phosphates, fine to very } \\
\text { fine, well sorted, subrounded to rounded; } 1 \text { to } 3 \text { percent detrital carbonates; } 25 \text { to } \\
30 \text { percent clay and silt. }\end{array}$ \\
\hline 3 & $157-160$ & $\begin{array}{l}\text { Sandy clay, grayish-olive }(10 \mathrm{Y} 4 / 2) ; \text { clay and silt; } 35 \text { to } 40 \text { percent quartzose as } \\
\text { above; } 3 \text { to } 5 \text { percent heavy minerals and phosphates as above; } 1 \text { to } 3 \text { percent detrital } \\
\text { carbonates. }\end{array}$ \\
\hline 4 & $160-164$ & $\begin{array}{l}\text { Sandy clay, pale-olive }(10 \mathrm{Y} 7 / 2) \text { to light-olive-gray }(5 \text { Y } 5 / 2) \text {; clay and silt; } 3 \text { to } \\
35 \text { percent quartzose as above; } 5 \text { to } 10 \text { percent heavy minerals and phosphates as } \\
\text { above; } 3 \text { to } 5 \text { percent detrital carbonates. }\end{array}$ \\
\hline 6 & $164-170$ & Sandy clay, light-olive-gray ( 5 Y $5 / 2)$; as above. \\
\hline
\end{tabular}




\begin{tabular}{|c|c|c|}
\hline $\begin{array}{l}\text { Thick- } \\
\text { ness } \\
\text { (feet) }\end{array}$ & $\begin{array}{l}\text { Depth below } \\
\text { land surface } \\
\text { (feet) }\end{array}$ & Description \\
\hline 4 & $0-4$ & $\begin{array}{l}\text { Sand, grayish-orange ( } 10 \text { YR } 7 / 4) \text { to yellowish-gray ( } 5 \text { Y } 7 / 2) \text {; quartzose, medium to } \\
\text { fine, well sorted, angular to subangular; } 1 \text { to } 3 \text { percent heavy minerals, medium to } \\
\text { fine, well sorted, subrounded to rounded. }\end{array}$ \\
\hline 3 & $4-7$ & $\begin{array}{l}\text { Marl, light-olive-gray ( } 5 \text { Y } 5 / 2 \text { ); micrite, clay and silt size particles; } 30 \text { to } 35 \\
\text { percent quartzose, medium to very fine, moderately sorted, angular to subangular; } 20 \\
\text { to } 25 \text { percent detrital carbonates and shell fragments. }\end{array}$ \\
\hline 3 & $7-10$ & $\begin{array}{l}\text { Sand, yellowish-gray ( } 5 \text { Y } 7 / 2 \text { ); quartzose, medium to very fine, moderately sorted, } \\
\text { angular to subrounded; about } 20 \text { to } 25 \text { percent marl; } 1 \text { to } 3 \text { percent heavy minerals, } \\
\text { fine to very fine, subangular to rounded; } 5 \text { to } 10 \text { percent detrital carbonates and } \\
\text { shell fragments. }\end{array}$ \\
\hline 4 & $10-14$ & $\begin{array}{l}\text { Sand, yellowish-gray ( } 5 \text { Y } 7 / 2 \text { ); quartzose as above; } 3 \text { to } 5 \text { percent heavy minerals, } \\
\text { fine to very fine, well sorted, subangular to rounded; } 1 \text { to } 3 \text { percent detrital car- } \\
\text { bonates; about } 3 \text { to } 5 \text { percent mud, clay and silt size particles. }\end{array}$ \\
\hline 3 & $14-17$ & $\begin{array}{l}\text { Sand, yellowish-gray }(5 \text { Y } 7 / 2) \text { to light-olive-gray }(5 Y 7 / 2) \text {; quartzose as above; } 3 \\
\text { to } 5 \text { percent heavy minerals, fine to very fine, well sorted, subrounded to rounded; } \\
\text { about } 10 \text { percent mud, clay and silt size. }\end{array}$ \\
\hline 3 & $17-20$ & $\begin{array}{l}\text { Sand, light-olive-gray ( } 5 \text { Y } 5 / 2) \text {; quartzose, fine to very fine, well sorted, a } \\
\text { to subrounded; } 3 \text { to } 5 \text { percent heavy minerals as above; about } 10 \text { percent mud. }\end{array}$ \\
\hline 7 & $20-27$ & $\begin{array}{l}\text { Sand, medium-gray (N 5) to medium-bluish-gray ( } 5 \text { B } 5 / 1 \text { ); quartzose, fine to very } \\
\text { fine, well sorted, subangular to subrounded; } 5 \text { to } 10 \text { percent heavy minerals, medium } \\
\text { to very fine, moderately sorted, subrounded to rounded; } 20 \text { to } 25 \text { percent detrital } \\
\text { carbonates and shell fragments. }\end{array}$ \\
\hline 3 & $27-30$ & $\begin{array}{l}\text { Sand, medium-bluish-gray ( } 5 \text { B } 5 / 1 \text { ) to olive-gray ( } 5 \text { Y } 4 / 1) \text {; quartzose as above; } 10 \text { to } \\
15 \text { percent heavy minerals and phosphates, medium to very fine, moderately sorted, } \\
\text { subangular to rounded; } 20 \text { to } 25 \text { percent detrital carbonates and shell fragments; } \\
\text { about } 5 \text { percent mud. }\end{array}$ \\
\hline 4 & $30-34$ & $\begin{array}{l}\text { Limestone, medium-bluish-gray ( } 5 \text { B } 5 / 1 \text { ); sandy, sparse biosparite; } 10 \text { to } 15 \text { percent } \\
\text { quartz, fine to very fine, subangular to subrounded; } 3 \text { to } 5 \text { percent heavy minerals, } \\
\text { fine to very fine, subangular to rounded; very porous, vugs; poorly to moderately } \\
\text { cemented; interbedded with about } 40 \text { percent sand, medium-bluish-gray ( } \mathrm{B} 5 / 1 \text { ) to } \\
\text { light-olive-gray ( } 5 \mathrm{Y} 6 / 1 \text { ); quartzose, medium to very fine, moderately sorted, an- } \\
\text { gular to subangular; } 3 \text { to } 5 \text { percent heavy minerals, fine to very fine, well sorted, } \\
\text { subrounded to rounded; } 35 \text { to } 40 \text { percent detrital carbonates and shell fragments, } \\
\text { abundant bivalve fragments, olivella, Chione. }\end{array}$ \\
\hline 3 & $34-37$ & $\begin{array}{l}\text { Sand, light-gray ( } \mathrm{N} 7 \text { ) to light-bluish-gray }(5 \mathrm{~B} 7 / 1) \text {; quartzose, medium to very } \\
\text { fine, moderately sorted, angular to subangular; } 5 \text { to } 10 \text { percent heavy minerals, me- } \\
\text { dium to very fine, moderately sorted, subrounded to rounded; } 35 \text { to } 40 \text { percent detri- } \\
\text { tal carbonates and shell fragments, abundant bivalve fragments; interbedded with } \\
\text { about } 30 \text { percent limestone as above. }\end{array}$ \\
\hline 3 & $37-40$ & $\begin{array}{l}\text { Limestone, medium-light-gray }(\mathrm{N}) 6 \text {; sandy, sparse biosparite; } 5 \text { to } 10 \text { percent quartz, } \\
\text { medium to very fine, angular to subrounded; } 3 \text { to } 5 \text { percent heavy minerals, medium to } \\
\text { very fine, subrounded to rounded; very porous, moldic, vugs; moderately to well ce- } \\
\text { mented; interbedded with about } 20 \text { percent sand, light-olive-gray (5 Y } 6 / 1 \text { ); quartz- } \\
\text { ose, medium to very fine, moderately sorted, angular to subangular; } 5 \text { to } 10 \text { percent } \\
\text { heavy minerals and phosphates, medium to very fine, subrounded to rounded; } 20 \text { to } 25 \\
\text { percent detrital carbonates and shell fragments, Cardita and other bivalves. }\end{array}$ \\
\hline 4 & $40-44$ & $\begin{array}{l}\text { Limestone, medium-gray ( } \mathrm{N} \text { ); sandy, sparse biosparite, bivalvia; } 10 \text { to } 15 \text { percent } \\
\text { quartz, medium to very fine, moderately sorted, angular to subangular; moderately } \\
\text { cemented; moldic, vugs, very porous; interbedded with about } 30 \text { percent sand; detrital } \\
\text { carbonates and shell fragments; } 25 \text { to } 30 \text { percent quartzose, medium to very fine, } \\
\text { moderately sorted, angular to subangular; } 3 \text { to } 5 \text { percent heavy minerals and } \\
\text { phosphates, medium to very fine, subangular to rounded. }\end{array}$ \\
\hline 3 & $44-47$ & $\begin{array}{l}\text { Limestone, medium-gray (N } 5 \text { ); sandy, sparse biosparite, bivalvia; } 10 \text { percent quartz, } \\
\text { medium to very fine, angular to subrounded; } 5 \text { to } 10 \text { percent heavy minerals and } \\
\text { phosphates, medium to very fine, subangular to rounded; moderately cemented; moldic, } \\
\text { vugs, very porous; interbedded with about } 30 \text { percent sand as above. }\end{array}$ \\
\hline 3 & $47-50$ & Limestone interbedded with sand as above. \\
\hline 4 & $50-54$ & $\begin{array}{l}\text { Limestone, medium-gray (N 5) to light-olive-gray ( } 5 \mathrm{Y} 6 / 1) \text {; sandy, sparse biosparite; } \\
10 \text { to } 20 \text { percent quartz, medium to very fine, angular to subrounded; } 3 \text { to } 5 \text { percent } \\
\text { heavy minerals, medium to very fine, subrounded to rounded; moderately to well ce- } \\
\text { mented; vugs, very porous; interbedded with } 20 \text { percent sand; detrital carbonates, } \\
\text { very coarse to very fine, shell fragments; } 30 \text { to } 35 \text { percent quartzose, medium to very } \\
\text { fine, moderately sorted, angular to subangular; } 3 \text { to } 5 \text { percent heavy minerals, medium } \\
\text { to very fine, moderately sorted, subangular to rounded. }\end{array}$ \\
\hline
\end{tabular}




\begin{tabular}{|c|c|c|}
\hline $\begin{array}{l}\text { Thick- } \\
\text { ness } \\
\text { (feet) }\end{array}$ & $\begin{array}{l}\text { Depth below } \\
\text { land surface } \\
\text { (feet) }\end{array}$ & Description \\
\hline 3 & $54-57$ & Limestone interbedded with sand as above. \\
\hline 3 & $57-60$ & $\begin{array}{l}\text { Sand, light-gray (N } 7 \text { ); quartzose, medium to very fine, moderately sorted, angular to } \\
\text { subrounded; } 3 \text { to } 5 \text { percent heavy minerals, medium to very fine, moderately sorted, } \\
\text { subrounded to rounded; } 30 \text { to } 35 \text { percent detrital carbonates and shell fragments; in- } \\
\text { terbedded with about } 30 \text { percent limestone, medium-gray (N } 5 \text { ); sandy, sparse biospar- } \\
\text { ite; } 15 \text { to } 20 \text { percent quartz, medium to very fine, angular to subrounded; } 3 \text { to } 5 \text { per- } \\
\text { cent heavy minerals, medium to very fine, subrounded to rounded; moderately cemented; } \\
\text { moldic, vugs, very porous. }\end{array}$ \\
\hline 4 & $60-64$ & $\begin{array}{l}\text { Sand, light-olive-gray }(5 \mathrm{Y} 6 / 1) \text {; quartzose, medium to very fine, moderately sorted, } \\
\text { angular to subangular; } 5 \text { to } 10 \text { percent heavy minerals and phosphates, medium to very } \\
\text { fine, moderately sorted, subrounded to rounded; } 35 \text { to } 40 \text { percent detrital carbonates } \\
\text { and shell fragments; interbedded with about } 40 \text { percent limestone, medium-dark-gray } \\
\text { (N 4); sandy, sparse biosparite; } 15 \text { to } 20 \text { percent quartz, medium to very fine, an- } \\
\text { gular to subrounded; } 3 \text { to } 5 \text { percent heavy minerals, medium to very fine, subrounded } \\
\text { to rounded; moderately cemented; vugs, very porous. }\end{array}$ \\
\hline 3 & $64-67$ & $\begin{array}{l}\text { Limestone, medium-light-gray }(\mathrm{N} 6) \text { to yellowish-gray }(5 \mathrm{Y} 8 / 1) \text {; sandy, packed bio- } \\
\text { sparite, Chione, Conopeum, Tellina; } 5 \text { to } 10 \text { percent quartz, medium to fine, angular } \\
\text { to subangular; } 1 \text { to } 3 \text { percent heavy minerals, medium to very fine, subrounded to } \\
\text { rounded; moderately to well cemented; moldic, vugs, very porous; interbedded with } \\
\text { about } 20 \text { percent sand; detrital carbonates and shell fragments; } 20 \text { to } 25 \text { percent } \\
\text { quartzose, coarse to very fine, poorly sorted, angular to subangular; } 3 \text { to } 5 \text { percent } \\
\text { heavy minerals and phosphates, medium to very fine, moderately sorted, subrounded to } \\
\text { rounded. }\end{array}$ \\
\hline 3 & $67-70$ & Limestone as above; interbedded with 30 percent sand as above. \\
\hline 4 & $70-74$ & $\begin{array}{l}\text { Sand, yellowish-gray }(5 \mathrm{Y} 7 / 2) \text {; detrital carbonates and shell fragments, oliva, Tel- } \\
\text { lina, barnacles, Chione, Cardita; } 25 \text { to } 30 \text { percent quartzose, medium to very fine, } \\
\text { moderately sorted, angular to subangular; } 3 \text { to } 5 \text { percent heavy minerals and phos- } \\
\text { phates, medium to very fine, moderately sorted, subrounded to rounded; interbedded } \\
\text { with about } 40 \text { percent limestone as above. }\end{array}$ \\
\hline 3 & $74-77$ & $\begin{array}{l}\text { Sand as above; interbedded with about } 10 \text { percent limestone as above; poorly cemented; } \\
\text { Turritella. }\end{array}$ \\
\hline 3 & $77-80$ & $\begin{array}{l}\text { Shell and shell fragments, yellowish-gray }(5 \text { Y } 7 / 2) \text {; Turritella, Tellina, olivella, } \\
\text { Cardita, bryozoans, Chione; } 20 \text { to } 25 \text { percent detrital carbonates, very coarse to very } \\
\text { fine; } 20 \text { to } 25 \text { percent quartzose, medium to very fine, moderately sorted, angular to } \\
\text { subangular; } 3 \text { to } 5 \text { percent heavy minerals and phosphates, medium to very fine, moder- } \\
\text { ately sorted, subrounded to rounded; interbedded with about } 20 \text { percent limestone, } \\
\text { medium-light-gray (N } 6) \text {; sandy, packed biosparite; } 20 \text { to } 25 \text { percent quartz, medium to } \\
\text { very fine, angular to subangular; } 3 \text { to } 5 \text { percent heavy minerals and phosphates, me- } \\
\text { dium to very fine, subrounded to rounded; poorly cemented; moldic, vugs, very porous. }\end{array}$ \\
\hline 4 & $80-84$ & Shell and shell fragments as above; interbedded with limestone as above. \\
\hline 3 & $84-87$ & 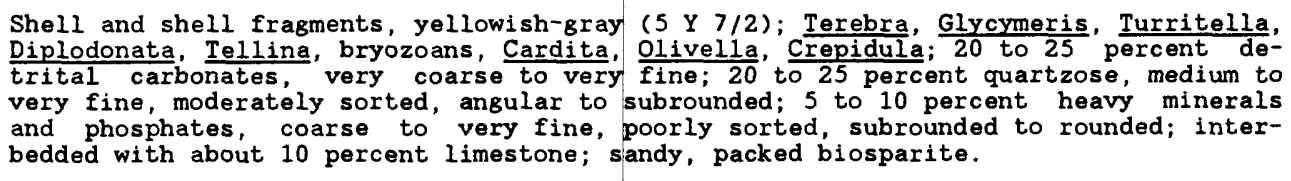 \\
\hline 3 & $87-90$ & $\begin{array}{l}\text { Shell and shell fragments as above; } \frac{\text { Chlamys, }}{\text { Cancellaria, worm shells, }} \text { Calliostoma, } \\
\text { Chione, limpet; interbedded with about } 5 \text { percent limestone; rock fragments. }\end{array}$ \\
\hline 4 & $90-94$ & $\begin{array}{l}\text { Shell and shell fragments, yellowish-gray }(5 \mathrm{Y} 8 / 1) \text {; Turritella, Turbonilla, Tellina, } \\
\text { bryozoans, limpets, oysters, abundant bivalve fragments, barnacles; } 15 \text { to } 20 \text { percent } \\
\text { detrital carbonates, very coarse to very fine; } 20 \text { to } 25 \text { percent quartzose, medium to } \\
\text { very fine, moderately sorted, angular to subangular; } 5 \text { to } 10 \text { percent heavy minerals } \\
\text { and phosphates, medium to very fine, moderately sorted, subrounded to rounded; inter- } \\
\text { bedded with about } 5 \text { percent coquina. }\end{array}$ \\
\hline 6 & $94-100$ & $\begin{array}{l}\text { Sand, medium-gray }(\mathrm{N}, 5) \text { to yellowish-gray }(5 \mathrm{Y} 7 / 2) \text {; detrital carbonates and shell } \\
\text { fragments; Glycymeris, Chione, Turritella; } 30 \text { to } 35 \text { percent quartzose, medium to very } \\
\text { fine, moderately sorted, angular to subrounded; } 5 \text { to } 10 \text { percent heavy minerals and } \\
\text { phosphates, medium to very fine, moderately sorted, subangular to rounded; about } 3 \\
\text { percent rock fragments. }\end{array}$ \\
\hline 7 & $100-107$ & $\begin{array}{l}\text { Sand, medium-light-gray (N } 6) \text { to yellowish-gray }(5 \mathrm{Y} 8 / 1) \text {; detrital carbonates and } \\
\text { sheli fragments; Plicatula, echinoid plates, Limopsis, Anadara, oyster shells, bryo- } \\
\text { zoans, Turritella, limpets; } 25 \text { to } 30 \text { percent quartzose, medium to very fine, moder- } \\
\text { ately sorted, angular to subangular; } 5 \text { to } 10 \text { percent heavy minerals and phosphates, } \\
\text { medium to very fine, moderately sorted, subrounded to rounded; interbedded with about } \\
5 \text { percent limestone; packed biosparite. }\end{array}$ \\
\hline
\end{tabular}




\begin{tabular}{|c|c|c|}
\hline $\begin{array}{l}\text { Thick- } \\
\text { ness } \\
\text { (feet) }\end{array}$ & $\begin{array}{l}\text { Depth below } \\
\text { land surface } \\
\text { (feet) }\end{array}$ & Description \\
\hline 3 & $107-110$ & $\begin{array}{l}\text { Shell and shell fragments, yellowish-gray }(5 \text { Y } 8 / 1) \text { to light-gray (N } 7) \text {; abundant } \\
\text { mollusks; } 20 \text { to } 25 \text { percent detrital carbonates, very coarse to very fine; } 20 \text { to } 25 \\
\text { percent quartzose as above; } 3 \text { to } 5 \text { percent heavy minerals as above. }\end{array}$ \\
\hline 7 & $110-117$ & $\begin{array}{l}\text { Sand, medium-gray (N 5) to yellowish-gray ( } 5 \text { Y } 8 / 1) \text {; detrital carbonates and shell } \\
\text { fragments, abundant mollusks; } 35 \text { to } 40 \text { percent quartzose, medium to very fine, moder- } \\
\text { ately sorted, angular to subangular; } 3 \text { to } 5 \text { percent heavy minerals and phosphates, } \\
\text { medium to very fine, moderately sorted, subrounded to rounded. }\end{array}$ \\
\hline 3 & $117-120$ & Sand as above; Turritella. \\
\hline 4 & $120-124$ & $\begin{array}{l}\text { Sand, light-olive-gray ( } 5 \mathrm{Y} 6 / 1) \text { to medium-light-gray (N } 6) \text {; detrital carbonates, } \\
\text { coarse to very fine; } 15 \text { to } 20 \text { percent shell fragments, mollusks; } 35 \text { to } 40 \text { percent } \\
\text { quartzose as above; } 3 \text { to } 5 \text { percent heavy minerals and phosphates as above; inter- } \\
\text { bedded with about } 5 \text { percent limestone, light-olive-gray ( } 5 \mathrm{Y} 6 / 1) \text {; packed biosparite; } \\
\text { poorly cemented; moldic, vus, very porous. }\end{array}$ \\
\hline 3 & $124-127$ & $\begin{array}{l}\text { Limestone, yellowish-gray }(5 \mathrm{Y} 7 / 2) \text {; sandy, sparse biosparite; } 15 \text { to } 20 \text { percent } \\
\text { quartzose, medium to very fine, angular to subrounded; } 3 \text { to } 5 \text { percent heavy minerals, } \\
\text { medium to very fine, subrounded to rounded; well cemented; moldic, vugs, moderately } \\
\text { to very porous. }\end{array}$ \\
\hline 3 & $127-130$ & $\begin{array}{l}\text { Sand, light-gray (N } 7) \text { to yellowish-gray ( } 5 \text { Y } 8 / 1) \text {; quartzose, medium to very fine, } \\
\text { moderately sorted, angular to subangular; } 3 \text { to } 5 \text { percent heavy minerals and phos- } \\
\text { phates, medium to very fine, subrounded to rounded; } 35 \text { to } 40 \text { percent detrital carbon- } \\
\text { ates and shell fragments; bivalvia, barnacles, bryozoans; interbedded with about } 10 \\
\text { percent limestone, yellowish-gray ( } 5 \text { Y } 7 / 2 \text { ); sandy, sparse biosparite; about 10 per- } \\
\text { cent quartz, medium to very fine, angular to subrounded; } 3 \text { to } 5 \text { percent heavy miner- } \\
\text { als, medium to very fine, subrounded to rounded; moderately cemented; vugs, moldic, } \\
\text { moderately porous. }\end{array}$ \\
\hline 10 & $130-140$ & $\begin{array}{l}\text { Sand, very light gray ( } N 8) \text { to yellowish-gray ( } 5 \text { Y } 8 / 1) \text {; quartzose, medium to fine, } \\
\text { moderately sorted, angular to subrounded; } 3 \text { to } 5 \text { percent heavy minerals and phos- } \\
\text { phates, medium to very fine, moderately sorted, subrounded to rounded; } 15 \text { to } 20 \\
\text { percent detrital carbonates and shell fragments; } 5 \text { to } 10 \text { percent streaks of clay and } \\
\text { silt. }\end{array}$ \\
\hline 4 & $140-144$ & $\begin{array}{l}\text { Sand, light-olive-gray ( } 5 \text { Y } 6 / 1) \text {; quartzose, medium to very fine, moderately sorted, } \\
\text { angular to subrounded; } 1 \text { to } 3 \text { percent heavy minerals and phosphates, medium to very } \\
\text { fine, moderately sorted, subrounded to rounded; } 5 \text { to } 10 \text { percent detrital carbonates, } \\
\text { very coarse to very fine; about } 5 \text { percent clay and silt. }\end{array}$ \\
\hline 3 & $144-147$ & $\begin{array}{l}\text { Sand, yellowish-gray }(5 \mathrm{Y} 8 / 1) \text { to pale-olive }(10 \mathrm{Y} 6 / 2) \text {; quartzose, fine to very } \\
\text { fine, well sorted, angular to subrounded; } 1 \text { to } 3 \text { percent heavy minerals and phos- } \\
\text { phates, fine to very fine, well sorted, subrounded to rounded; } 1 \text { to } 3 \text { percent detri- } \\
\text { tal carbonates; about } 10 \text { percent clay and silt. }\end{array}$ \\
\hline 13 & $147-160$ & $\begin{array}{l}\text { Sand, light-olive-gray ( } 5 \text { Y } 5 / 2 \text { ); quartzose, fine to very fine, well sorted, angular } \\
\text { to subangular; } 1 \text { to } 3 \text { percent heavy minerals and phosphates, fine to very fine, well } \\
\text { sorted, subrounded to rounded; } 1 \text { to } 3 \text { percent detrital carbonates; } 5 \text { to } 10 \text { percent } \\
\text { clay and silt. }\end{array}$ \\
\hline 6 & $160-166$ & $\begin{array}{l}\text { Sand, light-olive-gray ( } 5 \text { Y } 5 / 2 \text { ); quartzose, fine to very fine, well sorted, angular } \\
\text { to subrounded; } 1 \text { to } 3 \text { percent heavy minerals and phosphates as above; } 1 \text { to } 3 \text { percent } \\
\text { heavy minerals and phosphates as above; } 1 \text { to } 3 \text { percent detrital carbonates; } 15 \text { to } 20 \\
\text { percent clay and silt. }\end{array}$ \\
\hline 9 & $166-175$ & $\begin{array}{l}\text { Clayey sand, light-olive-gray ( } 5 \text { Y } 5 / 2) \text {; quartzose as above; } 1 \text { to } 3 \text { percent heavy } \\
\text { minerals and phosphates as above; } 3 \text { to } 5 \text { percent detrital carbonates; } 20 \text { to } 25 \text { per- } \\
\text { cent clay and silt. }\end{array}$ \\
\hline 10 & $175-185$ & $\begin{array}{l}\text { Clayey sand, grayish-olive (10 Y } 4 / 2) \text {; quartzose as above; } 5 \text { to } 10 \text { percent heavy min- } \\
\text { erals and phosphates as above; } 3 \text { to } 5 \text { percent detrital carbonates; } 30 \text { to } 35 \text { percent } \\
\text { clay and silt. }\end{array}$ \\
\hline 5 & $185-190$ & $\begin{array}{l}\text { Sandy clay, grayish-olive }(10 \mathrm{Y} 4 / 2) \text {; clay and silt; } 30 \text { to } 35 \text { percent quartzose as } \\
\text { above; } 3 \text { to } 5 \text { percent heavy minerals and phosphates as above; } 3 \text { to } 5 \text { percent detrital } \\
\text { carbonates. }\end{array}$ \\
\hline
\end{tabular}




\begin{tabular}{ccc}
\hline $\begin{array}{c}\text { Thick- } \\
\text { ness } \\
\text { (feet) }\end{array}$ & $\begin{array}{c}\text { Depth below } \\
\text { land surface } \\
\text { (feet) }\end{array}$ & Description \\
\hline
\end{tabular}

$40-4$ Sand, pale-yellowish-brown (10 YR 6/2); quartzose, medium to very fine, moderately sorted, angular to subangular; 1 to 3 percent heavy minerals, fine to very fine, well sorted, subangular to rounded; about 3 to 5 percent organic debris.

Sandy marl, light-olive-gray ( 5 Y 5/2); micrite, clay and silt; 30 to 35 percent quartzose, fine to very fine, well sorted, angular to subangular; 1 to 3 percent heavy minerals as above; 5 to 10 percent detrital carbonates and shell fragments.

$3 \quad 7-10$

Sand, light-olive-gray ( $5 Y 6 / 1$ ); quartzose, fine to very fine, well sorted, angular to subrounded; 1 to 3 percent heavy minerals as above; 5 to 10 percent detrital carbonates and shell fragments; about 10 percent silt and clay.

Sand, yellowish-gray ( $5 Y 7 / 2$ ); quartzose, medium to very fine, moderately sorted, angular to subrounded; 1 to 3 percent heavy minerals, fine to very fine, well sorted, subrounded to rounded; 1 to 3 percent detrital carbonates.

Sand, light-olive-gray ( $5 \mathrm{Y}$ 6/1); quartzose as above; 1 to 3 percent heavy minerals as above; 3 to 5 percent detrital carbonates and shell fragments; about 10 percent silt and clay.

Sand, light-olive-gray ( 5 Y $6 / 1$ ); quartzose, medium to very fine, moderately sorted, angular to subrounded; 5 to 10 percent heavy minerals, medium to very fine, moderately sorted, subangular to rounded; 25 to 30 percent detrital carbonates and shell fragments.

$420-24$

Sand, light-olive-gray ( 5 Y $5 / 2$ ); quartzose, medium to very fine, moderately sorted, angular to subrounded; 5 to 10 percent heavy minerals, fine to very fine, well sorted, subrounded to rounded; 5 to 10 percent detrital carbonates and shell fragments.

$6 \quad 24-30$

Muddy sand, dark-yellowish-brown ( 10 YR 4/2); quartzose as above; 1 to 3 percent heavy minerals as above; 3 to 5 percent detrital carbonates; about 25 to 30 percent organic mud, clay and silt size.

Sandy, olive-gray ( 5 Y 3/2); quartzose, medium to very fine, moderately sorted, angular to subrounded; 3 to 5 percent heavy minerals and phosphates, medium to very fine, moderately sorted, angular to rounded; 20 to 25 percent detrital carbonates and sheli fragments; about 10 percent organics.

$6 \quad 34-40$

Shelly sandy, light-olive-gray ( 5 Y 5/2); quartzose as above; 5 to 10 percent heavy minerals and phosphates as above; 10 to 15 percent detrital carbonates; 20 to 25 percent shells and shell fragments; Chione, Cardita, Ostrea, Prunum, Busycon, Conus, Latirus, Typhis.

$4 \quad 40-44$

Sand, olive-gray ( 5 Y 4/1); quartzose, medium to very fine, moderately sorted, angular to subrounded; 10 to 15 percent heavy minerals and phosphates, medium to very fine, well sorted, subangular to rounded; 3 to 5 percent detrital carbonates; 3 to 5 percent mud, clay and silt.

$644-50$

Muddy sand, brownish-black ( 5 YR 2/1); quartzose, medium to very fine, moderately sorted, angular to subangular; 20 to 25 percent mud, clay and silt size; 5 to 10 percent detrital carbonates.

$450-54$

Sand, olive-gray ( $5 \mathrm{Y} 4 / 1$ ); quartzose, medium to very fine, moderately sorted, angular to subangular; 3 to 5 percent heavy minerals and phosphates, medium to very fine, well sorted, angular to rounded; 3 to 5 percent detrital carbonates; 3 to 5 percent mud, clay and silt.

Sand, light-olive-gray ( $5 \mathrm{Y} 6 / 1$ ); quartzose, medium to very fine, moderately sorted, angular to subrounded; 5 to 10 percent heavy minerals and phosphates, medium to very fine, moderately to well sorted; 20 to 25 percent detrital carbonates and shell fragments.

$460-64$

Sand, yellowish-gray (5 Y 8/1); quartzose, medium to fine, well sorted, angular to subangular; 5 to 10 percent heavy minerals and phosphates, medium to very fine, moderately to well sorted, subrounded to rounded; 15 to 20 percent detrital carbonates and shell fragments, Chione, Nassarius, Prunum, Cardita.

Marly sand, light-olive-gray ( $5 Y 5 / 2$ ); quartzose, fine to very fine, well sorted, angular to subangular; 5 to 10 percent heavy minerals and phosphates, fine to very fine, well sorted, subrounded to rounded; about 10 percent marl, clay and silt size; 5 to 10 percent detrital carbonates and shell fragments.

$10 \quad 67-77$

Marly sand, light-olive-gray $(5 \mathrm{Y} 6 / 1)$ as above; 20 to 25 percent marl, clay and silt size. 


\begin{tabular}{|c|c|c|}
\hline $\begin{array}{l}\text { Thick- } \\
\text { ness } \\
\text { (feet) }\end{array}$ & $\begin{array}{l}\text { Depth below } \\
\text { land surface } \\
\text { (feet) }\end{array}$ & Description \\
\hline 3 & $77-80$ & $\begin{array}{l}\text { Marly sand, light-olive-gray ( } 5 \text { Y } 5 / 2) \text {; as above; interbedded with about } 25 \text { percent } \\
\text { limestone, grayish-black ( } 2) \text {; fossiliferous micrite; } 5 \text { to } 10 \text { percent quartzose, } \\
\text { medium to very fine, angular to subrounded; moldic, moderately porous; moderately to } \\
\text { well cemented. }\end{array}$ \\
\hline 4 & $80-84$ & $\begin{array}{l}\text { Sand, light-olive-gray }(5 \text { Y } 5 / 2) \text {; quartzose, medium to very fine, well sorted, angu- } \\
\text { lar to subrounded; } 5 \text { to } 10 \text { percent heavy minerals and phosphates, medium to very } \\
\text { fine, well sorted, subrounded to rounded; } 30 \text { to } 35 \text { percent detrital carbonates and } \\
\text { shell fragments, Turritella, Cancellaria; about } 5 \text { percent marl, silt and clay. }\end{array}$ \\
\hline 3 & $84-87$ & Marly sand, light-olive-gray $(5 \mathrm{Y} 6 / 1)$; as above; 10 percent marl, clay and silt. \\
\hline 3 & $87-90$ & $\begin{array}{l}\text { Sandy shell, light-olive-gray }(5 \mathrm{Y} 6 / 1) \text {; shells and shell fragments, Cancellaria, } \\
\text { Glycymeris, Plicatula, Crepidula, Fasciolaria, Olivella, Chione, other gastropods and } \\
\text { bivalves; } 15 \text { to } 20 \text { percent detrital carbonates, very coarse to very fine; } 30 \text { to } 35 \\
\text { percent quartzose, fine to very fine, well sorted, angular to subrounded; } 5 \text { to } 10 \\
\text { percent heavy minerals and phosphates, fine to very fine, well sorted, subrounded; } \\
5 \text { to } 10 \text { percent heavy minerals and phosphates, fine to very fine, well sorted, } \\
\text { subrounded to rounded. }\end{array}$ \\
\hline 10 & $90-100$ & $\begin{array}{l}\text { Shells and shell fragments, yellowish-gray ( } 5 \mathrm{Y} 8 / 1) \text {; Chione, Turritella, Terebra, } \\
\text { Conus, Cancellaria, Plicatula, Olivella, Lunatia, Busycon, Mitra, coral, barnacles, } \\
\text { Oliva; } 20 \text { to } 25 \text { percent detrital carbonates; } 20 \text { to } 25 \text { percent quartzose, medium to } \\
\text { very fine, moderately sorted, angular to subangular; } 5 \text { to } 10 \text { percent heavy minerals } \\
\text { and phosphates, fine to very fine, well sorted, subrounded to rounded; partly ce- } \\
\text { mented coquina. }\end{array}$ \\
\hline 4 & $100-104$ & 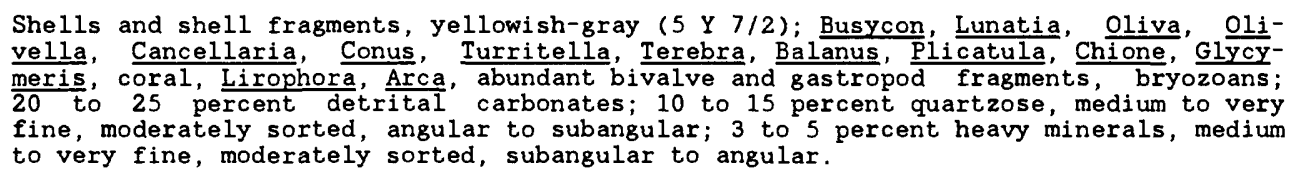 \\
\hline 3 & $104-107$ & $\begin{array}{l}\text { Shells and shell fragments as above; echinoid plates; } 20 \text { to } 25 \text { percent quartz as } \\
\text { above; about } 3 \text { to } 5 \text { percent partly cemented rock fragments. }\end{array}$ \\
\hline 3 & $107-110$ & $\begin{array}{l}\text { Sandy shell, yellowish-gray }(5 \mathrm{Y} 7 / 2) \text {; shells and shell fragments as above, Turri- } \\
\text { tella, echinoid plates, and bryozoans; } 25 \text { to } 30 \text { percent detrital carbonates, very } \\
\text { coarse to very fine; } 20 \text { to } 25 \text { percent quartzose as above; } 3 \text { to } 5 \text { percent heavy miner- } \\
\text { als and phosphates as above. }\end{array}$ \\
\hline 4 & $110-114$ & 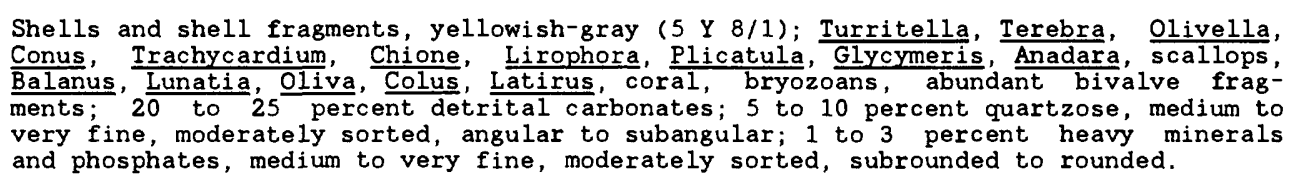 \\
\hline 6 & $114-120$ & $\begin{array}{l}\text { Sandy shell, light-olive-gray }(5 \text { Y } 5 / 2) ; \text { shells and shell fragments as above; } 20 \text { to } \\
25 \text { percent detrital carbonates; } 10 \text { to } 20 \text { percent quartzose as above; } 3 \text { to } 5 \text { percent } \\
\text { heavy minerals and phosphates as above. }\end{array}$ \\
\hline 7 & $120-127$ & 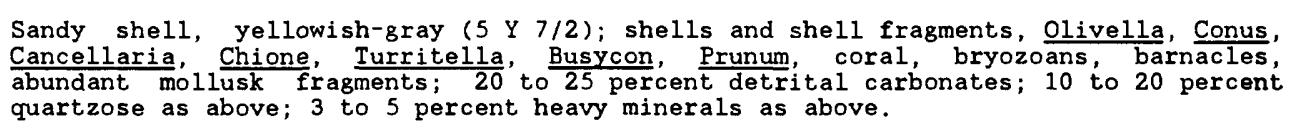 \\
\hline 3 & $127-130$ & $\begin{array}{l}\text { Shelly sand, light-olive-gray }(5 \mathrm{Y} 5 / 2) \text {; quartzose, medium to very fine, moderately } \\
\text { sorted, angular to subangular; } 30 \text { to } 35 \text { percent shelis and shell fragments as above; } \\
20 \text { to } 25 \text { percent detrital carbonates, very coarse to very fine; } 3 \text { to } 5 \text { percent heavy } \\
\text { minerals and phosphates, medium to very fine, moderately sorted, subrounded to } \\
\text { rounded. }\end{array}$ \\
\hline 4 & $130-134$ & $\begin{array}{l}\text { Shelly sand, light-olive-gray }(5 \text { Y } 6 / 1) ; \text { quartzose, coarse to very fine, poorly } \\
\text { sorted, angular to subrounded; } 30 \text { to } 40 \text { percent detrital carbonates and shell frag- } \\
\text { ments; } 3 \text { to } 5 \text { percent heavy minerals and phosphates, medium to very fine, moderately } \\
\text { sorted, subrounded to rounded; interbedded with about } 10 \text { percent limestone; sandy, } \\
\text { sparse biosparite; } 20 \text { to } 30 \text { percent quartzose, medium to very fine, angular to sub- } \\
\text { rounded; } 3 \text { to } 5 \text { percent heavy minerals and phosphates, fine to very fine, subrounded } \\
\text { to rounded; poorly cemented; very porous. }\end{array}$ \\
\hline
\end{tabular}

Shelly sand as above; interbedded with 10 percent limestone as above. 
Well PB-1558--Continued

\begin{tabular}{|c|c|c|}
\hline $\begin{array}{l}\text { Thick- } \\
\text { ness } \\
\text { (feet) }\end{array}$ & $\begin{array}{l}\text { Depth below } \\
\text { land surface } \\
\text { (feet) }\end{array}$ & Description \\
\hline 3 & $137-140$ & $\begin{array}{l}\text { Limestone, light-olive-gray }(5 \mathrm{Y} 5 / 2) \text {; sandy, sparse biomicrite, mollusks; } 10 \text { to } 20 \\
\text { percent quartz, medium to very fine, moderately sorted, angular to subrounded; } 5 \text { to } \\
10 \text { percent heavy minerals and phosphates, coarse to very fine, poorly sorted, sub- } \\
\text { rounded to rounded; moldic, vags, moderately to very porous; moderately cemented; } \\
\text { interbedded with about } 30 \text { percent sand, light-gray (N } 7) \text { to yellowish-gray }(5 \mathrm{Y} 8 / 1) \text {; } \\
\text { quartzose, medium to very fine, moderately sorted, angular to subrounded; } 3 \text { to } 5 \\
\text { percent heavy minerals and phosphates, medium to very fine, moderately sorted, sub- } \\
\text { rounded to rounded; } 35 \text { to } 40 \text { percent detrital carbonates and shell fragments. }\end{array}$ \\
\hline 4 & $140-144$ & $\begin{array}{l}\text { Limestone as above; interbedded with about } 40 \text { percent sand, } 1 \text { ight-olive-gray ( } 5 \text { Y } \\
6 / 1 \text { ); quartzose as above; } 10 \text { percent heavy minerals and phosphates, very coarse to } \\
\text { very fine, poorly sorted, subrounded to rounded; } 35 \text { to } 40 \text { percent detrital carbonates } \\
\text { and shell fragments, echinoid plates, Anadara. Chione, abundant bivalves, Oliva, } \\
\text { bryozoans. }\end{array}$ \\
\hline 3 & $144-147$ & $\begin{array}{l}\text { Marl, light-olive-gray ( } 5 \text { Y } 5 / 2 \text { ) to yellowish-gray }(5 \mathrm{Y} 7 / 2) \text {; micrite, clay and silt; } \\
20 \text { to } 30 \text { percent quartzose, medium to very fine, moderately sorted, angular to sub- } \\
\text { rounded; } 3 \text { to } 5 \text { percent heavy minerals and phosphates as above; } 10 \text { to } 20 \text { percent de- } \\
\text { trital carbonates and shell fragments. }\end{array}$ \\
\hline 3 & $147-150$ & $\begin{array}{l}\text { Sand, light-olive }(5 \mathrm{Y} 5 / 2) \text {; quartzose as above; } 5 \text { to } 10 \text { percent heavy minerals and } \\
\text { phosphates as above; about } 20 \text { to } 30 \text { percent marl; } 20 \text { to } 30 \text { percent detrital carbon- } \\
\text { ates and shell fragments. }\end{array}$ \\
\hline 4 & $150-154$ & $\begin{array}{l}\text { Marl, grayish-olive-green ( } 5 \text { GY } 3 / 2) \text {; micrite, silt and clay; interbedded with about } \\
40 \text { percent sand, light-gray (N } 7) \text { to light-olive-gray }(5 \mathrm{Y} / 1) \text {; quartzose, medium to } \\
\text { very fine, moderately sorted, angular to subrounded; } 10 \text { percent heavy minerals and } \\
\text { phosphates, very coarse to very fine, poorly sorted, subrounded to rounded; } 30 \text { to } 40 \\
\text { percent detrital carbonates and shell fragments, bryozoans, barnacles, bivalves, } \\
\text { Chione, plicatula. }\end{array}$ \\
\hline 3 & $154-157$ & $\begin{array}{l}\text { Marl, grayish-olive-green }(5 \text { GY } 3 / 2) \text {; micrite, silt and clay; about } 10 \text { percent } \\
\text { quartzose, very fine, well sorted, angular to subangular; } 10 \text { percent heavy minerals } \\
\text { and phosphates, fine to very fine, well sorted, subrounded to rounded. }\end{array}$ \\
\hline 3 & $157-160$ & Marl with sand as in 150 to 154 feet. \\
\hline 4 & $160-164$ & $\begin{array}{l}\text { Marl, grayish-olive-green ( } 5 \text { GY } 3 / 2) \text {; } \$ 11 t \text {, clay and micrite; interbedded with about } \\
30 \text { percent sand; quartzose, medium to very fine, moderately sorted, angular to suban- } \\
\text { gular; 10 percent heavy minerals and phosphates, very coarse to very fine, poorly } \\
\text { sorted, subrounded to rounded; } 30 \text { percent detrital carbonates and shell fragments. }\end{array}$ \\
\hline 3 & $164-167$ & Marl with sand as above. \\
\hline 13 & $167-180$ & $\begin{array}{l}\text { Marl, grayish-olive }(10 \mathrm{Y} 4 / 2) \text {; silt, clay and micrite; interbedded with } 40 \text { to } 50 \\
\text { percent sand, light-olive-gray (5 } 6 / 1) \text {; quartz, heavy minerals and phosphates as } \\
\text { above; } 30 \text { to } 40 \text { percent detrital carbonates and sheil fragments, bryozoans, Cardita, } \\
\text { barnacles, Olivella, Tellina, Ostrea, Plicatula, Glycymeris, Chione. }\end{array}$ \\
\hline 5 & $180-185$ & Marl as above; interbedded with 30 to 40 percent sand and shell as above. \\
\hline 15 & $185-200$ & $\begin{array}{l}\text { Marl as above; interbedded with } 30 \text { to } 40 \text { percent sand, grayish-olive }(10 \mathrm{Y} 4 / 2) \text {; } \\
\text { quartzose, medium to very fine, moderately sorted, angular to subangular; } 10 \text { percent } \\
\text { heavy minerals and phosphates, very coafse to very fine, poorly sorted, subrounded to } \\
\text { rounded; } 30 \text { to } 40 \text { percent detrital carbonates and shell fragments, Plicatula, Glycy- } \\
\text { meris, Turritella, limpets, bryozoans, coral, barnacles. }\end{array}$ \\
\hline
\end{tabular}


We11 PB-1562

Lat $26^{\circ} 48^{\prime} 56^{\prime \prime}$, long $80^{\circ} 20^{\prime} 37^{\prime \prime}$

Sec. 15, T. 42 S., R, $40 \mathrm{E}$.

\begin{tabular}{ccc}
\hline $\begin{array}{c}\text { Thick- } \\
\text { ness } \\
\text { (feet) }\end{array}$ & $\begin{array}{c}\text { Depth below } \\
\text { land surface } \\
\text { (feet) }\end{array}$ & Description \\
\hline
\end{tabular}

$40-4$ Sand, dark-yellowish-brown (10 YR 4/2); quartzose, medium to very fine, moderately sorted, subangular to subrounded; 1 to 3 percent heavy minerals, fine to very fine, well sorted, rounded to subrounded; about 10 percent mud, clay and silt size.

$34-7$

Sandy marl, light-olive-gray ( 5 Y 5/2); micrite; 25 to 30 percent quartzose, fine to very fine, well sorted, subangular to subrounded; 1 to 3 percent heavy minerals, fine to very fine, well sorted, rounded to subrounded; 5 to 10 percent detrital carbonates, coarse to very fine; 5 to 10 percent organics.

$3 \quad 7-10$

Sandy marl light-olive-gray $(5 \mathrm{Y} 6 / 1)$ to olive-gray ( 5 Y 4/1); micrite; 20 to 25 percent quartz as above; 1 to 3 percent heavy minerals as above; 5 to 10 percent detrital carbonates, coarse to very fine; 5 to 10 percent organics; about 10 to 15 percent shells at 10 feet, Chione, Glycymeris.

$4 \quad 10-14$

Muddy sand, light-olive-gray ( 5 Y 6/11); quartzose, fine to very fine, well sorted, subangular to angular; 1 to 3 percent heavy minerals as above; 5 to 10 percent detrital carbonates and shell fragments; about 25 to 30 percent micrite.

$3 \quad 14-17$

Limestone, very light gray (N 8) to medium-gray (N 6); sandy, sparse biomicrite; Chione, Turritella, Terebra, Anadora; calcite-filled pore spaces; 20 to 25 percent quartzose, medium to very fine, moderately sorted, subangular to subrounded; 3 to 5 percent heavy minerals, fine to very fine, well sorted, rounded to subrounded; interbedded with about 30 percent mar1, micrite; 20 to 25 percent quartzose, medium to very fine, moderately sorted, subangular to subrounded; 3 to 5 percent heavy minerals, fine to very fine, well sorted, rounded to subrounded; about 25 to 30 percent detrital carbonates and she11 fragments, oysters.

$3 \quad 17-20$

Muddy sand, medium-gray (N 5) to 1ight-olive-gray ( $5 \mathrm{Y} 6 / 1$ ); quartzose, medium to very fine, moderately sorted, subangular to subrounded; 3 to 5 percent heavy minerals and phosphates, fine to very fine, well sorted, rounded to subrounded; about 25 to 25 percent micrite; 10 to 15 percent detrital carbonates and shell fragments, Chione; interbedded with about 5 to 20 percent rock fragments.

Sand, light-olive-gray ( 5 Y $6 / 1$ ); quartzose, medium to very fine, subangular to subrounded; 5 to 10 percent heavy minerals, fine to very fine well sorted rounded to subrounded; 20 to 25 percent detrital carbonates and sheil fragments, Hyalina, Chione, Tellina; about 5 percent micrite.

$3 \quad 24-27$

Sand, dark-yellowish-brown (10 YR 4/2); quartzose, medium to very fine, moderately sorted, subangular to rounded; 5 to 10 percent heavy minerals, fine to very fine, well sorted, subrounded to rounded; 5 to 10 percent detrital carbonates; about 10 percent micrite.

$3 \quad 27-30$

Muddy sand, olive-gray (5 Y 4/1); quartzose, fine to very fine, well sorted, subangular to subrounded; 10 to 15 percent heavy minerals, fine to very fine, well sorted, rounded to subrounded; 1 to 3 percent detrital carbonates; about 10 percent mud, clay and silt size.

$430-34$

Muddy sand, olive-gray ( 5 Y $3 / 2$ ); quartzose, medium to very fine, moderately sorted, angular to subrounded; 10 to 15 percent heavy minerals, medium to very fine, well sorted, rounded to subrounded; 3 to 5 percent detrital carbonates; about 15 to 20 percent mud, clay and silt size.

$3 \quad 34-37$

Sand, olive-gray ( 5 Y 4/1); quartzose, fine to very fine, well sorted, subangular to subrounded; 10 to 15 percent heavy minerals, fine to very fine, well sorted, rounded to subrounded; about 5 to 10 percent mud, clay and silt size.

$3 \quad 37-40$

Sand, olive-gray ( 5 Y 4/1) to dark-yellowish-brown (10 YR 4/2); quartzose, fine to very fine, well sorted, subangular to subrounded; 5 to 10 percent heavy minerals, fine to very fine, well sorted, rounded to subrounded; 3 to 5 percent detrital carbonates and shell fragments; about 3 percent mud, clay and silt size.

Muddy sand, olive-black ( 5 Y 2/1); quartzose, medium to very fine, moderately sorted, subangular to subrounded; 1 to 3 percent heavy minerals as above; 1 to 3 percent detrital carbonates; 20 to 25 percent organic mud, clay and silt size.

Muddy sand as above.

$3 \quad 47-50$

Muddy sand, olive-gray ( 5 Y 4/1); quartzose as above; 3 to 5 percent heavy minerals as above; 3 to 5 percent detrital carbonates; about 10 percent mud, clay and silt size.

Muddy sand, light-olive-gray ( 5 Y 5/2); quartzose, medium to very fine, moderately sorted, subangular to subrounded; 3 to 5 percent heavy minerals, fine to very fine, well sorted, rounded to subrounded; 5 to 10 percent detrital carbonates and she11 fragments; 15 to 20 percent micrite. 
We11 PB-1562--Continued

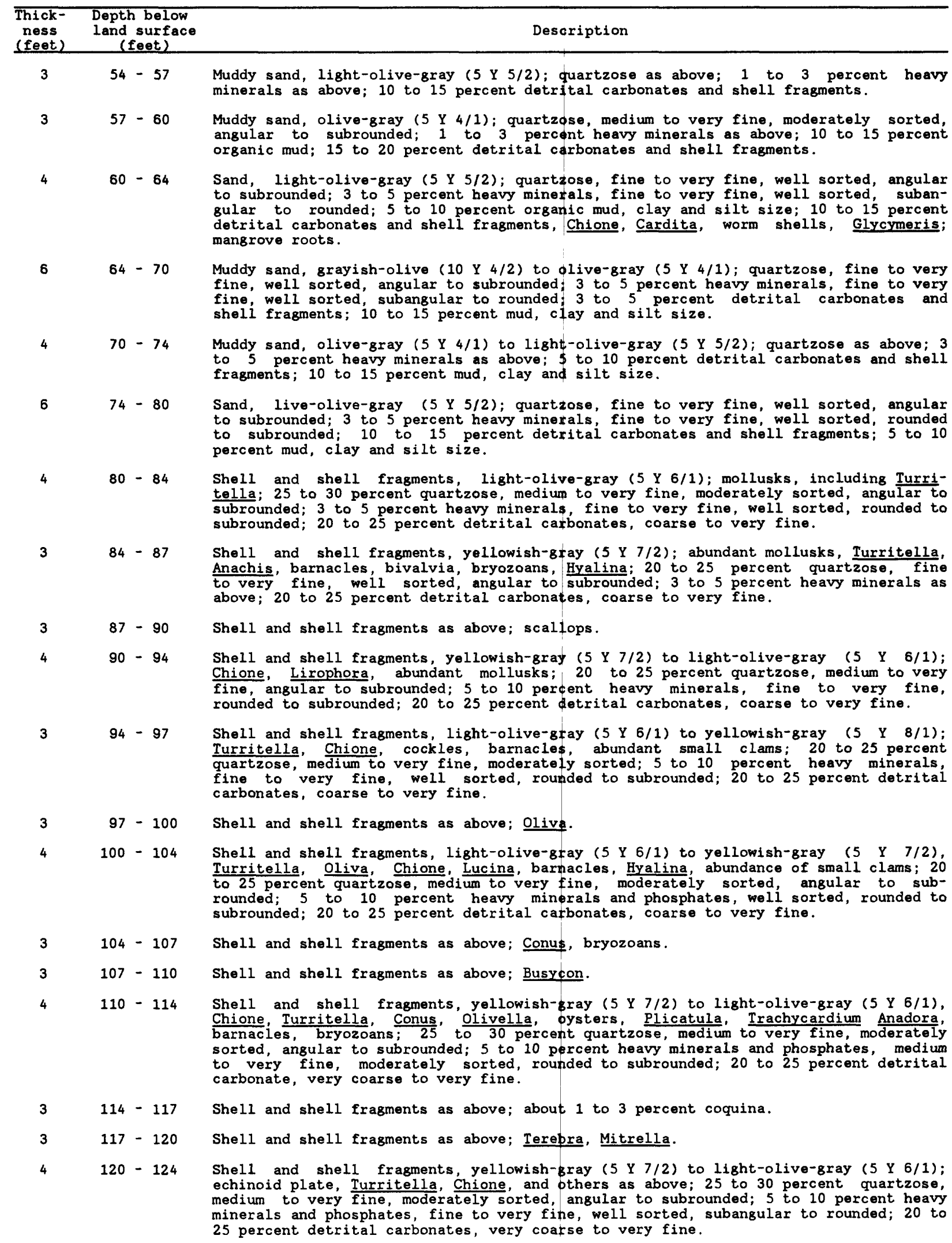




\begin{tabular}{|c|c|c|}
\hline $\begin{array}{l}\begin{array}{l}\text { Thick- } \\
\text { ness } \\
\text { (feet) }\end{array} \\
\end{array}$ & $\begin{array}{c}\text { Depth below } \\
\text { land surface } \\
\text { (feet) }\end{array}$ & Description \\
\hline 3 & $124-127$ & $\begin{array}{l}\text { Shells and shell fragments, light-olive-gray }(5 \text { y } 5 / 2) ; \text { Oliva, Chione, abundance of } \\
\text { small clam shells, Turritella, bryozoan; } 20 \text { to } 25 \text { percent quartzose, fine to very } \\
\text { fine, well sorted, subangular to subrounded; } 5 \text { to } 10 \text { percent heavy minerals and } \\
\text { phosphates as above; } 25 \text { to } 30 \text { percent detrital carbonates; } 3 \text { to } 5 \text { percent silt and } \\
\text { clay-size particles. }\end{array}$ \\
\hline 3 & $127-130$ & $\begin{array}{l}\text { Sand, light-olive-gray }(5 \mathrm{Y} 5 / 2) \text {; detrital carbonates, coarse to very fine; } 20 \text { to } 25 \\
\text { percent shells and shell fragments; } 10 \text { to } 15 \text { percent quartzose, fine to very fine, } \\
\text { well sorted, angular to subrounded; } 5 \text { to } 10 \text { percent heavy minerais and phosphates, } \\
\text { fine to very fine, well sorted, subangular to rounded; } 15 \text { to } 20 \text { percent clay and } \\
\text { silt-size particles. }\end{array}$ \\
\hline 4 & $130-134$ & $\begin{array}{l}\text { Shell and shell fragments, as in } 120 \text { to } 124 \text { feet, with Turritella, Terebra, Chione, } \\
\text { echinoid plates, and other bivalves; interbedded with about 20 percent limestone } \\
\text { becoming well cemented at } 134 \text { feet; medium-gray (N } 5 \text { ) packed biosparite; bivalvia and } \\
\text { other mollusks; } 20 \text { to } 25 \text { percent quartzose, medium to very fine, moderately sorted, } \\
\text { angular to subrounded; } 3 \text { to } 5 \text { percent heavy minerals, medium to very fine, moderately } \\
\text { sorted, subrounded to rounded; moderately to well cemented; very porous. }\end{array}$ \\
\hline 3 & $134-137$ & $\begin{array}{l}\text { Limestone, light-olive-gray }(5 \mathrm{H} 5 / 2) \text { to grayish-olive }(10 \text { Y } 4 / 2) \text {; sandy, sparse } \\
\text { biosparite to biomicrite in places, mollusks; } 10 \text { to } 15 \text { percent quartzose, medium to } \\
\text { very fine, subangular to subrounded; } 3 \text { to } 5 \text { percent heavy minerals, fine to very } \\
\text { fine, rounded to subrounded; moldic, vugs; well cemented; very porous; interbedded } \\
\text { with about } 30 \text { percent sand; detrital carbonates, very coarse to very fine; } 20 \text { to } 25 \\
\text { percent quartzose, medium to very fine, moderately sorted, angular to subrounded; } 3 \\
\text { to } 5 \text { percent heavy minerals, fine to very fine, well sorted, rounded to subrounded; } \\
\text { about } 10 \text { percent clay and silt in places. }\end{array}$ \\
\hline 3 & $137-140$ & $\begin{array}{l}\text { Sand, light-olive-gray }(5 \mathrm{Y} 6 / 1) \text { to yellowish-gray }(5 \mathrm{Y} 7 / 2) \text {; quartzose, medium to } \\
\text { very fine, moderately sorted, angular to subrounded; } 3 \text { to } 5 \text { percent heavy minerals, } \\
\text { fine to very fine, rounded to subrounded; } 25 \text { to } 30 \text { percent detrital carbonates and } \\
\text { shell fragments; interbedded with } 10 \text { percent limestone as above; interbedded with } 10 \\
\text { percent sandstone, yellowish-gray }(5 \mathrm{Y} / 1) \text {; quartzose, medium to very fine, angular } \\
\text { to rounded; } 3 \text { to } 5 \text { percent heavy minerals, medium to very fine, angular to rounded; } 5 \\
\text { to } 10 \text { percent detrital carbonates and phosphates, coarse to very fine; about } 20 \text { per- } \\
\text { cent sparite matrix; } 10 \text { to } 15 \text { percent shells and shell fragments. }\end{array}$ \\
\hline
\end{tabular}

Sand, interbedded with sandstone as above.

$3 \quad 144-147$

Limestone, light-olive-gray ( 5 Y 6/1); sandy, sparse biosparite, mollusks; 25 to 30 percent quartzose, medium to fine, subangular to subrounded, moderately sorted; $S$ to 10 percent heavy minerals, fine to very fine, well sorted, rounded to subrounded; interbedded with about 20 percent sand; quartzose, medium to very fine, moderately sorted, angular to subrounded; 3 to 5 percent heavy minerals, fine to very fine, well sorted, subrounded to rounded; 35 to 40 percent detrital carbonates and shell fragments.

Limestone, dusky-yellow-green ( 5 GY $5 / 2$ ) to light-olive-gray ( 5 Y $5 / 2$ ); sandy, sparse biomicrite, mollusks; 5 to 10 percent detrital carbonates; 30 to 35 percent quartzose, medium to very fine, moderately sorted, subangular to angular; $S$ to 10 percent heavy minerals, fine to very fine, well sorted, subangular to rounded; moldic; well cemented; very porous; interbedded with 40 to 45 percent sand, light-olive-gray ( 5 Y $6 / 1)$; quartzose, medium to very fine, well sorted, angular to subrounded; 5 to 10 percent heavy minerals fine to very fine, well sorted, rounded to subrounded; 25 to 30 percent detrital carbonates and shell fragments.

Sand, light-olive-gray ( $5 \mathrm{Y} 6 / 1$ ) to yellowish-gray ( $5 \mathrm{Y} 7 / 2)$; quartzose, fine to very fine, well sorted, angular to subrounded; 5 to 10 percent heavy minerals and phosphates, fine to very fine, well sorted, subangular to rounded; 15 to 20 percent detrital carbonates, very coarse to very fine; 20 to 25 percent shell and shell fragments, Colus, Hyalina, abundant bivalves; itnerbedded with about 10 percent limestone, light-olive-gray ( 5 Y $5 / 2$ ) to dusky-yellow-green ( $5 \mathrm{GY} 5 / 2$ ); sandy, sparse biomicrite; 20 to 25 percent quartzose, fine to very fine, well sorted, subangular to subrounded; 3 to 5 percent heavy minerals, fine to very fine, well sorted, rounded to subrounded; 5 to 10 percent detrital carbonates, medium to fine.

Sandy clay, grayish-olive (10 Y 4/2); silt and clay; 30 to 35 percent quartzose, medium to very fine, moderately sorted, subangular to subrounded; 3 to 5 percent heavy minerals and phosphates, medium to very fine, subrounded to rounded; 20 to 25 percent detrital carbonates and shell fragments; interbedded with about 20 percent limestone; sandy, sparse biomicrite as above; poorly cemented; moderately to slightly porous.

Clayey, shelly sand, yellowish-gray ( 5 Y $7 / 2$ ) to pale-olive (10 Y 6/2); quartzose, medium to very fine, moderately sorted, subangular to subrounded; 5 to 10 percent heavy minerals and phosphates, coarse to very fine, poorly sorted, subrounded to rounded; 10 to 15 percent clay and silt; 20 to 25 percent shells and shell fragments, Turritella, Tellina. 
We11 PB-1562--Continued

\begin{tabular}{|c|c|c|}
\hline $\begin{array}{l}\text { Thick- } \\
\text { ness } \\
\text { (feet) }\end{array}$ & $\begin{array}{l}\text { Depth below } \\
\text { land surface } \\
\text { (feet) }\end{array}$ & Description \\
\hline 3 & $164-167$ & $\begin{array}{l}\text { Clayey, shelly sand, light-olive-gray }(5 Y 5 / 2) \text { as above; } 20 \text { to } 25 \text { percent clay and } \\
\text { silt. }\end{array}$ \\
\hline 3 & $167-170$ & $\begin{array}{l}\text { Sandy, shelly clay, grayish-olive }(10 \% 4 / 2) \text {; clay and silt; } 25 \text { to } 30 \text { percent quartz- } \\
\text { ose, medium to very fine, subangular to subrounded; } 5 \text { to } 10 \text { percent heavy minerals } \\
\text { and phosphates, coarse to very fine, subrounded to rounded; } 25 \text { to } 30 \text { percent carbon- } \\
\text { ates and shell fragments, Tellina. }\end{array}$ \\
\hline 4 & $170-174$ & $\begin{array}{l}\text { Shelly clay, grayish-olive-green }(5 \mathrm{GY} 3 / 2) \text {; silt and clay; } 10 \text { to } 15 \text { percent quartz- } \\
\text { ose, medium to very fine, subangular to subrounded; } 3 \text { to } 5 \text { percent heavy minerals and } \\
\text { phosphates, coarse to very fine, subrounded to rounded; } 15 \text { to } 20 \text { percent detrital } \\
\text { carbonates and shell fragments, Telling, bryozoans, abundant bivalve pieces. }\end{array}$ \\
\hline 3 & $174-177$ & $\begin{array}{l}\text { Sandy clay, light-olive-gray }(5 Y 6 / 1) \text { to grayish-olive-green }(5 \mathrm{GY} 3 / 2) \text {; silt and } \\
\text { clay; } 30 \text { to } 35 \text { percent quartzose as above; } 3 \text { to } 5 \text { percent heavy minerals and phos- } \\
\text { phates as above; } 15 \text { to } 20 \text { percent detrital carbonates and shell fragments. }\end{array}$ \\
\hline 3 & $177-180$ & $\begin{array}{l}\text { Sandy, shelly clay, grayish-olive-green }(5 \mathrm{GY} 3 / 2) \text {; silt and clay; } 25 \text { to } 30 \text { percent } \\
\text { quartzose, medium to very fine, moderately sorted, subangular to subrounded; } 3 \text { to } 5 \\
\text { percent heavy minerals and phosphates, coarse to very fine, moderately sorted, sub- } \\
\text { rounded to rounded; } 20 \text { to } 25 \text { percent detrital carbonates and shell fragments. }\end{array}$ \\
\hline 4 & $180-184$ & 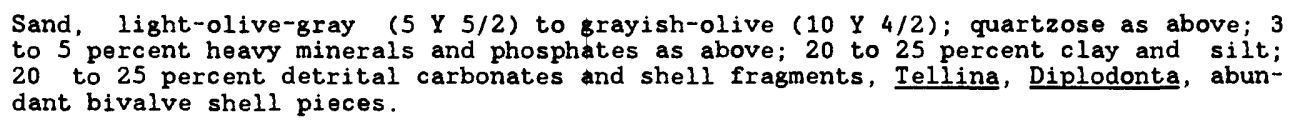 \\
\hline 3 & $184-187$ & Sandy, shelly clay as in 177 to 180 feet. \\
\hline 3 & $187-190$ & Sandy, shelly clay as in 177 to 180 feet. \\
\hline 5 & $190-195$ & $\begin{array}{l}\text { Sandy clay, grayish-olive ( } 10 \mathrm{Y} 4 / 2) \text {; clay and silt; } 25 \text { to } 30 \text { percent quartzose, fine } \\
\text { to very fine, well sorted, subangular to subrounded; } 3 \text { to } 5 \text { percent heavy minerals } \\
\text { and phosphates, fine to very fine, well sorted, subrounded to rounded; } 10 \text { to } 15 \text { per- } \\
\text { cent shells and shell fragments, echinoid plates. }\end{array}$ \\
\hline 5 & $195-200$ & Sandy, shelly clay, grayish-olive $(10 \Psi 4 / 2)$, as in 177 to 180 feet. \\
\hline 5 & $200-205$ & $\begin{array}{l}\text { Sandy, shelly clay, grayish-olive }(10 Y 4 / 2) \text {; clay and silt; } 25 \text { to } 30 \text { percent quartz- } \\
\text { ose, fine to very fine, well sorted, subangular to subrounded; } 3 \text { to } 5 \text { percent heavy } \\
\text { minerals and phosphates, fine to very fine, well sorted, subrounded to rounded; } 20 \text { to } \\
25 \text { percent detrital carbonates and shell fragments. }\end{array}$ \\
\hline 5 & $205-210$ & Sandy, shelly clay as above. \\
\hline 10 & $210-220$ & $\begin{array}{l}\text { Sandy clay, grayish-olive-green ( } 5 \mathrm{GY} 3 / 2) \text {; clay and silt; } 10 \text { to } 15 \text { percent quartz- } \\
\text { ose, fine to very fine, well sorted, subangular to subrounded; } 3 \text { to } 5 \text { percent heavy } \\
\text { minerals and phosphates, fine to very fine, well sorted, subrounded to rounded; } 5 \text { to } \\
10 \text { percent shells and shell fragments. }\end{array}$ \\
\hline 10 & $220-230$ & $\begin{array}{l}\text { Clay, grayish-olive-green }(5 \text { GY } 3 / 2) \text {; clay and silt; } 5 \text { to } 10 \text { percent quartzose, very } \\
\text { fine, well sorted, subangular to subrounded; } 3 \text { to } 5 \text { percent heavy minerals, very } \\
\text { fine, well sorted, subrounded to rounded; } 5 \text { to } 10 \text { percent shells and shell fragments. }\end{array}$ \\
\hline 5 & $230-235$ & $\begin{array}{l}\text { Clay as above; } 15 \text { to } 20 \text { percent shells and shell fragments, Tellina, coral, abundant } \\
\text { bivalve fragments. }\end{array}$ \\
\hline 10 & $235-245$ & $\begin{array}{l}\text { Sandy clay, grayish-olive-green ( } 5 \text { GY } 3 / 2 \text { ); silt and clay; } 20 \text { to } 25 \text { percent quartz- } \\
\text { ose, fine to very fine, well sorted, subangular to subrounded; } 3 \text { to } 5 \text { percent heavy } \\
\text { minerals and phosphates, coarse to very fine, subrounded to rounded; } 15 \text { to } 20 \text { percent } \\
\text { shells and shell fragments. }\end{array}$ \\
\hline 5 & $245-250$ & $\begin{array}{l}\text { Sandy, shelly clay, light-olive-gray }(5 \text { Y } 5 / 2 \text { ) to grayish-olive }(10 \text { Y } 4 / 2) \text {; clay and } \\
\text { silt; } 20 \text { to } 25 \text { percent quartzose, medium to very fine, moderately sorted, subangular } \\
\text { to subrounded; } 3 \text { to } 5 \text { percent heavy minerals, fine to very fine, well sorted, sub- } \\
\text { rounded to rounded; } 20 \text { to } 25 \text { percent detrital carbonates and shell fragments, Turri- } \\
\text { tella, Tellina, Terebra, Cerodrilla, limpets, Anadora. }\end{array}$ \\
\hline
\end{tabular}


We11 PB-1564

Lat $26^{\circ} 45^{\prime} 55^{\prime \prime}$, long $80^{\circ} 15^{\prime} 17^{\prime \prime}$

Sec. 4, T. 43 S., R. 41 E.

$\begin{array}{cr}\begin{array}{c}\text { Thick- } \begin{array}{c}\text { ness } \\ \text { (feet) }\end{array} \\ 4\end{array} & \begin{array}{r}\text { Depth bel } \\ \text { land surf } \\ \text { (feet) }\end{array} \\ 10 & 0-4 \\ 3 & 14-17 \\ 3 & 17-20 \\ 4 & 20-24 \\ 6 & 24-30 \\ 3 & 37-40 \\ 4 & 34-34 \\ 3 & \end{array}$

$4 \quad 40-44$

Sand, dusky-brown (5 YR 2/2); quartzose, medium to very fine, moderately sorted, angular to subrounded; 1 to 3 percent carbonates; 20 to 25 percent organic mud and debris.

Sand, dark-yellowish-brown (10 YR 4/2); quartzose, fine to very fine, well sorted, angular to subrounded; about 1 percent heavy minerals, fine to very fine, subrounded to rounded; 1 to 3 percent detrital carbonates; 10 to 20 percent mud, micrite, silt and clay.

Sand, moderate-yellowish-brown (10 YR 5/4); quartzose, fine to silt, well sorted, angular to subrounded; about 1 percent heavy minerals, fine to very fine, angular to rounded.

Sand, moderate-yellowish-brown (10 YR 5/4); quartzose, fine to very fine, well sorted, angular to subangular; about 1 percent heavy minerals as above; about 5 to 10 percent mud, silt size.

Sand, pale-yellowish-brown ( 10 YR $6 / 2$ ); quartzose, medium to very fine, moderately sorted, angular to subangular; 1 percent heavy minerals as above; about 10 percent mud, silt size.

and, dark-yellowish-brown (10 YR 4/2); quartzose, medium to very fine, moderately sorted, angular to subrounded; about 1 percent heavy minerals, fine to very fine, subrounded to rounded; about 10 percent mud, silt size.

Sand, olive-gray ( $5 \mathrm{Y} 4 / 1)$; quartzose as above; 1 to 3 percent heavy minerals as above; about 10 to 20 percent mud, silt and clay size.

Mar1, olive-gray ( 5 Y 4/1) to dark-yellowish-brown (10 YR 4/2); silt, clay and micrite; 40 to 50 percent quartzose as above; 3 to 5 percent heavy minerals as above.

Marl, olive-gray (5 Y 4/1) to moderate-yellowish-brown (10 YR 5/4); silt, clay and micrite; 30 to 40 percent quartzose as above; 3 to 5 percent heavy minerals; 5 to 10 percent carbonates, medium to very fine; interbedded with about 20 percent limestone; sandy, sparse intrasparite to sandy, sparse intramicrite; moderately cemented; impermeable.

Sand, light-olive-gray ( 5 Y 6/1); quartzose, medium to very fine, moderately sorted, angular to subangular; 3 to 5 percent heavy minerals, medium to fine, well sorted, subrounded to rounded; 40 to 50 percent detrital carbonates, coarse to very fine; about 10 percent limestone nodules; sandy, sparse biosparite; poorly cemented.

Sand, light-olive-gray ( $5 \mathrm{Y} 6 / 1)$ to yellowish-gray ( $5 \mathrm{Y} 7 / 2)$; quartzose, medium to very fine, angular to subangular; 3 to 5 percent heavy minerals, fine to very fine, well sorted, subrounded to rounded; 40 to 50 percent detrital carbonates and shell fragments, Arca, Chione, Anadara, Turritella, abundant mollusks.

Sand, light-olive-gray ( $5 \mathrm{Y} 5 / 2$ ); as above; Arca, Chione, Cerithiopsis, Ficus, Murex.

Sand, light-olive-gray ( 5 Y 5/2); detrital carbonates and shell fragments, Chione, Cardita, Terebra, Cancellaria, Trigonostoma; 30 to 40 percent quartzose, medium to very fine, moderately sorted, angular to subangular; 3 to 5 percent heavy minerals, fine to very fine, well sorted, subangular to rounded; about 5 percent micrite.

Sandy shel1, light-olive-gray ( 5 Y 5/2); Oliva, Terebra, Olivella, Cylichna, Cancellaria, Murex, worm shells, Anadara, Pecten, Diunricella, Echinochama, Ventricolaria, Lucina, Chione, Cardita, limpet; 20 to 30 percent detrital carbonates, coarse to fine; 20 to 30 percent quartzose, medium to very fine, moderately sorted, angular to subangular; 5 to 10 percent heavy minerals, medium to very fine, moderately sorted, subrounded to rounded; about 10 percent limestone; sandy, sparse biosparite; poorly cemented.

$6 \quad 64-70$

Sandy shell, light-olive-gray ( 5 Y 6/1); as above.

$4 \quad 70-74$

Sand, light-olive-gray ( $5 Y$ 6/1) to yellowish-gray ( $5 Y 7 / 2)$; quartzose, coarse to very fine, poorly sorted, angular to subrounded; 3 to 5 percent heavy minerals, loose to very fine, poorly sorted, subrounded to rounded; about 40 percent detrital carbonates and shell fragments as above.

Sand, light-olive-gray ( 5 Y $5 / 2$ ); quartzose, medium to very fine, moderately sorted, angular to subangular; 3 to 5 percent heavy minerals and phosphates, medium to very fine, moderately sorted, subrounded to rounded; 30 to 40 percent detrital carbonates and shell fragments. 


\begin{tabular}{|c|c|c|}
\hline $\begin{array}{l}\text { Thick- } \\
\text { ness } \\
\text { (feet) }\end{array}$ & $\begin{array}{l}\text { Depth below } \\
\text { land surface } \\
\text { (feet) }\end{array}$ & Description \\
\hline 7 & $77-84$ & $\begin{array}{l}\text { Sandy shell, yellowish-gray }(5 \mathrm{Y} 7 / 2) \text {; detrital carbonates and shell fragments as } \\
\text { above; } 30 \text { to } 40 \text { percent quartzose, coarse to very fine, poorly sorted, angular to } \\
\text { subrounded; } 3 \text { to } 5 \text { percent heavy minerals and phosphates, coarse to very fine, poorly } \\
\text { sorted, subrounded to rounded; about } 10 \text { percent limestone rock fragments, medium- } \\
\text { bluish-gray }(5 \mathrm{~B} 5 / 1) \text {; sandy, sparse intrasparite; poorly cemented. }\end{array}$ \\
\hline 6 & $84-90$ & Sandy shell, yellowish-gray $(5 Y 7 / 2)$ to light-olive-gray (5 Y $5 / 2)$; as above. \\
\hline 7 & $90-97$ & 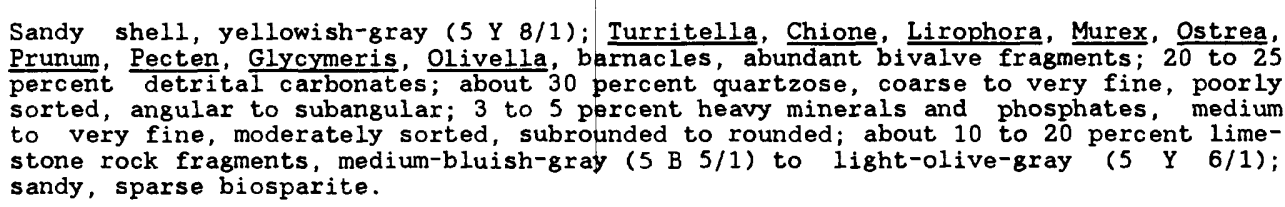 \\
\hline 3 & $97-100$ & $\begin{array}{l}\text { Sand, yellowish-gray }(5 \mathrm{Y} 7 / 2) \text { to olive-gray }(5 \mathrm{Y} 4 / 1) \text {; detrital carbonates, very } \\
\text { coarse to very fine; } 20 \text { to } 25 \text { percent shelis and shell fragments; about } 30 \text { percent } \\
\text { quartzose, medium to very fine, moderately sorted, angular to subangular; } 3 \text { to } 5 \\
\text { percent heavy minerals and phosphates as above; about } 10 \text { to } 20 \text { percent limestone rock } \\
\text { fragments as above. }\end{array}$ \\
\hline 4 & $100-104$ & $\begin{array}{l}\text { Sand, yellowish-gray }(5 \mathrm{Y} 8 / 1) \text {; detrital carbonates and shell fragments, bryozoans, } \\
\text { Cardita, worm shells, Olivella, Terebra, Conus, barnacles, Glycymeris; } 20 \text { to } 30 \\
\text { percent quartzose as above; } 3 \text { to percent heavy minerals as above; } 10 \text { to } 20 \text { percent } \\
\text { limestone rock fragments, medium-bluish-gray }(5 \mathrm{~B} 5 / 1) \text {. }\end{array}$ \\
\hline 3 & $104-107$ & $\begin{array}{l}\text { Sand, light-olive-gray }(5 \mathrm{Y} 6 / 1) \text {; detrital carbonates and shell fragments as above; } \\
30 \text { percent quartzose as above; } 3 \text { to } 5 \text { percent heavy minerals and phosphates, medium } \\
\text { to very fine, moderately sorted, subrounded to rounded. }\end{array}$ \\
\hline 3 & $107-110$ & $\begin{array}{l}\text { Sand, yellowish-gray }(5 \mathrm{Y} 8 / 1) \text { to dark-gray (N } 3) \text {; detrital carbonates and shell } \\
\text { fragments; Iurritella; } 20 \text { to } 30 \text { percent quartzose as above; } 5 \text { to } 10 \text { percent heavy } \\
\text { minerals and phosphates, coarse to very fine, poorly sorted, subrounded to rounded. }\end{array}$ \\
\hline 4 & $110-114$ & $\begin{array}{l}\text { Sand, yellowish-gray }(5 \mathrm{Y} 8 / 1) \text { to medium-dark-gray }(\mathrm{N} 4) \text {; detrital carbonates, very } \\
\text { coarse to very fine; } 20 \text { to } 30 \text { percent shells and shell fragments, Murex, Architecton- } \\
\text { ica, Turritella, Chione, Ostrea, barnacles, Glycymeris, scallops, Anadara, bryozoans, } \\
\text { echinoid plates; about } 20 \text { percent quartzose, medium to very fine, moderately sorted, } \\
\text { angular to subangular; } 3 \text { to } 5 \text { percent heavy minerals and phosphates, medium to very } \\
\text { fine, moderately sorted, subrounded to rounded; about } 5 \text { percent limestone; sandy, } \\
\text { sparse biosparite; poorly cemented; moldic, moderately porous. }\end{array}$ \\
\hline 3 & $114-117$ & Sand as above; 20 to 30 percent quartzose. \\
\hline 3 & $117-120$ & $\begin{array}{l}\text { Sand, light-olive-gray }(5 \mathrm{Y} 6 / 1) \text {; detrital carbonates and shell fragments, echinoid } \\
\text { plates; } 30 \text { to } 40 \text { percent quartzose, medium to very fine, moderately sorted, angular } \\
\text { to subangular; } 5 \text { to } 10 \text { percent heavy minerals and phosphates, medium to very fine, } \\
\text { moderately sorted, subangular to rounded; about } 5 \text { percent limestone nodules; sandy, } \\
\text { sparse biosparite; poorly cemented; moderately porous. }\end{array}$ \\
\hline 10 & $120-130$ & $\begin{array}{l}\text { Sand, light-gray (N } 7 \text { ); quartzose, medium to very fine, moderately sorted, angular to } \\
\text { subangular; about } 20 \text { percent detrital carbonates and shell fragments; } 3 \text { to } 5 \text { percent } \\
\text { heavy minerals and phosphates, coarse to very fine, poorly sorted, subangular to } \\
\text { rounded; about } 10 \text { percent streaks of micrite and silt. }\end{array}$ \\
\hline 4 & $130-134$ & $\begin{array}{l}\text { Sand, light-olive-gray }(5 \mathrm{Y} 6 / 1) \text {; quartzose, medium to very fine, moderately to well } \\
\text { sorted, angular to subrounded; } 10 \text { to } 20 \text { percent detrital carbonates; } 3 \text { t } 5 \text { percent } \\
\text { heavy minerals and phosphates, medium to very fine, subangular to rounded; about } 10 \\
\text { percent micrite and silt; interbedded with about } 10 \text { percent sandstone nodules, light- } \\
\text { olive-gray ( } 5 \mathrm{Y} 5 / 2) \text {; quartzose, fine to very fine, subangular to rounded; } 3 \text { to } 5 \\
\text { percent heavy minerals and phosphates as above, micritic matrix; poorly cemented. }\end{array}$ \\
\hline 3 & $134-137$ & $\begin{array}{l}\text { Sand, light-olive-gray ( } 5 \mathrm{Y} 5 / 2) \text { to yellowish-gray }(5 \mathrm{Y} / / 2) \text {; quartzose as above; } 3 \\
\text { to } 5 \text { percent heavy minerals and phosphates as above; about } 10 \text { percent detrital car- } \\
\text { bonates; about } 20 \text { percent micrite and silt. }\end{array}$ \\
\hline 3 & $137-140$ & Sand, light-olive-gray $(5 Y 6 / 1)$; as above. \\
\hline 10 & $140-150$ & $\begin{array}{l}\text { Sand, light-olive-gray ( } 5 \mathrm{Y} 6 / 1) \text {; quartzose, medium to very fine, moderately sorted, } \\
\text { anguiar to subrounded; } 3 \text { to } 5 \text { percent heavy minerals and phosphates as above; } 10 \\
\text { percent detrital carbonates and shell ffagments; about } 20 \text { percent micrite and silt; } \\
\text { interbedded with about } 10 \text { to } 20 \text { percent limestone, light-olive-gray }(5 \mathrm{Y} 5 / 2) \text { to } \\
\text { medium-light-gray (N } 6) \text {; sandy intramicfite; quartzose, medium to very fine, moder- } \\
\text { ately sorted, angular to subrounded; } 3 \text { to } 5 \text { percent heavy minerals and phosphates, } \\
\text { medium to very fine, moderately sorted, subrounded to rounded; poorly cemented; vugs, } \\
\text { poorly to moderately porous. }\end{array}$ \\
\hline
\end{tabular}


Well PB-1564--Continued

\begin{tabular}{|c|c|c|}
\hline $\begin{array}{l}\text { Thick- } \\
\text { ness } \\
\text { (feet) }\end{array}$ & $\begin{array}{l}\text { Depth below } \\
\text { land surface } \\
\text { (feet) }\end{array}$ & Description \\
\hline 4 & $150-154$ & $\begin{array}{l}\text { Sand, light-gray (N } 7) \text { to light-olive-gray }(5 \mathrm{Y} 6 / 1) \text {; quartzose, medium to very fine, } \\
\text { moderately sorted, angular to subangular; } 3 \text { to } 5 \text { percent heavy minerals and phos- } \\
\text { phates, coarse to very fine, poorly sorted, subangular to rounded; about } 20 \text { percent } \\
\text { detrital carbonates and shell fragments; about } 20 \text { percent micrite, silt and clay. }\end{array}$ \\
\hline 3 & $154-157$ & Sand, light-olive-gray $(5 \mathrm{Y} 5 / 2)$; as above; 20 to 30 percent micrite, silt and clay. \\
\hline 3 & $157-160$ & $\begin{array}{l}\text { Lime mud, light-olive-gray ( } 5 \text { Y } 5 / 2) \text {; micrite, clay and silt; } 30 \text { to } 40 \text { percent } \\
\text { quartzose, medium to very fine, moderately sorted, angular to subrounded; } 10 \text { to } 20 \\
\text { percent detrital carbonates; } 3 \text { to } 5 \text { percent heavy minerals and phosphates, fine to } \\
\text { very fine, well sorted, subrounded to rounded. }\end{array}$ \\
\hline 7 & $160-167$ & $\begin{array}{l}\text { Sand, medium-light-gray (N } 6) \text { to light-olive-gray }(5 \mathrm{Y} 6 / 1) ; \text { quartzose, coarse to } \\
\text { very fine, poorly sorted, subangular to subrounded; } 3 \text { to } 5 \text { percent heavy minerals and } \\
\text { phosphates, medium to very fine, moderately sorted, subrounded to rounded; about } 30 \\
\text { percent detrital carbonates and shell fragment; about } 10 \text { percent micrite and silt; } \\
\text { interbedded with about } 10 \text { to } 20 \text { percent limestone; sandy biomicrite; } 30 \text { to } 40 \text { percent } \\
\text { quartzose as above; } 3 \text { to } 5 \text { percent heavy minerals and phosphates as above; poorly to } \\
\text { moderately cemented; poorly to moderately porous. }\end{array}$ \\
\hline 3 & $167-170$ & $\begin{array}{l}\text { Marl, grayish-olive }(10 \text { y } 4 / 2) \text {; micrite, silt and clay; about } 30 \text { percent quartzose, } \\
\text { fine to very fine, well sorted, angular to subangular; about } 20 \text { percent heavy miner- } \\
\text { als, fine to very fine, well sorted, subrounded to rounded; about } 5 \text { percent detrital } \\
\text { carbonates. }\end{array}$ \\
\hline 4 & $170-174$ & $\begin{array}{l}\text { Sand, light-olive-gray ( } 5 \text { Y } 5 / 2) \text {; quartzose, medium to very fine, moderately sorted, } \\
\text { angular to subrounded; } 5 \text { to } 10 \text { percent heavy minerals and phosphates, fine to very } \\
\text { fine, well sorted, subrounded to rounded; about } 20 \text { percent detrital carbonates and } \\
\text { sheli fragments; about } 20 \text { to } 30 \text { percent marl, micrite, silt and clay. }\end{array}$ \\
\hline 3 & $174-177$ & $\begin{array}{l}\text { Marl, grayish-olive-green ( } 5 \text { GY } 3 / 2 \text { ); micrite, silt and clay; about } 30 \text { percent } \\
\text { quartzose, fine to very fine, well sorted, angular to subrounded; } 5 \text { to } 10 \text { percent } \\
\text { heavy minerals and phosphates, fine to very fine, well sorted, subrounded to rounded; } \\
3 \text { to } 5 \text { percent detrital carbonates. }\end{array}$ \\
\hline 3 & $177-180$ & Marl, grayish-olive ( 10 Y $4 / 2)$; same as above. \\
\hline 7 & $180-187$ & $\begin{array}{l}\text { Marl, grayish-olive }(10 \mathrm{Y} 4 / 2) \text {; micrite, silt and clay; about } 30 \text { percent quartzose, } \\
\text { medium to very fine, moderately sorted, angular to subrounded; } 5 \text { to } 10 \text { percent heavy } \\
\text { minerals and phosphates, fine to very fine, well sorted, subrounded to rounded; about } \\
10 \text { percent detrital carbonates and shell fragments. }\end{array}$ \\
\hline 8 & $187-195$ & Marl, same as above; about 40 percent quartzose. \\
\hline 5 & $195-200$ & $\begin{array}{l}\text { Marl, grayish-olive }(10 \mathrm{Y} 4 / 2) \text {; micrite, silt and clay; about } 30 \text { percent quartzose, } \\
\text { fine to very fine, well sorted, angular to subangular; } 5 \text { to } 10 \text { percent heavy minerals } \\
\text { and phosphates, fine to very fine, well sorted, subrounded to rounded. }\end{array}$ \\
\hline 5 & $200-205$ & $\begin{array}{l}\text { Marl as above; about } 10 \text { percent detrital carbonates and shell fragments, barnacles, } \\
\text { oysters, Tellina, other bivalves. }\end{array}$ \\
\hline 5 & $205-210$ & Marl as in 195 to 200 feet. \\
\hline 4 & $210-214$ & $\begin{array}{l}\text { Marl, grayish-olive }(10 \mathrm{Y} 4 / 2) \text { to } 1 \text { ight-olive-gray }(5 \mathrm{Y} 6 / 1) \text {; micrite, silt and clay; } \\
30 \text { to } 40 \text { percent quartzose as above; } 5 \text { to } 10 \text { percent heavy minerals as above; } 5 \text { to } 10 \\
\text { percent detrital carbonates and shell fragments as above. }\end{array}$ \\
\hline 6 & $214-220$ & $\begin{array}{l}\text { Marl, grayish-olive }(10 \mathrm{Y} 4 / 2) \text {; micrite, silt and clay; about } 30 \text { percent quartzose, } \\
\text { fine to very fine, well sorted, angular to subangular; } 5 \text { to } 10 \text { percent heavy minerals } \\
\text { and phosphates, fine to very fine, well sorted, subrounded to rounded. }\end{array}$ \\
\hline
\end{tabular}


Lat $26^{\circ} 41^{\prime} 01^{\prime \prime}$, long $80^{\circ} 16^{\prime} 30^{\prime \prime}$

Sec. 32, T. 43 S., R. $41 \mathrm{E}$

\begin{tabular}{|c|c|c|}
\hline $\begin{array}{l}\text { Thick- } \\
\text { ness } \\
\text { (feet) }\end{array}$ & $\begin{array}{l}\text { Depth below } \\
\text { land surface } \\
\text { (feet) }\end{array}$ & Description \\
\hline 4 & $0-4$ & $\begin{array}{l}\text { Sand, dark-yellowish-brown }(10 \text { YR } 4 / 2) \text {; quartzose, medium to very fine, moderately } \\
\text { sorted, angular to subrounded; about } 1 \text { percent heavy minerals, fine to very fine, } \\
\text { subrounded to rounded; } 30 \text { to } 40 \text { percent marl; micrite, silt and clay. }\end{array}$ \\
\hline 3 & $4-7$ & $\begin{array}{l}\text { Marl, dark-yellowish-brown ( } 10 \text { YR } 4 / 2) \text {; micrite, silt and clay; about } 40 \text { percent } \\
\text { quartzose, medium to very fine, moderately sorted, angular to subrounded; about } 1 \\
\text { percent heavy minerals as above; interbedded with about } 20 \text { percent limestone, } \\
\text { yellowish-gray ( } 5 \text { Y } 7 / 2) \text {; sandy, packed intramicrite; } 30 \text { to } 40 \text { percent quartzose, } \\
\text { medium to very fine, angular to subrounded; moderately cemented; semiconfining. }\end{array}$ \\
\hline 3 & $7-10$ & $\begin{array}{l}\text { Sand, dark-yellowish-brown }(10 \text { YR } 4 / 2) \text {; quartzose, medium to very fine, moderately } \\
\text { sorted, angular to subangular; about } 1 \text { percent heavy minerals as above; } 5 \text { to } 10 \\
\text { percent detrital carbonates; about } 30 \text { to } 40 \text { percent marl; interbedded with about } 20 \\
\text { percent limestone as above. }\end{array}$ \\
\hline 4 & $10-14$ & $\begin{array}{l}\text { Sandstone, light-olive-gray }(5 Y \mathrm{Y} 6 / 1) \text { to yellowish-gray }(5 \mathrm{Y} 7 / 2) \text {; quartzose, coarse } \\
\text { to very fine, poorly sorted, angular to subrounded; about } 1 \text { percent heavy minerals, } \\
\text { fine to very fine, subangular to rounded; about } 40 \text { percent micritic matrix; moder } \\
\text { ately to well cemented; semiconfining; interbedded with about } 40 \text { percent sand and } \\
\text { shell, Chione. Crepidula, Glycymeris, Cardita, Prunum, Terebra, Turritella; about } 20 \\
\text { percent marl. }\end{array}$ \\
\hline 1 & $14-15$ & $\begin{array}{l}\text { Limestone, yellowish-gray }(5 \mathrm{Y} 7 / 2) \text {; sandy intramicrite; } 30 \text { to } 40 \text { percent quartzose, } \\
\text { coarse to very fine, poorly sorted, angular to subrounded; } 1 \text { percent heavy minerals, } \\
\text { fine to very fine, angular to rounded; well cemented; semiconfining. }\end{array}$ \\
\hline 2 & $15-17$ & $\begin{array}{l}\text { Sand, light-olive-gray }(5 \text { Y } 6 / 1) \text {; quartzose, coarse to very fine, poorly sorted, } \\
\text { angular to subrounded; } 3 \text { to } 5 \text { percent heavy minerals, fine to very fine, well sorted, } \\
\text { subrounded to rounded; } 30 \text { percent shells and shell fragments as in } 10 \text { to } 14 \text { feet. }\end{array}$ \\
\hline 7 & $17-24$ & $\begin{array}{l}\text { Sand, dusky-yellow }(5, Y, 6 / 4) \text { to light-olive-gray ( } 5 \text { Y } 6 / 1) \text {; quartzose, coarse to } \\
\text { fine, moderately sorted, angular to subangular; } 3 \text { to } 5 \text { percent heavy minerals, medium } \\
\text { to fine, well sorted, angular to rounded; } 10 \text { to } 20 \text { percent detrital carbonates and } \\
\text { shell fragments, Chione, olivella, Prunum, coral. }\end{array}$ \\
\hline 3 & $24-27$ & $\begin{array}{l}\text { Sand, light-olive-gray ( } 5 \text { Y } 6 / 1) \text {; quartzose, medium to fine, well sorted, angular to } \\
\text { subangular; } 5 \text { to } 10 \text { percent heavy minerals, medium to fine, well sorted, subrounded } \\
\text { to rounded; about } 10 \text { percent detrital carbonates and shell fragments. }\end{array}$ \\
\hline 3 & $27-30$ & $\begin{array}{l}\text { Sand as above; about } 20 \text { to } 30 \text { percent detrital carbonates and shell fragments; } \text { Ana- } \\
\text { dara, Lirophora, Chione, Prunum, coral, Lucina; interbedded with about } 30 \text { to } 40 \\
\text { percent calcareous quartz sandstone; quartzose, medium to fine, well sorted, angular } \\
\text { to subrounded; } 20 \text { to } 30 \text { percent shells and shell fragments, micritic matrix; } 3 \text { to } 5 \\
\text { percent heavy minerals, fine to very fine, subangular to rounded; moderately ce- } \\
\text { mented; semiporous, vugs. }\end{array}$ \\
\hline 4 & $30-34$ & $\begin{array}{l}\text { Sand, yellowish-gray ( } 5 \text { Y } 8 / 1) \text {; quartzose, coarse to fine, moderately sorted, angular } \\
\text { to subangular; } 5 \text { percent heavy minerals, fine to very fine, well sorted, subrounded } \\
\text { to rounded; } 20 \text { percent detrital carbonates and shell fragments; about } 5 \text { to } 10 \text { percent } \\
\text { sandstone as above; loosely cemented. }\end{array}$ \\
\hline 3 & $34-37$ & $\begin{array}{l}\text { Sand as above; about } 20 \text { to } 30 \text { percent detrital carbonates and shell fragments; inter- } \\
\text { bedded with about } 5 \text { to } 10 \text { percent limestone; sandy, sparse biosparite; very loosely } \\
\text { cemented; moderately to very porous. }\end{array}$ \\
\hline 3 & $37-40$ & $\begin{array}{l}\text { Sand, yellowish-gray }(5 \text { Y } 7 / 2) \text {; quartzose, coarse to very fine, poorly sorted, angu- } \\
\text { lar to subrounded; } 5 \text { to } 10 \text { percent heavy minerals and phosphates, fine to very fine, } \\
\text { well sorted, subrounded to rounded; about } 30 \text { percent detrital carbonates and shells. }\end{array}$ \\
\hline 4 & $40-44$ & Sand, yellowish-gray ( $5 Y$ 8/1) to light-olive-gray $(5 Y 6 / 1)$; as above. \\
\hline 3 & $44-47$ & $\begin{array}{l}\text { Sand, light-olive-gray ( } 5 \text { Y } 5 / 1) \text {; quartzose, medium to silt size, moderately sorted, } \\
\text { angular to subrounded; } 5 \text { to } 10 \text { percent heavy minerals, medium to very fine, moder- } \\
\text { ately sorted, subrounded to rounded; } 30 \text { to } 40 \text { percent detrital carbonates and shell } \\
\text { fragments. }\end{array}$ \\
\hline 3 & $47-50$ & $\begin{array}{l}\text { Limestone, dark-gray ( } \mathrm{N} 3 \text { ); fossiliferous micrite, worm shells, gastropods, bivalves; } \\
\text { interbedded with about } 40 \text { percent sand, yellowish-gray ( } 57 / 2) \text {, quartzose, medium } \\
\text { to silt size, moderately sorted, angular to subangular; } 3 \text { to } 5 \text { percent heavy minerals } \\
\text { and phosphates, medium to very fine, moderately sorted, subrounded to rounded; } 20 \text { to } \\
30 \text { percent detrital carbonates and shell fragments, Chione, Prunum, Busycon, Strom- } \\
\text { bus. }\end{array}$ \\
\hline
\end{tabular}




\begin{tabular}{|c|c|}
\hline $\begin{array}{l}\text { Thick- } \\
\text { ness } \\
\text { (feet) }\end{array}$ & $\begin{array}{l}\text { Depth bel } \\
\text { land surf } \\
\text { (feet) }\end{array}$ \\
\hline 4 & $50-5$ \\
\hline 3 & $54-5$ \\
\hline 3 & $57-6$ \\
\hline 4 & $60-\varepsilon$ \\
\hline 3 & $64-6$ \\
\hline 7 & $67-7$ \\
\hline 3 & $74-7$ \\
\hline 3 & $77-8$ \\
\hline 4 & $80-84$ \\
\hline
\end{tabular}

Description

Shells and shell fragments, yellowish-gray ( 5 Y 7/2) to light-olive-gray (5 Y 6/1); Strombus, Chione, Aequipecten, Cardita, Epitonium, Planorbis, abundant mollusk; 10 to 20 percent detrital carbonates, very coarse to medium; 30 percent quartzose, coarse to silt size, poorly sorted, angular to subrounded; 5 to 10 percent heavy minerals, medium to very fine, moderately sorted, subrounded to rounded; interbedded with about 30 to 40 percent limestone as above.

Shells and shell fragments as above; interbedded with about 20 to 30 percent limestone, (5 Y 6/1); sandy, sparse biomicrite; 30 percent quartz, medium to very fine, angular to subrounded; 5 to 10 percent heavy minerals, fine to very fine, subrounded to rounded; poorly cemented; poorly porous.

Limestone, medium-dark-gray (N 4 ) to yellowish-gray ( $5 \mathrm{Y} 7 / 2$ ); sandy, fossilifeorus micrite; 5 to 10 percent quartz, coarse to fine, angular to subrounded; moderately to well cemented; poorly porous; interbedded with about 30 percent sand, yellowish-gray ( $5 \mathrm{Y} 7 / 2$ ) to light-olive-gray ( $5 \mathrm{Y} 7 / 2)$; quartzose, coarse to very fine, poorly sorted, angular to subrounded; 3 to 5 percent heavy minerals, medium to very fine, moderately sorted, subrounded to rounded; 5 to 10 percent micrite; 30 to 40 percent detrital carbonates and shell fragments, Chione, Glycymeris, Prunum, Turritella.

Sand, yellowish-gray (5 Y 8/1) to medium-gray (N 5); quartzose, coarse to fine, moderately sorted, angular to subrounded; 30 to 40 percent detrital carbonates and shell fragments as above; interbedded with about 30 percent limestone as in 57 to 60 feet.

Sandy shell, light-olive-gray (5 Y 5/2); Turritella, Chione, barnacles, abundant bivalves; 0 to 20 percent detrital carbonates, very coarse to very fine; 20 to 30 percent quartzose as above; 5 to 10 percent heavy minerals, medium to very fine, moderately sorted, subrounded to rounded.

Sand, yellowish-gray ( 5 Y 7/2); quartzose, medium to fine, well sorted, angular to subrounded; 5 to 10 percent heavy minerals, medium to fine, well sorted, subrounded to rounded; 30 percent detrital carbonates and shell fragments, echinoid plates.

Sand as above; Chione, Conus, Prunum, barnacles.

Sand as above; 30 to 40 percent detrital carbonates and shell fragments, Busycon, Cancellaria.

Sandy shell, yellowish-gray (5 Y 7/2) to medium-dark-gray (N 4); detrital carbonates and shells, Conus, Turritella, Chione, Busycon, abundant mollusks; 30 to 40 percent quartzose, coarse to fine, moderately sorted, angular to subangular; 5 to 10 percent heavy minerals, medium to fine, well sorted, subrounded to rounded; interbedded with about 10 to 20 percent limestone, medium-dark-gray (N 4); sandy, sparse biosparite; about 30 percent quartz, medium to very fine, angular to subrounded; 5 percent heavy minerals, medium to fine, subrounded to rounded; poorly cemented; moderately porous.

Sandy shell as above; echinoid plates.

Sand, light-olive-gray ( 5 Y $6 / 1$ ); quartzose, coarse to fine, moderately sorted, angular to subangular; 5 to 10 percent heavy minerals, coarse to fine, moderately sorted, subrounded to rounded; 30 to 40 percent detrital carbonates and shell fragments.

Sandy shell, yellowish-gray $(5 Y 7 / 2)$ to light-olive-gray ( 5 Y 6/1); detrital carbonates and shell fragments, Busycon, Cancellaria, scallops, olivella, abundant bivalvia, Crepidula; 30 to 40 percent quartzose, coarse to fine as above; 5 to 10 percent heavy minerais, coarse to fine as above; interbedded with about 10 percent limestone, medium-light-gray (N 6); sandy, sparse biomicrite; about 10 percent quartz, coarse to fine; 3 to 5 percent heavy minerals, medium to fine; moderately cemented.

Sandy shell as above; Turritella, Architectonica.

Sandy shell, yellowish-gray (5 Y 7/2); detrital carbonates and shell fragments, Oliva, Cancellaria, Terebra, Chione, Solen, Chlamys, worm shells, Turritella, barnacles, abundant bivalvia; 30 to 40 percent quartzose, medium to very fine, moderately sorted, angular to subrounded; 5 to 10 percent heavy minerals, coarse to very fine, poorly sorted, subangular to rounded; about 10 percent calcareous concretions.

Sandy shell, yellowish-gray ( 5 Y $8 / 1$ ); detrital carbonates and shell fragments; 20 to 30 percent quartzose as above; 3 to 5 percent heavy minerals as above.

$3 \quad 107-110$

Sandy shell as in 100 to 104 feet.

$4 \quad 110-114$

Sandy shell, yellowish-gray (5 Y $7 / 2$ ); detrital carbonates and shell fragments; abundant bivalves, Turritella, bryozoans; 30 to 40 percent quartzose, coarse to very fine, poorly sorted, angular to subangular; 5 to 10 percent heavy minerals, medium to very fine, subrounded to rounded. 


\begin{tabular}{ccc}
\hline $\begin{array}{c}\text { Thick- } \\
\text { ness } \\
\text { (feet) }\end{array}$ & $\begin{array}{c}\text { Depth below } \\
\text { land surface } \\
\text { (feet) }\end{array}$ & Description \\
\hline
\end{tabular}

$3 \quad 117-120$

$7 \quad 120-127$

Sand, light-olive-gray ( 5 Y 6/1); quartzose as above; 3 to 5 percent heavy minerals as above; 30 to 40 percent detrital carbonates and sheil fragments.

Sand, light-olive-gray ( 5 Y 6/1); quartzose, medium to very fine, moderately sorted, angular to subrounded; 5 to 10 percent heavy minerals, medium to very fine, subrounded to rounded; 30 to 40 percent detrital carbonates and shell fragments; about 5 percent calcareous concretions

$3 \quad 127-130$

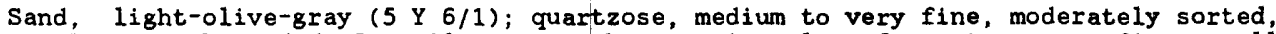
angular to subrounded; 5 to 10 percent heavy minerals, fine to very fine, well sorted, subrounded to rounded; 30 to 40 percent detrital carbonates and sheli fragments.

$4 \quad 130-134$

Sandy shell, yellowish-gray ( 5 Y 8/1) to medium-gray (N 5); detrital carbonates and shell fragments, Turritella, barnacles, bryozoans, scallops, abundant bivalvia; 30 to 40 percent quartzose, coarse to very fine, poorly sorted, angular to subrounded; 5 to 10 percent heavy minerals, fine to very fine, well sorted, subrounded to rounded.

Sand, light-olive-gray (5 Y 5/2); quartzose, fine to very fine, well sorted, angular to subrounded; 5 to 10 percent heavy minerals, fine to very fine, well sorted, subrounded to rounded; 30 to 40 percent detrital carbonates (medium to very fine) and shell fragments.

Sand, light-olive-gray ( 5 Y 6/1); quartzose, medium to very fine, moderately sorted, angular to subrounded; 5 to 10 percent heavy minerals, medium to very fine, subrounded to rounded; 30 to 40 percent detrital carbonates and shell fragments; 5 to 10 percent micrite, silt and clay

Sand, yellowish-gray (5 Y 8/1); quartzose, coarse to medium, well sorted, subangular to subrounded; 3 to 5 percent heavy minerals, coarse to very fine, poorly sorted, subrounded to rounded; 10 to 20 percent detrital carbonates and shell fragments, bryozoans, Busycon, scallops, and other bivalves; interbedded with 10 percent sandstone; quartz, coarse to medium, subangular to subrounded; 3 to 5 percent heavy minerals; 10 to 20 percent detrital carbonates and shell fragments, sparite matrix.

Sandstone, yellowish-gray (5 Y 8/1); grading into limestone in places; quartz, coarse to medium, well sorted, angular to subrounded; 3 to 5 percent heavy minerals, coarse to fine, moderately sorted, subrounded to rounded; 20 to 30 percent detrital carbonates and shell fragments, sparite matrix.

Sand as in 140 to 144 feet; with 10 percent sandstone.

Sand, yellowish-gray ( 5 Y 8/1); quartzose, coarse to medium, well sorted, angular to subrounded; about 5 percent heavy minerals, coarse to fine, moderately sorted, subrounded to rounded; 35 to 40 percent detrital carbonates and shell fragments; about 10 percent loosely consolidated sand.

Sand as above; about 20 percent limestone, yellowish-gray ( $5 \mathrm{Y} 8 / 1)$; sandy, sparse biosparite; about 40 percent quartz as above; about 5 percent heavy minerals as above; about 5 percent heavy minerals as above; moderately cemented; moderately porous.

$3 \quad 157-160$

Sand, yellowish-gray ( $5 \mathrm{Y} 8 / 1$ ); quartzose, coarse to medium, subangular to rounded, well sorted; 5 to 10 percent heavy minerals, coarse to medium, well sorted, subrounded to rounded; 25 to 30 percent detrital carbonates and shell fragments.

Sand, yellowish-gray ( 5 Y 8/1); quartzose as above; 5 to 10 percent heavy minerals as above; 30 to 40 percent detrital carbonates and shell fragments; about 20 percent loosely consolidated sandstone.

Sand, yellowish-gray ( $5 \mathrm{Y} 8 / 1$ ); quartzose, coarse to very fine, poorly sorted, angular to subrounded; 5 to 10 percent heavy minerals and phosphates, coarse to fine, subangular to rounded; moderately sorted; 20 to 30 percent detrital carbonates and shell fragments; about 10 percent micrite and silt, light-olive-gray $(5 \mathrm{Y} 5 / 2)$; interbedded with about 20 to 30 percent limestone, yellowish-gray ( 5 Y 7/2); sandy, packed biosparite, bivalvia; 30 percent quartz, medium to very fine, angular to subangular; 5 to 10 percent heavy minerals, medium to very fine, angular to subrounded; very porous; moderately cemented.

Sand light-olive-gray ( 5 Y $5 / 2$ ); quartzose, medium to very fine, moderately sorted, angular to subrounded; 10 percent heavy minerals, medium to very fine, subangular to rounded; about 30 percent detrital carbonates and shell fragments; about 10 to 20 percent silt and micrite. 


\begin{tabular}{|c|c|c|}
\hline $\begin{array}{l}\text { Thick- } \\
\text { ness } \\
\text { (feet) }\end{array}$ & $\begin{array}{l}\text { Depth below } \\
\text { land surface } \\
\text { (feet) }\end{array}$ & Description \\
\hline 3 & $174-177$ & $\begin{array}{l}\text { Sand, light-olive-gray ( } 5 \text { y } 5 / 2) \text {; quartzose, medium to very fine, moderately sorted, } \\
\text { angular to subrounded; } 5 \text { to } 10 \text { percent heavy minerals, medium to very fine, subangu- } \\
\text { lar to rounded; } 20 \text { to } 30 \text { percent detrital carbonates and shell fragments; } 20 \text { percent } \\
\text { silt and micrite. }\end{array}$ \\
\hline 3 & $177-180$ & $\begin{array}{l}\text { Sand, light-olive-gray }(5 \text { Y } 5 / 2) \text { to pale-olive }(10 \mathrm{Y} 6 / 2) \text {; quartzose, fine to very } \\
\text { fine, well sorted, angular to subrounded; } 5 \text { to } 10 \text { percent heavy minerals, fine to } \\
\text { very fine, well sorted, angular to rounded; about } 5 \text { percent shell fragments; } 20 \text { to } 30 \\
\text { percent silt and micrite. }\end{array}$ \\
\hline 4 & $180-184$ & $\begin{array}{l}\text { Sand, 1ight-olive-gray }(5 \mathrm{Y} 6 / 1) \text {; quartzose as above; } 5 \text { to } 10 \text { percent heavy minerals } \\
\text { as above; } 10 \text { to } 20 \text { percent detrital carbonates and shell fragments; about } 5 \text { to } 10 \\
\text { percent silt and micrite. }\end{array}$ \\
\hline 6 & $184-190$ & $\begin{array}{l}\text { Sand, light-olive-gray }(5 \text { Y } 5 / 2) \text {; quartzose as above; } 5 \text { to } 10 \text { percent heavy minerals } \\
\text { as above; } 5 \text { to } 10 \text { percent detrital carbonates and sheil fragments; } 20 \text { to } 30 \text { percent } \\
\text { silt and micrite. }\end{array}$ \\
\hline
\end{tabular}


We11 PB-1583

Lat $26^{\circ} 40^{\prime} 57^{\prime \prime}$, long $80^{\circ} 15^{\prime} 10^{\prime \prime}$

Sec. 28, T. 43 S., R. $41 \mathrm{E}$.

\begin{tabular}{ccc}
\hline $\begin{array}{c}\text { Thick- } \\
\text { ness } \\
\text { (feet) }\end{array}$ & $\begin{array}{c}\text { Depth below } \\
\text { land surface } \\
\text { (feet) }\end{array}$ & Description \\
\hline
\end{tabular}

40 - 4 Sand, dark-yellowish-brown (10 YR 4/2); quartzose, coarse to fine, moderately sorted, angular to subangular; 1 to 3 percent heavy minerals, medium to fine, subrounded to rounded; about 25 percent organic mud, micrite, silt, and clay.

3 4- 7 Marl, dark-yellowish-brown (10 YR 4/2); silt, clay, and micrite; sand as above from 5 to 7 feet.

$7 \quad 7-14$ Sand, dark-yellowish-gray (10 YR 4/2); quartzose, medium to very fine, moderately sorted, angular to subangular; 1 percent heavy minerals, fine to very fine, subrounded to rounded; about 25 percent organic mud, silt and clay size.

$3 \quad 14-17$ Sand as above; 10 to 20 percent mud, silt size.

$6 \quad 17-24$

Sand, pale-yellowish-brown (10 YR 6/2); quartzose, medium to very fine, moderately sorted, angular to subrounded; 1 percent heavy minerals, fine to very fine, subrounded to rounded; 10 to 20 percent mud, silt size; 70 percent marl from 18 to 20 feet.

$624-30$ Sand, dark-yellowish-brown (10 YR 4/2); quartzose as above; 1 percent heavy minerals as above; 10 to 20 percent mud, silt size.

$430-34$

Sand, dark-yellowish-gray (10 YR 4/2); quartzose, medium to very fine, moderately sorted, angular to subrounded; 1 to 3 percent heavy minerals, fine to very fine, subrounded to rounded, well sorted; about 3 percent carbonates, medium to very fine, angular to rounded; about 20 percent mud, silt size.

$3 \quad 34-37$

Marl, light-olive-gray ( $5 \mathrm{Y} 5 / 2$ ) to light-olive-brown ( $5 \mathrm{Y} 5 / 6)$; silt and clay; 40 percent quartzose, medium to very fine, moderately to well sorted, angular to subangular; 5 percent heavy minerals, medium to very fine, moderately sorted, subrounded to rounded; 1 to 3 percent carbonates, medium to very fine, angular to rounded; about 10 percent sandstone, olive-gray ( 5 Y $4 / 1$ ); quartz, medium to very fine, angular to subrounded to rounded; micritic matrix; moderately cemented; slightly porous.

$3 \quad 37-40$

Limestone, medium-dark-gray (N 4); sandy, fossiliferous sparite, calcite molds, Chione and other mollusks: 20 percent quartz, fine to very fine, angular to subrounded; $\frac{1}{3}$ percent heavy minerals, fine to very fine, subrounded to rounded; moderately to partially cemented; moldic, vugs, moderately porous to good porosity; interbedded with about 40 to 50 percent sand, light-olive-gray ( 5 Y 5/2); quartzose, fine to very fine, well sorted, angular to subangular; 5 percent heavy minerals, fine to very fine, subrounded to rounded; about 10 percent detrital carbonate fragments, medium to very fine; about 20 percent lime mud, silt size.

imestone, light-gray (N 7); sandy, sparse biosparite, well worn mollusk fragments; 20 to 30 percent quartz, fine to very fine, angular to subangular; 5 to 10 percent heavy minerals, fine to very fine, subrounded to rounded; moderately cemented; moderately porous to good porosity; interbedded with about 40 percent sand; quartzose, fine to very fine, well sorted, angular to subangular; 5 to 10 percent heavy minerals medium to very fine, subrounded to rounded; 40 percent detrital carbonate and sheil fragments, coarse to very fine, angular to rounded.

$3 \quad 44-47$

Limestone as above; gravel and concretions.

$7 \quad 47-54$

Sandstone, light-gray (N 7); gravel and concretions; quartzose, fine to very well sorted, angular to subangular; 5 to 10 percent heavy minerals, fine to very fine, well sorted, subrounded to roumded; 20 percent carbonate and shell fragments, medium to very fine; sparite matrix; well cemented; nodules and gravel; slightly to moderately porous; about 30 percent sand as above.

$654-60$

Limestone, light-gray (N 7 ); sandy, sparse biosparite, Turritella, abundant bivalvia; abundant calcite molds present; about 30 to 40 percent quartz, medium, well sorted, subangular to subrounded; about 10 percent heavy minerals and phosphates, coarse to fine, poorly sorted, subrounded to rounded; cavity-riddled gravel; moldic, good porosity; interbedded with about 20 to 30 percent sand; quartzose, medium to fine, well sorted, angular to subrounded; 10 percent heavy minerals and phosphates, coarse to fine, poorly sorted, subrounded to rounded; about 30 percent carbonates.

$460-64$

Limestone, yellowish-gray (5 Y 8/1) to medium-gray (N 5); sandy, sparse biosparite (biomicrite in places), barnacles, bivalvia; 20 to 30 percent quartzose, coarse to fine, poorly sorted, angular to subrounded; 5 to 10 percent heavy minerals and phosphates, coarse to fine, poorly sorted, subrounded to rounded; moderately cemented. cavity-riddled gravel; good porosity; interbedded with about 20 to 30 percent sand as above; quartzose, coarse to fine. 


\begin{tabular}{ccc}
\hline $\begin{array}{c}\text { Thick- } \\
\text { ness } \\
\text { (feet) }\end{array}$ & $\begin{array}{c}\text { Depth below } \\
\text { land surface } \\
\text { (feet) }\end{array}$ & Description \\
\hline
\end{tabular}

Limestone as above; interbedded with 20 to 30 percent sand; quartzose, coarse to fine, poorly sorted, angular to subrounded; 5 to 10 percent heavy minerals and phosphates, coarse to fine, poorly sorted, subrounded to rounded; about 30 percent detrital carbonates and shell fragments, bryozoans, Balanus, Anadara, Chione, Corbula.

Limestone, light-gray (N 7) to yellowish-gray ( 5 Y $7 / 2$ ); sandy, sparse biosparite; 20 to 30 percent quartzose, medium to fine, angular to subangular; 5 to 10 percent heavy minerals and phosphates, coarse to fine, subrounded to rounded; loosely cemented; cavity-riddled gravel; good porosity; interbedded with 30 percent sand and shell; quartzose, coarse to fine, angular to subrounded; 5 to 10 percent heavy minerals and phosphates, coarse to fine, subrounded to rounded; 30 to 40 percent detrital carbonates and shells, Busycon, Conopeum, Chione, shark teeth, Terebra, Turritella, Chlamys.

Calcareous sand, very light gray (N 8) to yellowish-gray (5 Y 8/1); quartzose, coarse to fine, poorly sorted, angular to subrounded; 5 to 10 percent heavy minerals and phosphates, coarse to fine, poorly sorted, subrounded to rounded; 30 to 40 percent detrital carbonates and shells, Turritella, Chione, Olivella, Tellina, Cardita, Chlamys, Terebra; interbedded with about 5 to 10 percent limestone nodules; sandy, packed biosparite.

Calcareous sand, yellowish-gray ( 5 Y 8/1); quartzose, coarse to fine, poorly sorted, angular to subrounded; 5 to 10 percent heavy minerals and phosphates, coarse to fine, poorly sorted, subrounded to rounded; about 40 percent detrital carbonates and shells, Chione, Turritella, Conus, Chlamys, Cancellaria, barnacles, olivella.

Calcareous sand, yellowish-gray ( 5 Y 8/1) to medium-dark-gray (N 4); as above.

$3 \quad 87-90$

Calcareous sand, medium-dark-gray (N 4); quartzose, medium to fine, moderately sorted, angular to subrounded; 5 to 10 percent heavy minerals and phosphates, coarse to fine, poorly sorted, subrounded to rounded; 40 percent detrital carbonates and shell fragments, Cancellaria, Turritella, Glycymeris, Echinochama, Prunum, Balanus, Septastrea, Plicatula, Chione

Calcareous sand, yellowish-gray ( $5 \mathrm{Y} 8 / 1$ ); quartzose, coarse to fine, poorly sorted, angular to subrounded; 5 to 10 percent heavy minerals and phosphates, coarse to fine, poorly sorted, subrounded to rounded; about 40 percent detrital carbonates and shell fragments, Glycymeris, Turritella, Prunum, Plicatula, Terebra, Cardita, Olivella, Lucina.

Calcareous sand as above; Chione, Turritella, Terebra, Balanus, Conus, Oliva, Plicatula, Corbula, Lucina, Strombus, worm shells, echinoid spines; interbedded with about 20 percent limestone rock fragments; sandy, sparse biosparite; 20 to 30 percent quartzose, coarse to fine, angular to subrounded; 5 to 10 percent heavy minerals and phosphates, medium to fine, subrounded to rounded; loosely cemented; moderately porous.

Limestone, medium-dark-gray (N 4) to yellowish-gray ( 5 Y 8/1); sandy, sparse biosparite, mollusks: 20 to 30 percent quartzose, medium to fine, moderately sorted, angular to subrounded; 3 to 5 percent heavy minerals and phosphates, medium to fine, moderately sorted, subrounded to rounded; moderately cemented; moderately porous; interbedded with about 30 to 40 percent calcareous sand; 40 percent quartzose, coarse to fine, poorly sorted, angular to subrounded; 5 to 10 percent heavy minerals and phosphates, coarse to fine, poorly sorted, subrounded to rounded; detrital carbonates and shell fragments, Cancellaria, Busycon, Corbula, Balanus, Turritella.

Calcareous sand, medium-dark-gray ( $N$ 4) to yellowish-gray ( $Y$ Y $8 / 1$ ) as above; interbedded with about 20 to 30 percent limestone as above.

Limestone, medium-gray (N 5); sandy, sparse biosparite, mollusks; 30 to 40 percent quartzose, coarse to fine, poorly sorted, angular to subrounded; 5 percent heavy minerals and phosphates, medium to fine, moderately sorted, subrounded to rounded: very well cemented; moldic, very porous; interlayered with about 20 to 30 percent sand; quartzose, coarse to fine, poorly sorted, angular to subrounded; 5 to 10 percent heavy minerals and phosphates, coarse to fine, poorly sorted, subrounded to rounded; about 30 percent detrital carbonates and shell fragments.

Calcareous sand, yellowish-gray ( $5 \mathrm{Y} \mathrm{8/1)} \mathrm{to} \mathrm{medium-gray} \mathrm{(N} \mathrm{5);} \mathrm{quartzose,} \mathrm{medium} \mathrm{to}$ fine, moderately sorted, angular to subrounded; 5 to 10 percent heavy minerals and phosphates, coarse to fine, poorly sorted, subrounded to rounded; 30 to 40 percent detrital carbonates and shell fragments, barnacles, Olivella, bivalves. 


\begin{tabular}{|c|c|c|}
\hline $\begin{array}{l}\text { Thick- } \\
\text { ness } \\
\text { (feet) } \\
\end{array}$ & $\begin{array}{c}\text { Depth below } \\
\text { land surface } \\
\text { (feet) }\end{array}$ & Description \\
\hline 4 & $120-124$ & $\begin{array}{l}\text { Calcareous sand, yellowish-gray ( } 5 \text { Y } 8 / 1) \text { to } 1 \text { ight-olive-gray ( } 5 \text { Y } 5 / 2) \text {; quartzose, } \\
\text { coarse to fine, poorly sorted, angular to subrounded; } 5 \text { to } 10 \text { percent heavy minerals } \\
\text { and phosphates, coarse to fine, poorly sorted, subrounded to rounded; } 30 \text { to } 40 \text { per- } \\
\text { cent detrital carbonates and sheil fragments; interbedded with about } 10 \text { to } 20 \text { percent } \\
\text { limestone rock fragments; sandy, sparse biosparite to biomicrite. }\end{array}$ \\
\hline 3 & $124-127$ & $\begin{array}{l}\text { Calcareous sand as above; interbedded with about } 25 \text { percent limestone; sandy, sparse } \\
\text { biomicrite to biosparite; } 30 \text { percent quartzose, coarse to fine, poorly sorted, an- } \\
\text { gular to subrounded; } 5 \text { to io percent heavy minerais and phosphates, coarse to fine, } \\
\text { poorly sorted, subrounded to rounded; loosely cemented; moldic, good porosity. }\end{array}$ \\
\hline 3 & $127-130$ & $\begin{array}{l}\text { Calcareous sand, yellowish-gray }(5 \mathrm{Y} 8 / 1) \text { as above; with about } 5 \text { to } 10 \text { percent lime- } \\
\text { stone rock fragments, light-olive-gray }(5 \mathrm{Y} 5 / 2) \text { as above. }\end{array}$ \\
\hline 4 & $130-134$ & Calcareous sand with limestone rock fragments as above. \\
\hline 6 & $134-140$ & $\begin{array}{l}\text { Calcareous sand, yellowish-gray ( } 5 \text { Y } 8 / 1) \text {; quartzose, coarse to fine, poorly sorted, } \\
\text { subrounded to rounded; } 5 \text { to } 10 \text { percent heavy minerals and phosphates, coarse t fine, } \\
\text { poorly sorted, subrounded to rounded; about } 30 \text { percent detrital carbonates and shell } \\
\text { fragments. }\end{array}$ \\
\hline 7 & $140-147$ & $\begin{array}{l}\text { Calcareous sand, very light gray }(N) \text { to yellowish-gray }(5 \mathrm{Y} 8 / 1) \text {; quartzose, coarse } \\
\text { to medium, subangular to rounded; } 5 \text { to } 10 \text { percent heavy minerals and phosphates as } \\
\text { above; } 20 \text { to } 30 \text { percent detrital carbonates and shell fragments; interbedded with } \\
\text { about } 20 \text { to } 30 \text { percent limestone; sandy, sparse biosparite; } 30 \text { percent quartzose, } \\
\text { coarse to medium, subangular to rounded; } 5 \text { to } 10 \text { percent heavy minerals and phos- } \\
\text { phates, coarse t fine, subrounded to rounded; loosely cemented; moldic, good poros- } \\
\text { ity. }\end{array}$ \\
\hline 3 & $147-150$ & $\begin{array}{l}\text { Calcareous sand, light-gray }(\mathrm{N} 7) \text { to yellowish-gray }(5 \mathrm{Y} 8 / 1) \text {; quartzose, coarse to } \\
\text { medium, moderately sorted, subangular to rounded; } 5 \text { to } 10 \text { percent heavy minerals and } \\
\text { phosphates, coarse to fine, poorly sorted, subrounded to rounded; about } 30 \text { percent } \\
\text { detrital carbonates and shell fragments, Balanus, Chlamys; about } 5 \text { percent micrite, } \\
\text { silt and clay, light-olive-gray }(5 \mathrm{Y} 5 / 2) \text {. }\end{array}$ \\
\hline 4 & $150-154$ & $\begin{array}{l}\text { Calcareous sand as above with grayish-olive (10 Y } 4 / 2) \text {; silt, clay and micrite in- } \\
\text { creasing. }\end{array}$ \\
\hline 3 & $154-157$ & $\begin{array}{l}\text { Calcareous sand, very light gray (N } 8) \text { to yellowish-gray ( } 5 \text { Y } 8 / 1) \text {; quartzose, coarse } \\
\text { to fine, poorly sorted, subangular to rounded; } 5 \text { to } 10 \text { percent phosphates as above; } \\
20 \text { to } 30 \text { percent detrital carbonates and shell fragments, Conus, echinoid plate, } \\
\text { Balanus; about } 10 \text { percent micrite, silt and clay, grayish-olive (10Y } 4 / 2) \text {. }\end{array}$ \\
\hline 3 & $157-160$ & Calcareous sand as above; 20 percent silt, clay and micrite. \\
\hline 4 & $160-164$ & $\begin{array}{l}\text { Sand, very light gray (N } 8) \text { to light-olive-gray ( } 5 \text { Y } 5 / 2) \text {; quartzose, coarse to fine, } \\
\text { pooriy sorted subangular to subrounded; } 10 \text { percent heavy minerals and phosphates, } \\
\text { coarse to fine, poorly sorted, subrounded to rounded; about } 20 \text { percent detritai } \\
\text { carbonates and shell fragments, Conqs, Balanus; about } 20 \text { percent silt, clay and } \\
\text { micrite. }\end{array}$ \\
\hline 6 & $164-170$ & $\begin{array}{l}\text { Silty sand, grayish-olive }(10 \mathrm{Y} 4 / 2) \text {; about } 40 \text { percent micrite, silt and clay; } \\
\text { quartzose, medium to very fine moderately sorted, angular to rounded; } 5 \text { to } 10 \text { percent } \\
\text { heavy minerals and phosphates, medium to very fine, moderately sorted, subrounded to } \\
\text { rounded; } 3 \text { to } 5 \text { percent detrital carbonates. }\end{array}$ \\
\hline 7 & $170-177$ & Silty sand as above; with silt and clay increasing. \\
\hline 3 & $177-180$ & $\begin{array}{l}\text { Silty sand, grayish-olive }(10 \mathrm{Y} 4 / 2) \text {; quartzose, fine to very fine, angular to suban- } \\
\text { gular, well sorted; about } 40 \text { percent } \$ \text { ilt, clay and lime mud; } 5 \text { to } 10 \text { percent heavy } \\
\text { minerals and phosphates, medium to very fine, moderately sorted, subrounded to } \\
\text { rounded; about } 5 \text { to } 10 \text { percent detrital carbonates and shell fragments, medium to } \\
\text { very fine, well worn. }\end{array}$ \\
\hline 10 & $180-190$ & $\begin{array}{l}\text { Sandy clay, grayish-olive }(10 \mathrm{Y} 4 / 2) \text {; silt, clay, and micrite; about } 30 \text { to } 40 \text { percent } \\
\text { quartzose as above; } 5 \text { to } 10 \text { percent heavy minerais and phosphates, fine to very fine, } \\
\text { well sorted, subrounded to rounded; } 3 \text { to } 5 \text { percent carbonates and shell fragments, } \\
\text { fine to very fine, well worn. }\end{array}$ \\
\hline
\end{tabular}




\begin{tabular}{|c|c|c|}
\hline $\begin{array}{l}\text { Thick- } \\
\text { ness } \\
\text { (feet) }\end{array}$ & $\begin{array}{l}\text { Depth below } \\
\text { land surface } \\
\text { (feet) }\end{array}$ & Description \\
\hline 4 & $0-4$ & $\begin{array}{l}\text { Organic soil, dusky-brown }(5 \mathrm{YR} 2 / 2) \text {; quartzose, medium to very fine, moderately } \\
\text { sorted, angular to subangular; organic mud and debris. }\end{array}$ \\
\hline 3 & $4-7$ & $\begin{array}{l}\text { Marl, olive-gray ( } 5 \text { Y } 4 / 1 \text { ); silt and clay; quartzose, fine to very fine, well sorted, } \\
\text { angular to subrounded; about } 30 \text { to } 40 \text { percent shells, Chione, Anadara, Terebra, Tel- } \\
\text { lina, Cardita, Marginella, Busycon. }\end{array}$ \\
\hline 3 & $7-10$ & Marl as above; about 30 percent shells. \\
\hline 4 & $10-14$ & $\begin{array}{l}\text { Marl, olive-gray ( } 5 \text { Y } 4 / 1 \text { ); silt and clay; quartzose, fine to very fine, well sorted, } \\
\text { anguiar to subrounded; } 1 \text { percent heavy minerals, very fine, subrounded to rounded; } 25 \\
\text { percent shells and shell fragments. }\end{array}$ \\
\hline 3 & $14-17$ & Marl as above; about 10 to 20 percent shells and shell fragments. \\
\hline 7 & $17-24$ & $\begin{array}{l}\text { Muddy sand, dark-yellowish-brown ( } 10 \text { YR } 4 / 2) \text { to } 1 \text { ight-olive-gray }(5 \mathrm{Y} 5 / 2) \text {; quartz- } \\
\text { ose, fine to very fine, well sorted, angular to subangular; about } 25 \text { percent silt and } \\
\text { clay; } 1 \text { to } 3 \text { percent heavy minerals as above; about } 1 \text { to } 3 \text { percent shell fragments. }\end{array}$ \\
\hline 3 & $24-27$ & $\begin{array}{l}\text { Muddy sand, light-olive-gray ( } 5 \text { Y } 5 / 2) \text {; quartzose as above; } 1 \text { to } 3 \text { percent heavy min- } \\
\text { erals as above; } 10 \text { to } 20 \text { percent silt and clay. }\end{array}$ \\
\hline 3 & $27-30$ & Muddy sand, light-olive-gray ( 5 Y $5 / 2$ ) to dark-yellowish-brown ( 10 YR $4 / 2$ ); as above. \\
\hline 4 & $30-34$ & Muddy sand, dark-yellowish-brown ( 10 YR $4 / 2$ ). \\
\hline 3 & $34-37$ & $\begin{array}{l}\text { Limestone, medium-light-gray }(N, 6) \text {; sandy, sparse biosparite; about } 40 \text { percent } \\
\text { quartzose, fine to very fine, well sorted, angular to subrounded; } 1 \text { to } 3 \text { percent } \\
\text { heavy minerals, fine to very fine, well sorted, subrounded to rounded; well cemented; } \\
\text { very porus. }\end{array}$ \\
\hline 3 & $37-40$ & $\begin{array}{l}\text { Limestone as above; interlayered with sand; quartzose, fine to very fine, well } \\
\text { sorted, angular to subangular; } 3 \text { to } 5 \text { percent heavy minerals, fine to very fine, well } \\
\text { sorted, subrounded to rounded; about } 10 \text { to } 20 \text { percent calcite. }\end{array}$ \\
\hline 7 & $40-47$ & $\begin{array}{l}\text { Sandy limestone, light-gray }(N 7) \text { to medium-dark-gray }(N 4) \text {; sandy, sparse biospar- } \\
\text { ite, abundant calcite; } 20 \text { to } 30 \text { percent quartzose, medium to fine, moderately sorted, } \\
\text { angular to subrourded; } 3 \text { percent heavy minerals, fine to very fine, well sorted, sub- } \\
\text { rounded to rounded; moderately cemented gravel; very porous; interbedded with about } \\
40 \text { to } 50 \text { percent sand; quartzose, medium to fine, moderately to well sorted, angular } \\
\text { to subrounded; } 3 \text { to } 5 \text { percent heavy minerals, fine to very fine, subrounded to } \\
\text { rounded; } 20 \text { to } 30 \text { percent calcite crystals and other carbonates. }\end{array}$ \\
\hline 3 & $47-50$ & $\begin{array}{l}\text { Limestone as above; interbedded with about } 30 \text { to } 40 \text { percent sand; quartzose, fine to } \\
\text { very fine, well sorted, angular to subrounded; } 5 \text { to } 10 \text { percent heavy minerals, fine } \\
\text { to very fine, well sorted, subrounded to rounded; } 10 \text { to } 20 \text { percent carbonates and } \\
\text { shell fragments, medium to very fine. }\end{array}$ \\
\hline 4 & $50-54$ & $\begin{array}{l}\text { Limestone, medium-light-gray }(\mathrm{N} 6) \text { to yellowish-gray }(5 \mathrm{Y} 7 / 2) \text {; sandy, sparse bio- } \\
\text { sparite; } 30 \text { percent quartzose, fine to very fine, well sorted, angular to subrounded; } \\
5 \text { percent heavy minerals, fine to very fine, well sorted, subrounded to rounded; } \\
\text { cavity-riddled gravel; very porous; about } 10 \text { to } 20 \text { percent dismicrite; interbedded } \\
\text { with about } 30 \text { to } 40 \text { percent sand as above. }\end{array}$ \\
\hline 3 & $54-57$ & $\begin{array}{l}\text { Limestone, light-gray }(\mathrm{N}, 7) \text { to yellowish-gray }(5 \mathrm{Y} 8 / 1) \text {; sandy, sparse biosparite, } \\
\text { abundant mollusks; } 10 \text { to } 20 \text { percent quartzose, medium to fine, angular to subrounded, } \\
\text { moderately sorted; } 5 \text { percent heavy minerals, medium to very fine, moderately sorted, } \\
\text { subrounded to rounded; cavity-riddled gravel, very porous; interbedded with } 30 \text { to } \\
40 \text { percent sand; quartzose, medium to very fine, moderately sorted, angular to sub- } \\
\text { rounded; } 5 \text { to } 10 \text { percent heavy minerals, fine to very fine, well sorted, subrounded } \\
\text { to rounded; } 30 \text { to } 40 \text { percent shell fragments and detrital carbonates. }\end{array}$ \\
\hline 3 & $57-60$ & $\begin{array}{l}\text { Sand, light-olive-gray }(5 \mathrm{Y} 6 / 1) \text { to yellowish-gray }(5 \mathrm{Y} 8 / 1) \text {; quartzose, coarse to } \\
\text { fine, poorly sorted, angular to subrounded; } 3 \text { to } 5 \text { percent heavy minerals and phos- } \\
\text { phates, medium to fine, moderately sorted, subangular to rounded; } 30 \text { to } 40 \text { percent } \\
\text { detrital carbonates and shell fragments, Balanus, gastropods, and bivalve fragments; } \\
\text { interbedded with about } 20 \text { percent limestone gravel; sandy, sparse biosparite; about } \\
30 \text { percent quartz, coarse to fine, angular to subrounded; } 3 \text { to } 5 \text { percent heavy miner- } \\
\text { als and phosphates, medium to very fine, subrounded to rounded; moderately cemented; } \\
\text { moderately porous, vugs. }\end{array}$ \\
\hline
\end{tabular}




\begin{tabular}{|c|c|c|}
\hline $\begin{array}{l}\text { Thick- } \\
\text { ness } \\
\text { (feet) }\end{array}$ & $\begin{array}{l}\text { Depth below } \\
\text { land surface } \\
\text { (feet) }\end{array}$ & Description \\
\hline 4 & $60-64$ & $\begin{array}{l}\text { Limestone, medium-gray (N } 5) \text {; sandy, sparse biosparite, packed biosparite in places, } \\
\text { Olivella, Turritella, Chione, Mitra; } 25 \text { percent quartz, medium to fine, moderately to } \\
\text { well sorted, angular to subrounded; } 5 \text { percent heavy minerals and phosphates, medium to } \\
\text { very fine, subrounded to rounded; well cemented with gravel in places; porous, moldic, } \\
\text { vugs; interlayered with about } 20 \text { to } 30 \text { percent sand, light-olive-gray ( } \mathrm{Y} \text {, } 6 / 1) \text {; } \\
\text { quartzose, medium to fine, moderately to well sorted, angular to subrounded; } 3 \text { to } 5 \\
\text { percent heavy minerals and phosphates, medium to very fine, moderately sorted, sub- } \\
\text { rounded to rounded; about } 30 \text { to } 40 \text { percent detrital carbonates and shell fragments. }\end{array}$ \\
\hline 3 & $64-67$ & $\begin{array}{l}\text { Sandy shell, light-olive-gray ( } 5 \text { Y } 6 / 1) \text { to yellowish-gray }(5 \mathrm{Y} 8 / 1) ; 20 \text { to } 30 \text { percent } \\
\text { quartzose as above; } 3 \text { to } 5 \text { percent heavy minerals and phosphates as above; shelis and } \\
\text { shell fragments and detrital carbonates, Anadara, Oliva, Glycymeris, Venericardia, } \\
\text { other moliusks; interbedded with about } 25 \text { percent limestone gravel as above. }\end{array}$ \\
\hline 3 & $67-70$ & $\begin{array}{l}\text { Sandy sheil as above; Turritella, Crepidula; interbedded with about } 20 \text { to } 30 \text { percent } \\
\text { limestone, light-gray ( } \mathrm{N} \text { (t) light-olive-gray }(5 \mathrm{Y} 6 / 1) \text {; sandy, packed biosparite } \\
\text { with sparse biosparite in places; } 10 \text { to } 20 \text { percent quartz, medium to fine, moderateiy } \\
\text { sorted, anguiar to subrounded; } 3 \text { to } 5 \text { percent heavy minerals, medium to very fine, } \\
\text { moderateiy sorted, subrounded to rounded; moderately cemented; porous. }\end{array}$ \\
\hline 4 & $70-74$ & $\begin{array}{l}\text { Limestone as above; well cemented with gravel; interbedded with about } 30 \text { percent sandy } \\
\text { hell as above. }\end{array}$ \\
\hline 3 & $74-77$ & Limestone gravel as above; interbedded with about 20 percent sandy sheil as above. \\
\hline 3 & $77-80$ & $\begin{array}{l}\text { Limestone gravel, light-gray }(\mathrm{N}, 7) \text { to yellowish-gray }(5 \mathrm{Y} / 1) \text {; sandy, packed bio- } \\
\text { sparite, moliusks; about } 20 \text { percent quart } 2 \text {, medium to fine, moderately sorted, angular } \\
\text { to subrounded; } 3 \text { percent heavy minerais, fine to very fine, well sorted, subrounded to } \\
\text { rounded; moderately cemented gravel; porous; interbedded with about } 30 \text { to } 40 \text { percent } \\
\text { sandy sheil, light-olive-gray }(5 \mathrm{Y} / 1) ; 20 \text { to } 30 \text { percent quartz, medilum to fine, mod- } \\
\text { erately sorted, angular to subrounded; } 3 \text { to } 5 \text { percent heavy minerals, medium to very } \\
\text { fine, moderately sorted, subrounded to rounded; shells and shell fragments and detri- }\end{array}$ \\
\hline
\end{tabular}

Limestone gravel as above; interbedded with sandy shell as above.

Limestone, light-olive-gray ( 5 Y 6/1); sandy, sparse biosparite to packed biosparite (biomicrite in places); 10 to 30 percent quartz, coarse to fine, poorly sorted, angular to subrounded; 3 to 5 percent heavy minerais and phosphates, medium to fine, moderately sorted, rounded to subangular; well to moderately cemented with with gravel; porous; interbedded with 30 to 40 percent sandy shell as above.

Sandy shell, yellowish-gray $(5 Y 8 / 1)$ to light-olive-gray ( $5 \mathrm{Y} 6 / 1$ ); about 30 percent quartzose, coarse to very fine, poorly sorted, angular to subrounded; 3 to 5 percent heavy minerals, medium to very fine, poorly sorted, subrounded to rounded; detrital carbonates, shelis and shell fragments, abundant bivalve fragments; interbedded with 30 percent limestone gravel; sandy, sparse biosparite to sparse biomicrite; moderately porous.

$490-94$

Sandy shell as above; interbedded with limestone gravel as above.

$3 \quad 94-97$

Sandy shell, yellowish-gray $(5 Y 8 / 1)$ to light-olive-gray $(5 \mathrm{Y} 6 / 1)$; about 30 percent quartzose, coarse to very fine, poorly sorted, anguiar to subrounded; 5 to 10 percent heavy minerals and phosphates, coarse to very fine, poorly sorted, subrounded to rounded; detrital carbonates, shelis and shell fragments.

$3 \quad 97-100$

Sandy shell as above; Olivella, Conus, Lirophora, Chlamys, echinoid plates; interbedded with about 10 percent limestione gravel, light-olive-gray (5Y $5 / 2)$; pooriy washed biomicrite; moderately cemented.

$\begin{array}{ll}4 & 100-104 \\ 3 & 104-107 \\ 3 & 107-110\end{array}$

Sandy shell as above; Crassatellities.

Sandy shell as above; Glycymeris, Mitra, shark teeth.

Sandy shell, medium-dark-gray (N 4) to yellowish-gray ( 5 Y 8/1); as above; Glycymeris, Oliva, Chlamys, Crassatellities; interlayered with about 10 to 20 percent limestone; packed biosparite; moderately to well cemented.

$4 \quad 110-114$

Sandy shell as above; interbedded with 10 to 20 percent limestone; packed biosparite; 25 percent quartz, medium to very fine; 5 percent heavy minerals, medium to very fine; moderately cemented; moderately porous.

$3 \quad 114-117$

Sandy shell, medium-gray (N 5) to yellowish-gray (5 Y 8/1); 30 percent quartzose, medium to very fine, moderately to poorly sorted, subrounded to angular; 5 to 10 percent heavy minerais and phosphates, medium to very fine, moderately sorted, subrounded to rounded; detrital carbonates, shells and shell fragments, mollusks, Anadara, Crassatellities, Conus, Glycymeris. 


\begin{tabular}{|c|c|c|}
\hline $\begin{array}{l}\text { Thick- } \\
\text { ness } \\
\text { (feet) }\end{array}$ & $\begin{array}{l}\text { Depth below } \\
\text { land surface } \\
\text { (feet) }\end{array}$ & Description \\
\hline 3 & $117-120$ & $\begin{array}{l}\text { Sandy shell, medium-light-gray (N } 6) \text { to yellowish-gray }(5 \mathrm{Y} 8 / 1) \text {; about } 30 \text { percent } \\
\text { quartzose, coarse to fine, poorly sorted, angular to subrounded; } 5 \text { to } 10 \text { percent } \\
\text { heavy minerals and phosphates, medium to very fine, poorly sorted, subrounded to } \\
\text { rounded; detrital carbonates, shells and shell fragments, Glycymeris, oltivella, } \\
\text { Conus, Chlamys, Crepidula, Chione, Crassatellities. }\end{array}$ \\
\hline 7 & $120-127$ & $\begin{array}{l}\text { Sandy shell, light-gray ( } 7 \text { ) to yellowish-gray ( } 5 \text { Y } 8 / 1) \text {; about } 40 \text { percent quartzose } \\
\text { as above; } 5 \text { to } 10 \text { percent heavy minerals and phosphates as above; detrital carbon- } \\
\text { ates, sheils and shell fragments as above; interbedded with about } 20 \text { to } 30 \text { percent } \\
\text { limestone; sandy, sparse biosparite, mollusk; } 40 \text { percent quartz, coarse to fine, } \\
\text { poorly sorted, angular to subrounded; about } 5 \text { percent heavy minerals and phosphates, } \\
\text { medium to very fine, subrounded to rounded; moderately cemented; porous. }\end{array}$ \\
\hline 3 & $127-130$ & $\begin{array}{l}\text { Sandy shell as above; Olivella, Polinices, Chlamys, Chione, coral, barnacles; inter- } \\
\text { bedded with about } 20 \text { to } 30 \text { percent limestone; sandy, sparse biosparite as above; } 30 \\
\text { to } 40 \text { percent quartz as above; moderately comented; porous. }\end{array}$ \\
\hline 4 & $130-134$ & $\begin{array}{l}\text { Sandy shell, light-gray (N } 7 \text { ) to yellowish-gray ( } 5 \text { Y } 8 / 1 \text { ); about } 30 \text { to } 40 \text { percent } \\
\text { quartzose, medium to very fine, poorly sorted, angular to subrounded; } 5 \text { to } 10 \text { percent } \\
\text { heavy minerals and phosphates, medium to very fine, moderately sorted, subrounded to } \\
\text { rounded; detrital carbonates and shell fragments. }\end{array}$ \\
\hline 3 & $134-137$ & $\begin{array}{l}\text { Limestone, light-olive-gray ( } 5 \text { Y } 6 / 1) \text {; sandy, sparse biomicrite, mollusks; } 30 \text { to } 40 \\
\text { percent quartz, medium to very fine, moderately sorted, angular to subrounded; about } \\
5 \text { percent heavy minerals, medium to very fine, moderately sorted, subrounded to } \\
\text { rounded; well cemented; porous, moldic; interbedded with about } 20 \text { to } 30 \text { percent sandy } \\
\text { shell as above. }\end{array}$ \\
\hline 3 & $137-140$ & $\begin{array}{l}\text { Sandy shell as above; interbedded with about } 10 \text { percent limestone as above; moder- } \\
\text { ately comented. }\end{array}$ \\
\hline 4 & $140-144$ & $\begin{array}{l}\text { Sand, light-gray (N 7) to yellowish-gray ( } 5 \text { Y } 8 / 1) \text {; quartzose, medium to very fine, } \\
\text { moderately sorted, angular to subrounded; } 5 \text { to } 10 \text { percent heavy minerals and phos- } \\
\text { phates, medium to very fine, moderately sorted, subrounded to rounded; about } 40 \\
\text { percent detrital carbonates and shell fragments, barnacles, bivalves and gastropod } \\
\text { pieces. }\end{array}$ \\
\hline 3 & $144-147$ & $\begin{array}{l}\text { Sand as above; } 30 \text { to } 40 \text { percent carbonates; interbedded with } 10 \text { to } 20 \text { percent lime- } \\
\text { stone gravel; sandy, sparse biosparite; } 40 \text { to } 50 \text { percent quartz; } 5 \text { to } 10 \text { percent } \\
\text { heavy minerais and phosphates; porous; moderately cemented. }\end{array}$ \\
\hline 3 & $147-150$ & $\begin{array}{l}\text { Sand, light-gray }(\mathrm{N} 7) \text {; quartzose, medium to fine, moderately sorted, angular to } \\
\text { rounded; } 5 \text { to } 10 \text { percent heavy minerals and phosphates, medium to very fine, moder- } \\
\text { ately sorted, subrounded to rounded; } 20 \text { to } 30 \text { percent detrital carbonates and shell } \\
\text { pieces. }\end{array}$ \\
\hline 14 & $150-164$ & Sand as above; with echinoid plates. \\
\hline 10 & $164-174$ & $\begin{array}{l}\text { Sand, light-gray (N } 7 \text { ); quartzose, medium to fine, moderately to well sorted, angular } \\
\text { to subrounded; about } 10 \text { percent heavy minerals and phosphates, medium to fine, moder- } \\
\text { ately to well sorted, subrounded to rounded; about } 25 \text { percent detrital carbonates and } \\
\text { shell pieces, echinoid plates; stringers of silt and clay, grayish-olive }(10 \mathrm{Y} 4 / 2) \text {. }\end{array}$ \\
\hline 3 & $174-177$ & $\begin{array}{l}\text { Sand, light-olive-gray }(5 \text { Y } 6 / 1) \text {; quartzose, medium to fine, well sorted, angular to } \\
\text { subrounded; } 5 \text { to } 10 \text { percent heavy minerals and phosphates, medium to fine, well } \\
\text { sorted, subrounded to rounded; } 10 \text { to } 20 \text { percent detrital carbonates and shell pieces, } \\
\text { echinoid plates; about } 10 \text { percent silt and clay, grayish-olive ( } 10 \mathrm{Y} 4 / 2 \text { ). }\end{array}$ \\
\hline 3 & $177-180$ & Sand as above; oyster shells. \\
\hline 10 & $180-190$ & $\begin{array}{l}\text { Silty sand, light-olive-gray }(5 \mathrm{Y} 6 / 1) \text {; quartzose, medium to fine, well sorted, angu- } \\
\text { lar to rounded; about } 5 \text { percent heavy minerals and phosphates, medium to very fine, } \\
\text { moderately sorted, subrounded to rounded; about } 10 \text { to } 20 \text { percent detrital carbonates } \\
\text { and shell pieces; about } 25 \text { percent silt and clay. }\end{array}$ \\
\hline 10 & $190-200$ & $\begin{array}{l}\text { Silty sand, light-olive-gray }(5 \text { Y } 6 / 1) \text {; quartzose, fine to very fine, well sorted, } \\
\text { angular to subrounded; } 5 \text { percent heavy minerals, fine to very fine, well sorted, } \\
\text { subrounded to rounded; about } 10 \text { percent detrital carbonates and shell pieces; about } \\
30 \text { percent silt and clay. }\end{array}$ \\
\hline 5 & $200-220$ & ove; 30 to 40 percent silt and clay. \\
\hline
\end{tabular}

